US Army Corps of Engineers ${ }_{\circledast}$ Engineer Research and Development Center

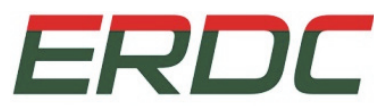
INNOVATIVE SOLUTIONS for a safer, better world

\title{
A Photogrammetric Method for Obtaining Soil Density
}

Ernest S. Berney IV, Naveen B. Ganesh, and Thad C. Pratt

June 2018
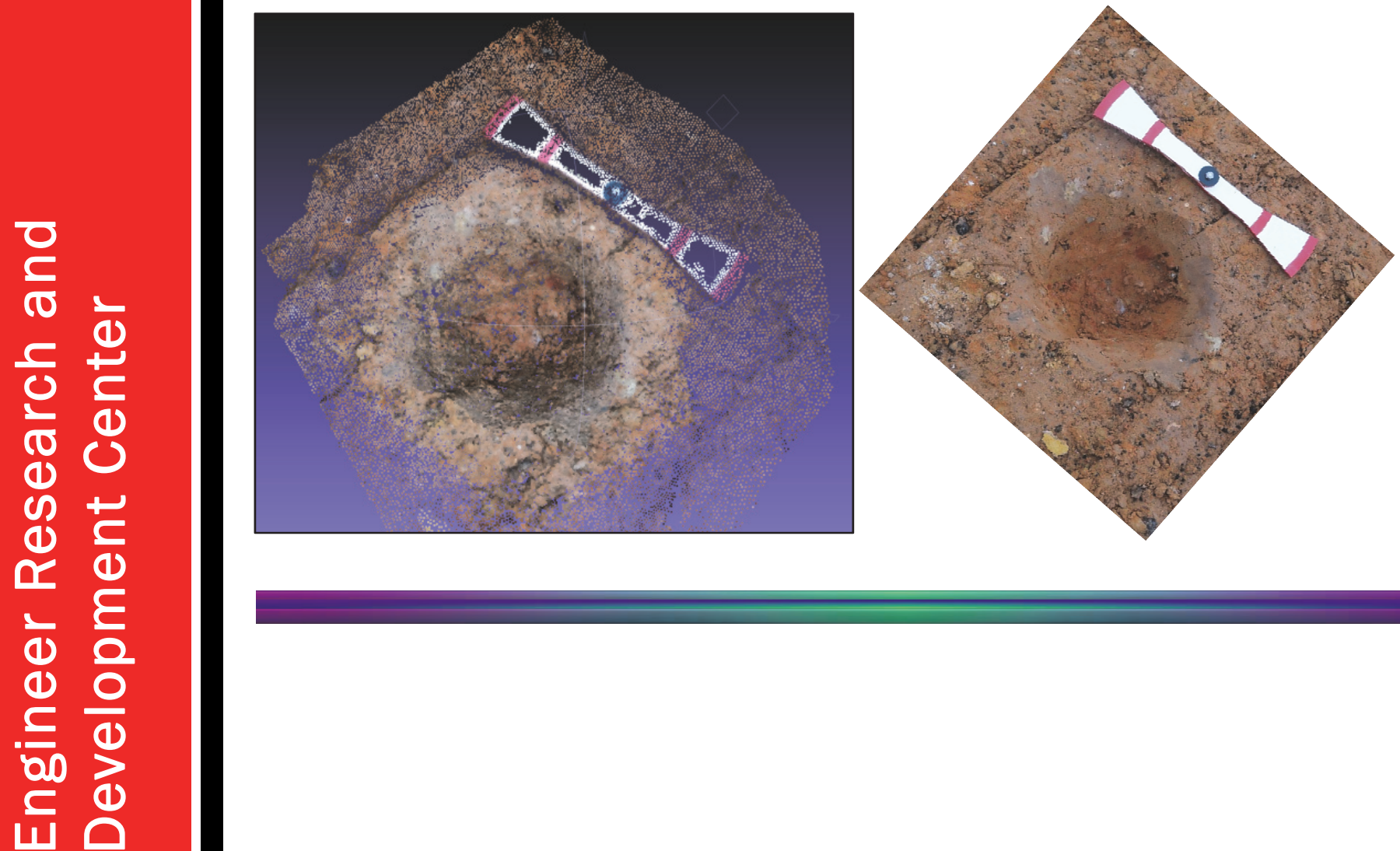
The U.S. Army Engineer Research and Development Center (ERDC) solves the nation's toughest engineering and environmental challenges. ERDC develops innovative solutions in civil and military engineering, geospatial sciences, water resources, and environmental sciences for the Army, the Department of Defense, civilian agencies, and our nation's public good. Find out more at www.erdc.usace.army.mil.

To search for other technical reports published by ERDC, visit the ERDC online library at http://acwc.sdp.sirsi.net/client/default. 


\title{
A Photogrammetric Method for Obtaining Soil Density
}

\author{
Ernest S. Berney IV \\ Geotechnical and Structures Laboratory \\ U.S. Army Engineer Research and Development Center \\ 3909 Halls Ferry Rd. \\ Vicksburg, MS 39180-6199 \\ Naveen B. Ganesh and Thad C. Pratt \\ Coastal and Hydraulics Laboratory \\ U.S. Army Engineer Research and Development Center \\ 3909 Halls Ferry Rd. \\ Vicksburg, MS 39180-6199
}

Final report

Approved for public release; distribution is unlimited.
Prepared for Headquarters, U.S. Army Corps of Engineers
Washington, DC 20314-1000
Under Project Number 447413




\section{Abstract}

There is a need for a simple, accurate soil density measurement system that does not require extensive calibration or significant health and safety measures for compaction quality control. This research describes the invention of a photogrammetric technique for obtaining the volume of an excavated hole in soil. This procedure requires a series of 8 to 16 digital photographs with a standard digital camera around the perimeter of an excavated hole with a reference scale in the scene. Algorithms convert the digital photographs into a colorized three-dimensional point cloud, which is automatically rotated into a plan view and displayed via the Matlab graphical user interface. Once the reference scale dimensions are input, the volume of the hole is calculated via a user selected ground plane. Once the mass of the excavated soil is input, the wet density of the soil is calculated by dividing by the volume of the hole. This procedure has been validated against both the nuclear density gauge and the sand cone apparatus and found to be equivalent in accuracy to both. This procedure enables soil density determination within 15 min with no replacement material, no specific excavated hole dimension, and no safety or health risks.

DISCLAIMER: The contents of this report are not to be used for advertising, publication, or promotional purposes. Citation of trade names does not constitute an official endorsement or approval of the use of such commercial products. All product names and trademarks cited are the property of their respective owners. The findings of this report are not to be construed as an official Department of the Army position unless so designated by other authorized documents. 


\section{Contents}

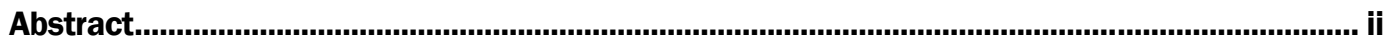

Figures and Tables.....................................................................................................................................

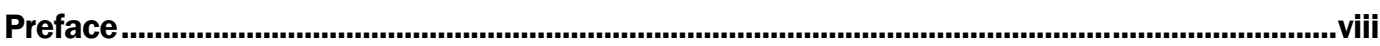

Unit Conversion Factors...........................................................................................................ix

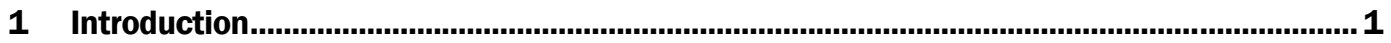

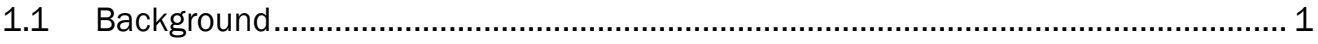

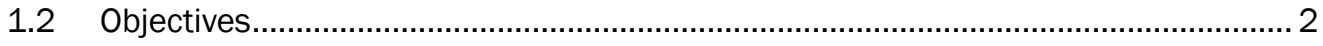

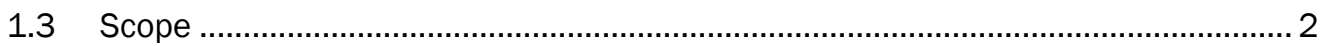

2 The Photogrammetry Technique .......................................................................................... 4

2.1 Equipment and procedure ............................................................................. 4

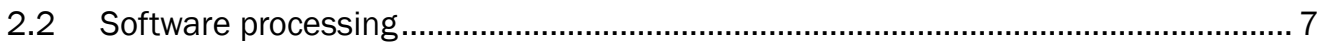

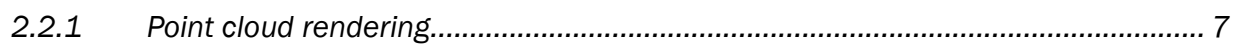

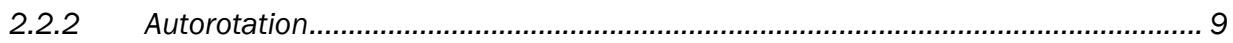

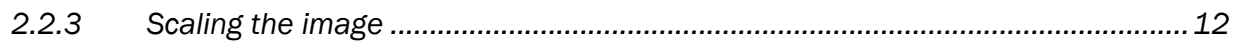

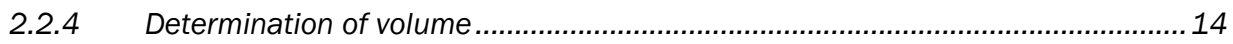

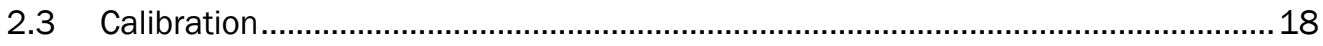

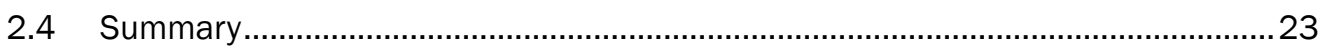

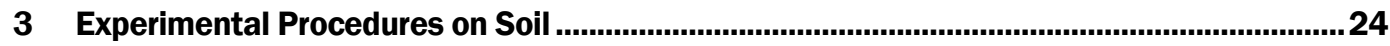

3.1 Phase one: Initial development of technique.................................................... 24

3.2 Phase 2: Validation of technique on constructed test sections................................27

3.3 Description of test instruments for comparison ......................................................28

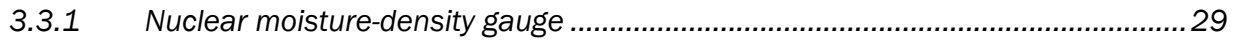

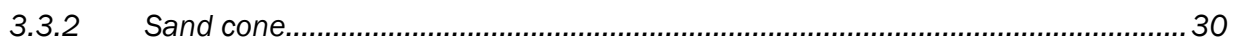

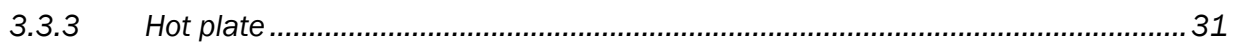

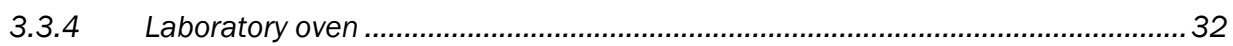

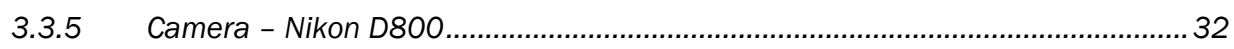

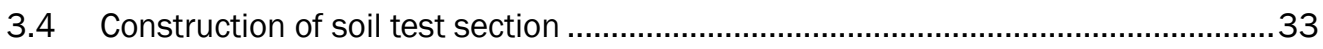

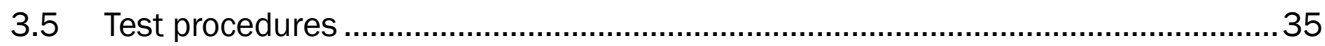

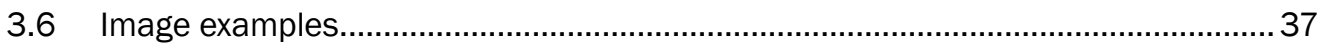

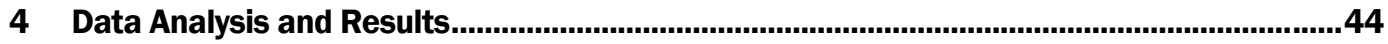

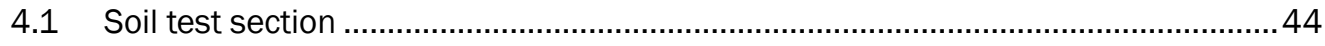

4.1.1 Range of soil conditions evaluated ....................................................................... 44

4.1.2 Hot plate moisture correlation to laboratory oven-dried procedure.......................45

4.2 Data comparisons ....................................................................................... 47

4.2.1 Sand cone versus nuclear density gauge ............................................................4 47

4.2.2 Photogrammetry correlations to NDG and sand cone - cumulative......................48

4.2.3 Photogrammetry correlations to NDG and sand cone - soil type..........................51

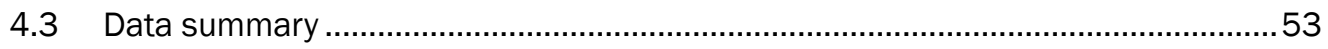


5 Conclusions and Recommendations ..............................................................................54

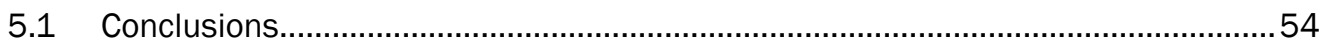

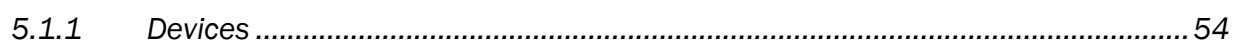

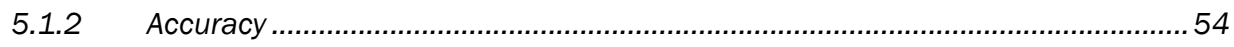

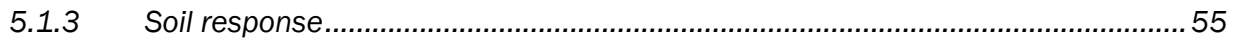

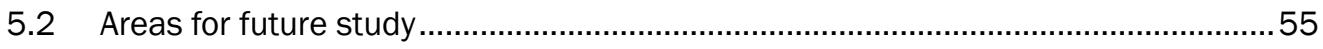

5.2.1 Hardware advancements in point cloud collection..................................................55

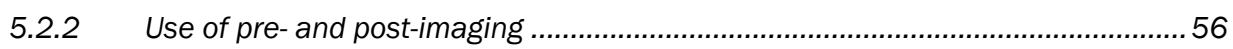

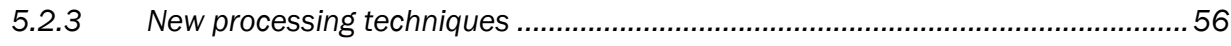

References................................................................................................................................. 57

Appendix A: Soil Characterization Data ..................................................................................59

Appendix B: Raw Experimental Data Collected and Photogrammetry Analysis........................ 71

\section{Report Documentation Page}




\section{Figures and Tables}

\section{Figures}

Figure 1. Components required to perform a photogrammetric analysis of soil density.

Figure 2. Using a shovel to excavate soil at a location where soil density is required. Note bowl to store soil in and red ring for calibrating distance.

Figure 3. Cross section and plan view of convex excavation of hole required for photographing.

Figure 4. Plan views of excavated holes and typical scales used for obtaining distance in the photographs (circular red ring or horizontal bar shown). Note the color red is used to provide good contrast with the surrounding soil.

Figure 5. Example of photographing hole to obtain imagery for processing. Note a red ring was painted onto a sand cone plate for scaling and for comparative density purposes. A digital SLR and a point-and-shoot digital camera were both used for comparative purposes of pixel density.

Figure 6. Typical positioning around the perimeter of the hole from which to obtain photographs.

Figure 7. ERDC developed GUI for photo-density analysis........................................................... 8

Figure 8. Digital picture of hole from SfM point cloud generation as compared to actual camera jpeg.

Figure 9. Three-dimensional point cloud displayed in GUI alongside unrotated (above) and rotated (below) cross sections in ERDC GUI.

Figure 10. Determination of extreme limits in X-Y-Z planes of a typical hemispherical hole.

Figure $11 \mathrm{a}, \mathrm{b}, \mathrm{c}$. Using the ERDC GUI to crop out data points outside the area of interest (a) and identifying the length of the reference scale (b) to obtain a more refined image for volume calculation (c).

Figure 12. Using the ERDC GUI to obtain z-datum for volume estimation and utilization of contour lines to establish the top of the excavation.

Figure 13. Determination of extreme X, Y, Z limits for volume calculation. ........................................ 16

Figure 14. Creation of encompassing cubic volume around excavated hole and subdivision into one-cubic pixel cubes.

Figure 15. Eliminate cubes not associated with hole volume and identify partial volumes with cubes intersecting face of the hole.

Figure 16. Summation of subdivided cubes in columns around surface of the x-y plane downward along the z-axis to the hole face.

Figure 17. Software output files from GUI for later reference.

Figure 18. Calibration platform with aluminum bowl and 15-in. diameter red ring for imaging (left) and close up view of aluminum bowl and texture (right).

Figure 19. Water calibration of aluminum bowl insert, empty (left) and filled with water (right). Soap was added to create a level surface.

Figure 20. Sand cone mounted on the calibration platform.

Figure 21. Cameras used in calibration experiment: Nikon D-800 (left), Nikon D-40 (center), Sony DSC-H70 (right). 
Figure 22. Graphical comparison of wet density between sand cone, NDG, and

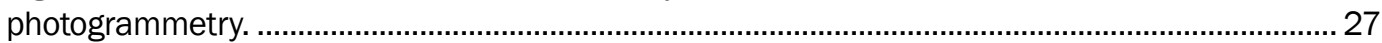

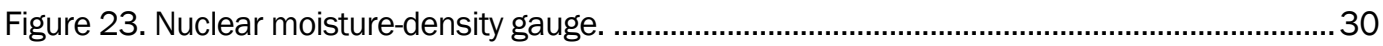

Figure 24. Sand cone density apparatus and accessories.......................................................... 31

Figure 25. Hot plate, scale, and accessories used to determine soil moisture content................32

Figure 26. Placing soil to build a testbed using a) dump truck and b) skid steer............................34

Figure 27. Soil compaction equipment: a) smooth drum roller and b) rubber tire compactor. 34

Figure 28. Use of plastic sheet on test strip to prevent soil adhering to the drum...........................35

Figure 29. Typical test item layout. ......................................................................................... 36

Figure 30. Testing of sand cone density and photogrammetry technique inside red ring. Sharpshooter shovel was used for some photogrammetry excavations. .

Figure 31. Example of sand cone versus photogrammetry holes. Note the photogrammetry technique is more conducive to a larger excavation

Figure 32.12 post-test locations of sand cone and photogrammetry samples on Limestone test section for both low and high compaction efforts.

Figure 33. CH-High plasticity clay soil excavation 38

Figure 34. SC-Clayey sand with gravel soil excavation.........................................................................

Figure 35. CL-Low plasticity clay soil excavation....................................................................... 40

Figure 36. GW-GC-Gravel with silty clay and sand soil excavation.................................................. 41

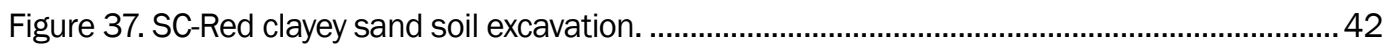

Figure 38. SC-Blended clayey sand soil excavation. ……….......................................................... 43

Figure 39. Moisture-density range tested for each soil type. Note: $M 1$ are samples tested at the lowest moisture content, M2 are samples tested at the highest moisture content............... 45

Figure 40. Comparison of hot plate versus oven-dried moisture content techniques. ...................... 46

Figure 41. Comparison of wet density between Sand Cone and NDG............................................. 47

Figure 42. Comparison of dry density between Sand Cone and NDG........................................... 48

Figure 43. Comparison wet density between NDG and photogrammetry method........................... 49

Figure 44. Comparison of dry density between NDG and photogrammetry method........................49

Figure 45. Comparison wet density between sand cone and photogrammetry method..................5 50

Figure 46. Comparison dry density between sand cone and photogrammetry method. ..................50

Figure 47 . Wet density comparisons between photogrammetry and NDG and sand cone with outliers noted in circles.

\section{Tables}

Table 1. Weighing trials of aluminum bowl with water added to determine hole volume..................20

Table 2. Sand cone jug calibration prior to density measurement of calibration bowl. .................... 21

Table 3. Volume of calibration mold using the sand cone method. .....................................................2 22

Table 4. Volume of calibration bowl using photogrammetric technique........................................... 23

Table 5. Data collected with Sony camera (2013 and 2014 software generations).........................2 25

Table 6. Statistical summary of phase one evaluation of photogrammetric technique..................... 26

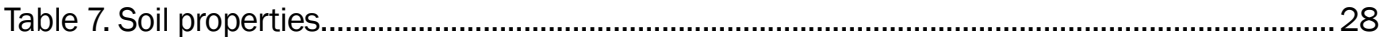




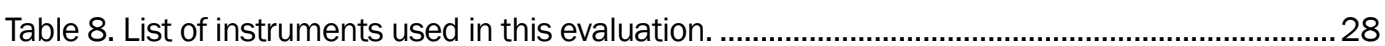

Table 9. Moisture levels used to prepare each soil for testing. ..........................................................33

Table 10. Range of relative density and moisture content achieved during construction................44

Table 11. Correlation of determination between photogrammetry method and NDG and sand cone method for each soil type tested. ................................................................................. 51

Table 12. Correlation of determination between photogrammetry method and NDG and sand cone method for each soil type tested with outliers removed...............................................51

Table 13. Statistical summary of phase two evaluation of photogrammetric technique.................53

Table 14. Statistical summary of phase two evaluation of photogrammetric technique with outliers removed. 


\section{Preface}

This report was prepared for Headquarters, U.S. Army Corps of Engineers and the U.S. Air Force Non-Nuclear Density Project. Mr. Jeb S. Tingle was the program manager of the Air Force project.

This work was performed by the Airfields and Pavements Branch (GMA) and the Concrete and Materials Branch (GMC), Engineering Systems and Materials Division (GM), U.S. Army Engineer Research and Development Center, Geotechnical and Structures Laboratory (ERDC-GSL). At the time of publication, Dr. Timothy W. Rushing was Chief, CEERD-GMA; Mr. Christopher M. Moore was Chief, CEERD-GMC; Dr. Gordon W. McMahon was Chief, CEERD-GM; and Ms. Pamela G. Kinnebrew, CEERDGZT, was Technical Director for Survivability and Protective Structures. The Deputy Director of ERDC-GSL was Dr. William P. Grogan, and the Director was Mr. Bartley P. Durst.

COL Bryan S. Green was the Commander of ERDC, and Dr. David W. Pittman was the Director. 


\section{Unit Conversion Factors}

\begin{tabular}{|l|l|l|}
\hline Multiply & By & To Obtain \\
\hline cubic yards & 0.7645549 & cubic meters \\
\hline feet & 0.3048 & meters \\
\hline inches & 0.0254 & meters \\
\hline pounds (force) & 4.448222 & newtons \\
\hline pounds (force) per foot & 14.59390 & newtons per meter \\
\hline pounds (force) per square foot & 47.88026 & pascals \\
\hline pounds (force) per square inch & 6.894757 & kilopascals \\
\hline pounds (mass) per cubic foot & 16.01846 & kilograms per cubic meter \\
\hline square feet & 0.09290304 & square meters \\
\hline tons (force) & $8,896.443$ & newtons \\
\hline
\end{tabular}




\section{Introduction}

\subsection{Background}

The moisture content and wet density of a soil are critical engineering properties that define its short and long term durability and strength. An acceptable range of moisture content and dry density (calculated from the wet density) for earthen construction is determined from the proctor laboratory test according to ASTM D1557 (ASTM 2012). Once this range of acceptable moisture content and density are established, measurement of these properties in the field during construction operations is essential to ensuring good quality control.

Currently, there are two options fielded in the military to obtain moisture content and density: the use of a nuclear density gauge (NDG) and the use of sand replacement known as the sand cone test. The NDG provides a rapid measure ( $2 \mathrm{~min}$ ) of both field moisture content and wet/dry density (Troxler 2016a). For CONUS-based operations, this is the preferred method of conducting quality control but is used sparingly in the OCONUS construction environment. The sand cone test requires a greater amount of field logistics to execute and typically requires $30 \mathrm{~min}$ or longer to conduct a test and provides only the wet density of the soil. A secondary device such as an oven, microwave, or hot plate is required to obtain moisture content (Berney et al. 2011). Both of these techniques have inherent difficulties in the military and an alternative that can capture an accurate measure of density in a compressed timeframe would be a welcome addition to the military inventory.

The U.S. military desires to replace the (NDG) because of the restrictive requirements for the gauge's transport, use, and storage associated with these instruments containing radioactive materials Cesium and Americium. Multiple studies at ERDC have identified potential electronic replacements to the NDG but none have yet been fielded due to limitations of the technology for obtaining accurate field measurements (Berney et al. 2013 and2014, Berney and Mejias-Santiago 2016). As a calibration standard for the NDG, the sand cone method requires a careful extraction of soil from the ground and replacement of the soil with calibrated clean sand that must be supplied to the jobsite in significant quantities given the multiple tests required during construction operations. As well, both techniques are 
subject to a maximum soil grain diameter of about $1 \mathrm{in}$. for the sand cone and 2 in. for the NDG beyond which either procedure begins to lose accuracy and reliability.

A suitable alternative to these devices that would be considered in a military scenario must meet two requirements. First, it must be as accurate as the sand cone test that represents the reference standard from which to compare other density data. Second, the test must be executable in significantly less time than the sand cone test and not require the transport of materials to conduct the test (i.e., any volume replacement material such as sand or water). The research described in this report seeks a technique to replace both the NDG and the reference standard sand cone that has the accuracy of the sand cone yet can be conducted in less than half the time, requires no replacement material, is non-nuclear, and can be executed on any size granular material making it the most versatile density technique available.

\subsection{Objectives}

This research effort sought to apply the principles of photogrammetry to obtain the volume of a hole dug from the ground from a series of digital photographs taken with a standard camera. The process of developing a three-dimensional point cloud from a series of overlapping digital photographs that provides both the shape and scale of the excavation is the input data used for the processing algorithms necessary to calculate the volume. The origins of this research came from the CALDERA program (Ehrgott et al. 2016), which developed a technique for obtaining volumes of large craters in soil created from buried explosives using photogrammetry in the manner described. The principles of that research were then applied to the constraints of obtaining volumes of small holes, approximately 6-in. in diameter, at a sufficient precision to be a suitable replacement for the sand cone test.

\subsection{Scope}

The research considered the development of algorithms that enable a rapid means to process three-dimensional digital point clouds to obtain accurate volumes of small holes. This photogrammetric technique was validated on a uniquely designed calibration platform to ensure its sufficiency. Lastly, validation of the technique through a series of data collection efforts across multiple test sites representing a wide range of 
compacted soils was undertaken and a comparison made between the NDG and sand cone test for accuracy and expediency. The goal is to present a stand-alone digital platform that can detect volumes of small holes dug for the purpose of quality control of soil density with the accuracy of the sand cone and the expediency of the NDG. 


\section{The Photogrammetry Technique}

The photogrammetry technique adopted to create a three-dimensional point cloud is described following the outline used in the ERDC patent application filed for this process with clarifications added for the practical application of the technique.

\subsection{Equipment and procedure}

Figure 1 illustrates the key components required to perform a soil density measurement using photogrammetry. These items include a calibration object (A), a container to hold excavated soil (B), a mass scale (C), an imaging apparatus (D), a device for excavating soil and flashlight for low light applications (E), and a computer (F).

Figure 1. Components required to perform a photogrammetric analysis of soil density.

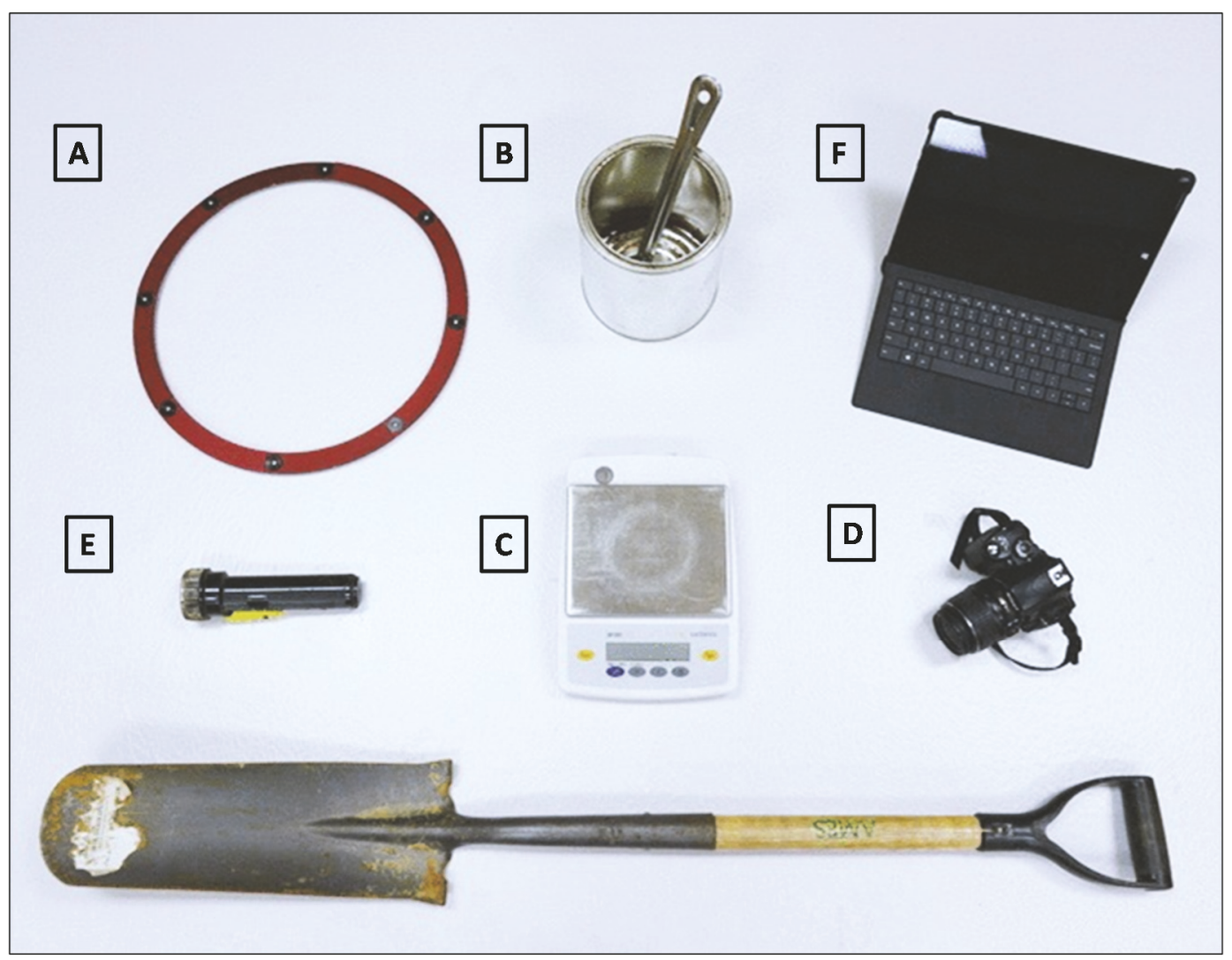

The calibration object (A) is any object having a known size that is placed in the scene with the photographs. For this research, the ideal arrangement was found to be a flat, annular ring having known inner and outer diameters. The dimensions of the calibration ring shown are 15 -in. outer 
diameter and 13-in. inner diameter. The ring also has joints, such that it can be folded into a size small enough to be inserted into the leg zipper pouch of an Army BDU.

To begin the technique the user digs a hole of any diameter or shape in the ground using a shovel or trowel (typically 6-8 in. in diameter for most soils) and to any depth (typically 4-6 in. for most soils) (Figure 2). However, the nature of the technique allows any size hole or shape to be dug to accommodate larger aggregate or irregular ground conditions. Care should be taken to collect any and all soil excavated from the hole and then place it in a container for weighing. The hole ideally will be dug in a convex shape to allow the camera the best angle in which to capture the surface features of the walls of the hole (Figure 3).

Once the hole has been excavated, the removed soil is weighed on a manual or digital balance to obtain the moist soil mass. A scale of known length is placed on the ground near or around the excavated hole to provide a distance reference within the software (Figure 4). It is suggested to use a colored scale that provides good contrast to the surrounding ground so the pixel extents of the scale can be readily identifiable in the software. A scale in a shade of red or alternating red and white along with a low reflective coating is ideal in the instance when a camera flash is used.

Figure 2. Using a shovel to excavate soil at a location where soil density is required. Note bowl to store soil in and red ring for calibrating distance.

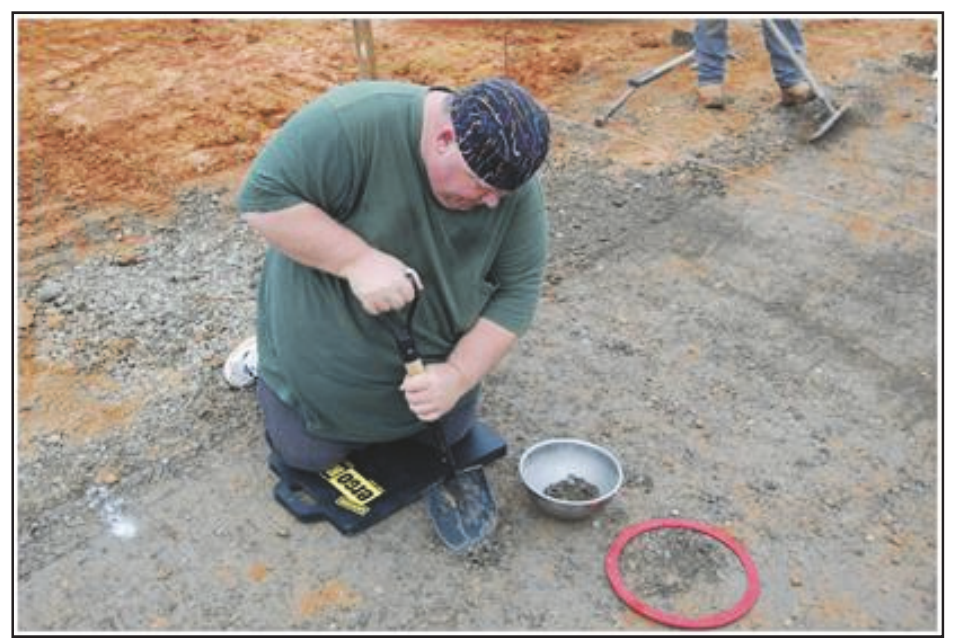


Figure 3. Cross section and plan view of convex excavation of hole required for photographing.

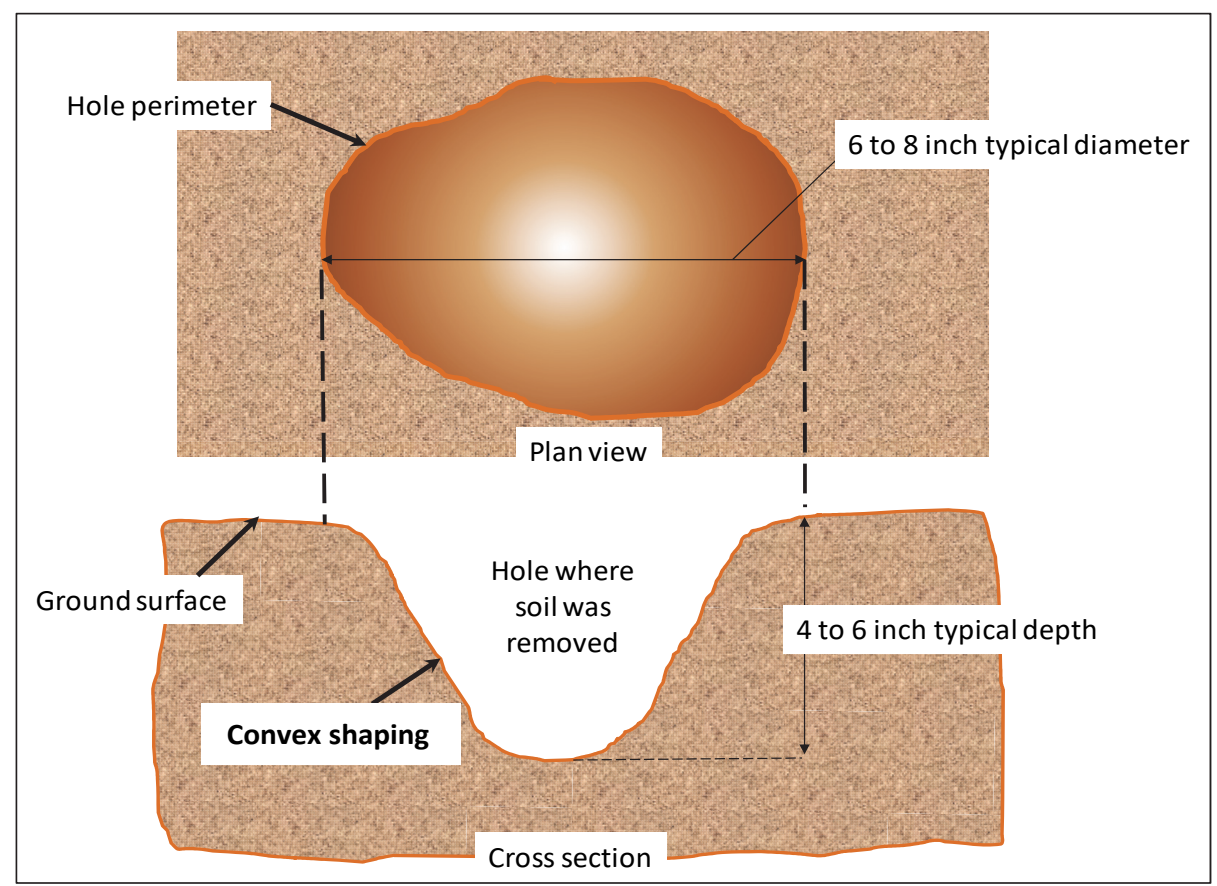

Figure 4. Plan views of excavated holes and typical scales used for obtaining distance in the photographs (circular red ring or horizontal bar shown). Note the color red is used to provide good contrast with the surrounding soil.
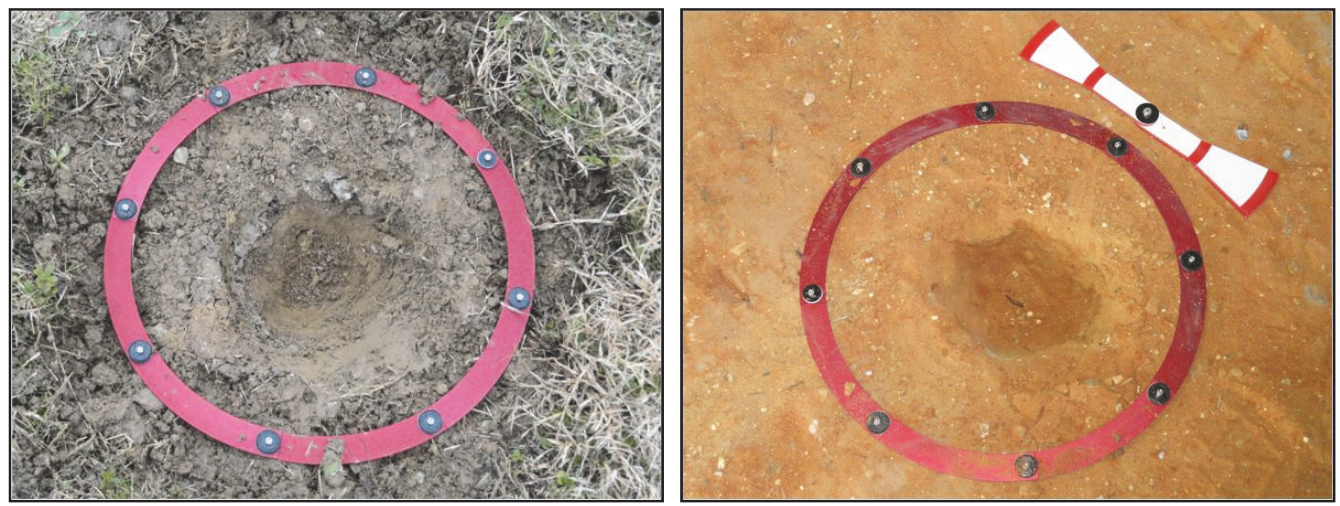

The user then takes a series of digital photographs from either a cellular telephone, single lens reflux, point-and-shoot camera or stills rendered from a video recording device. These stills should be taken at a relatively constant elevation around the perimeter of the hole capturing the hole from varying angles, typically at 45 -deg increments to obtain full coverage (Figure 5 and Figure 6). Approximately 8 to 16 photographs is sufficient to provide the required overlap between images to process the digital point cloud. Additional photographs can be taken of the hole, including zooming in to the interior of the hole to obtain more detailed surface textures to improve accuracy of the rendered point cloud. 
Figure 5. Example of photographing hole to obtain imagery for processing. Note a red ring was painted onto a sand cone plate for scaling and for comparative density purposes. A digital SLR and a point-and-shoot digital camera were both used for comparative purposes of pixel density.

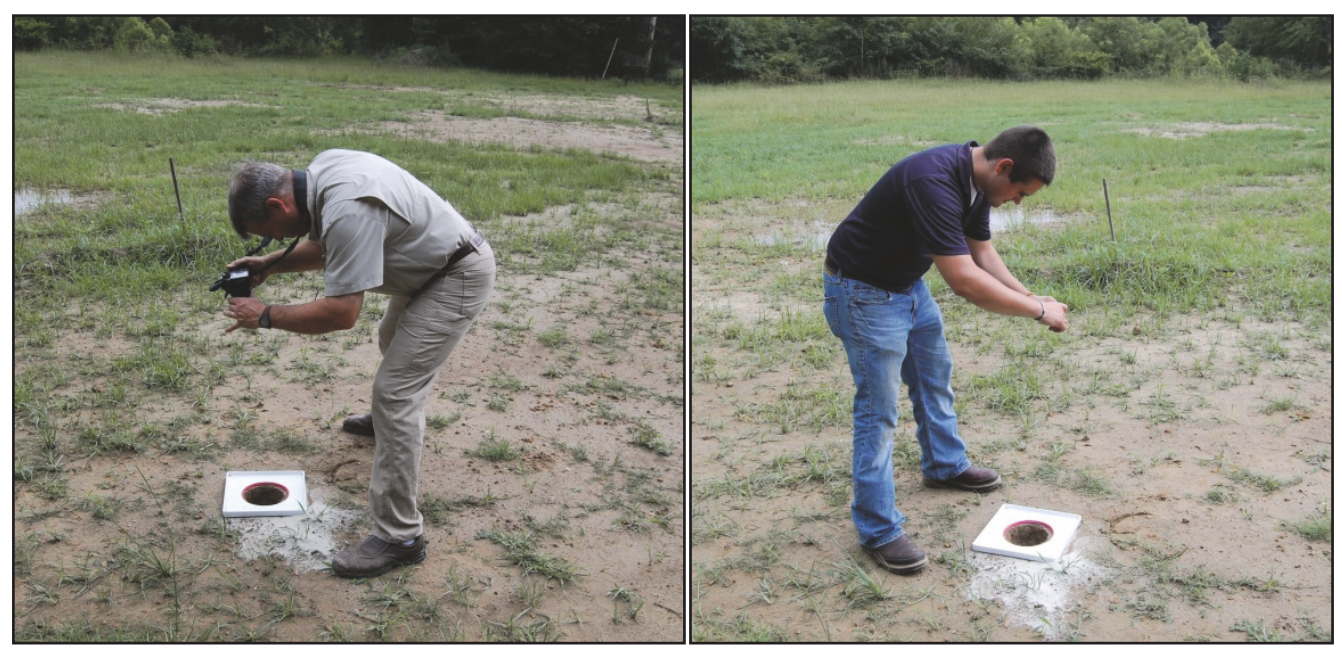

Figure 6. Typical positioning around the perimeter of the hole from which to obtain photographs.

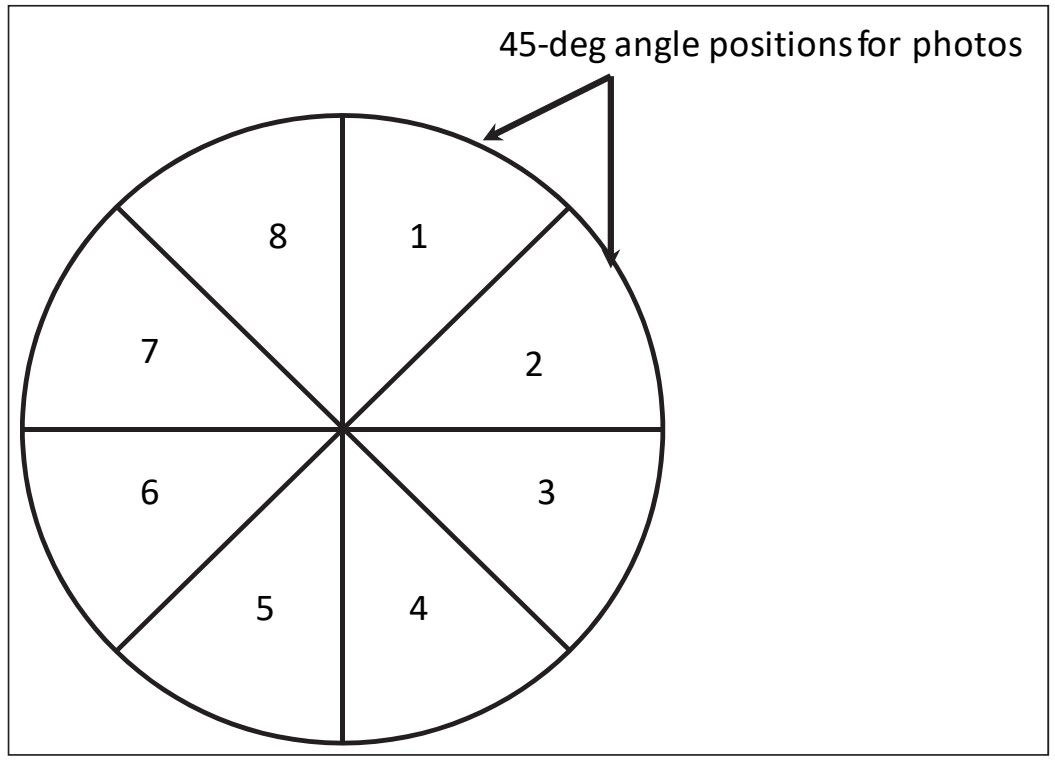

\subsection{Software processing}

\subsubsection{Point cloud rendering}

Once the photographs have been taken, they are put into a computer using Matlab executable software (Matlab 2012) installed to begin the data analysis. An example of the developed Matlab GUI interface is shown in Figure 7. 
Figure 7. ERDC developed GUI for photo-density analysis.

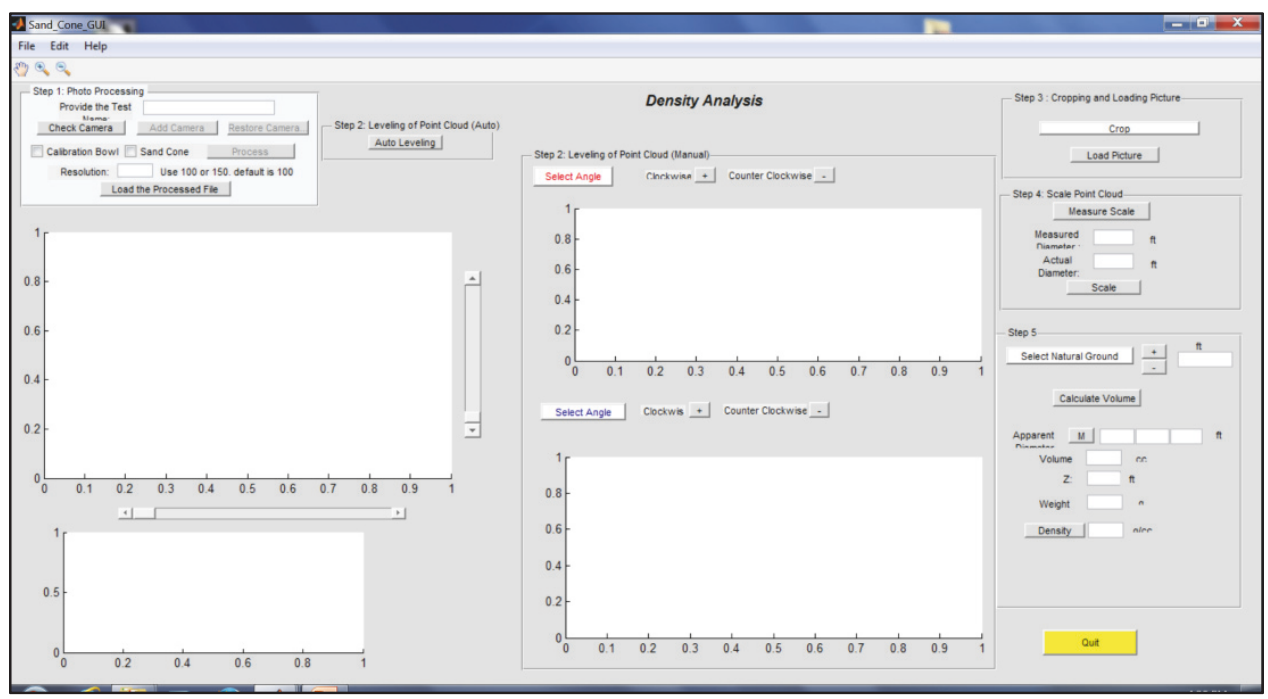

Once the user opens the GUI, they select the folder of photographs from which to perform computer vision processing to generate a threedimensional point cloud representation of the hole. In order for this process to occur in the GUI, the operator must input the size of the camera's chargecoupled device (CCD) chip if not already contained within the database of known camera CCD sizes. This is to ensure that a properly pixel-scaled point cloud is generated (a CCD dimension of near 4-mm is typical for most camera types). The GUI uses a public domain subroutine that employs the structure from motion (SfM) point cloud rendering algorithm that generates a three-dimensional point cloud from the still photographs (Figure 8). This process occurs by matching pixels associated with common features located within contiguous photographs to find commonality between images. The point cloud is then a plurality of pixels extracted from each digital image. Each pixel has a quasi-unique set of coordinate values along the $\mathrm{x}-, \mathrm{y}-\mathrm{and} \mathrm{z}-$ axis, along with a quasi-unique set of color levels using red, green and blue levels (denoted as R, G and B, respectively.) 
Figure 8. Digital picture of hole from SfM point cloud generation as compared to actual camera jpeg.
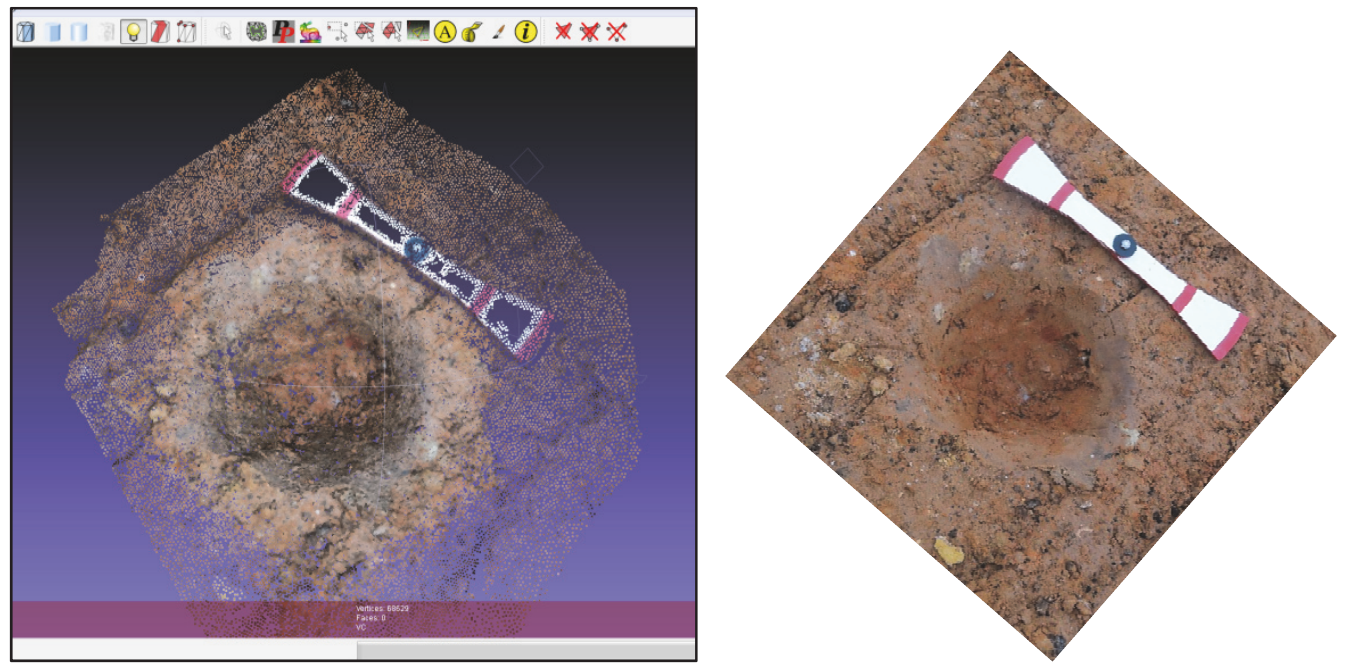

\subsubsection{Autorotation}

Once the point cloud is generated, the user is returned an oblique view of the point cloud in the GUI (Figure 9). This oblique view is a common occurrence in photo rendering software, when there are not reference points used to scale the initial image such as global positioning points. The user then clicks on the auto leveling button to place the image in a plan view (perpendicular to the screen) in order to perform the proper estimate of volume.

The autorotation methodology occurs by extracting the largest pixel ycoordinate data value ymax and the smallest pixel y-coordinate data value $\mathrm{y}_{\min }$ from the point cloud data object, along with the corresponding pixel zcoordinates, zymax and zymin, respectively (Figure 10).

Next the angle between the $\mathrm{x}$ and $\mathrm{y}$ planes, $\theta_{\mathrm{x}}$ and $\theta_{\mathrm{y}}$ are calculated. These angles can also be input manually in the GUI, if the user opts to not allow the autorotation sequence to occur. Then the x-axis angle of adjustment $\theta_{\mathrm{x}}$ is calculated using the following equation:

$$
\theta_{x}=\tan ^{-1}\left(\frac{z_{y \max }-z_{y \min }}{y_{\max }-y_{\min }}\right)-\tan ^{-1}\left(\frac{1-1}{y_{\min }+3-y_{\min }}\right)
$$


Figure 9. Three-dimensional point cloud displayed in GUI alongside unrotated (above) and rotated (below) cross sections in ERDC GUI.
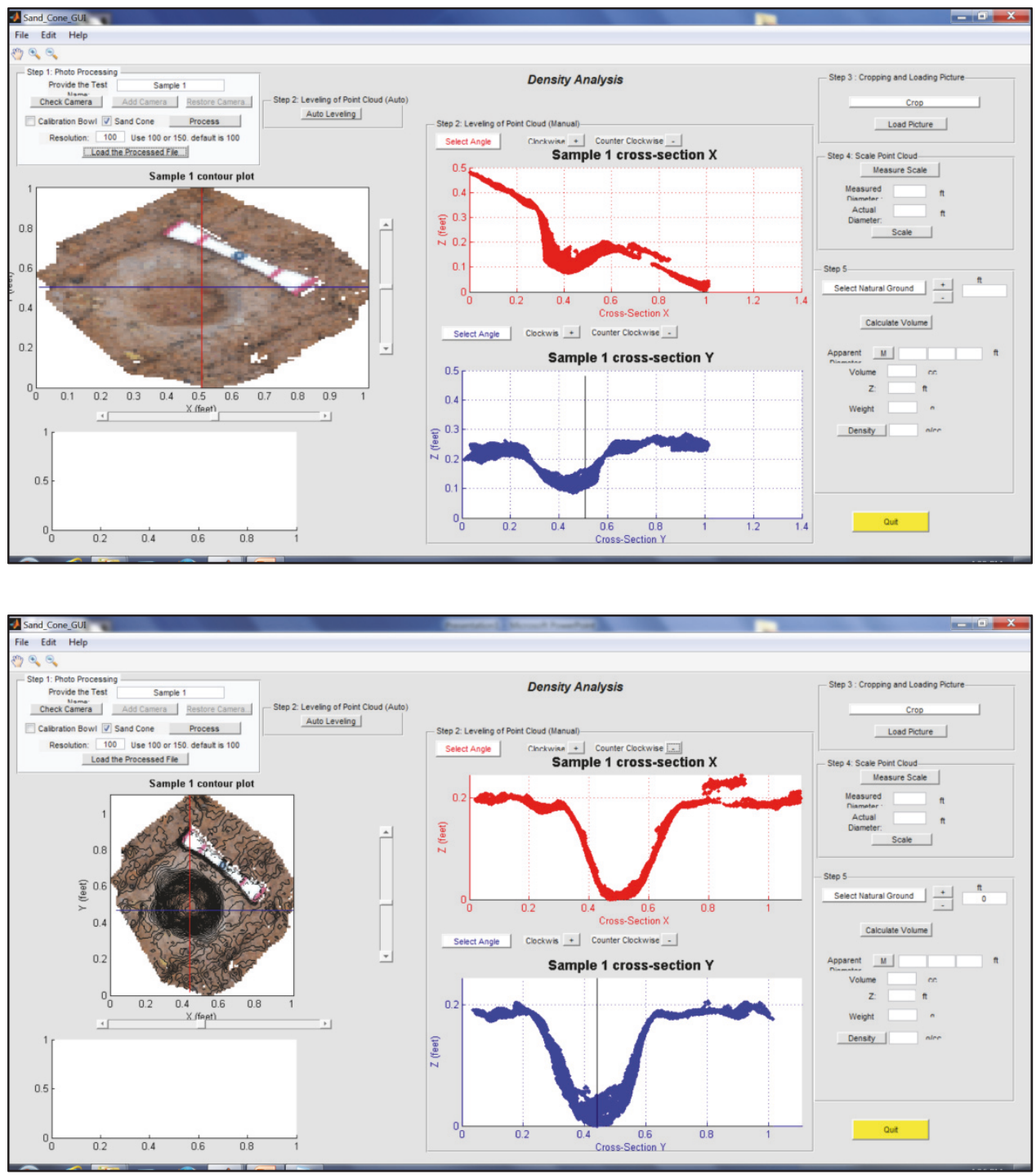
Figure 10. Determination of extreme limits in X-Y-Z planes of a typical hemispherical hole.
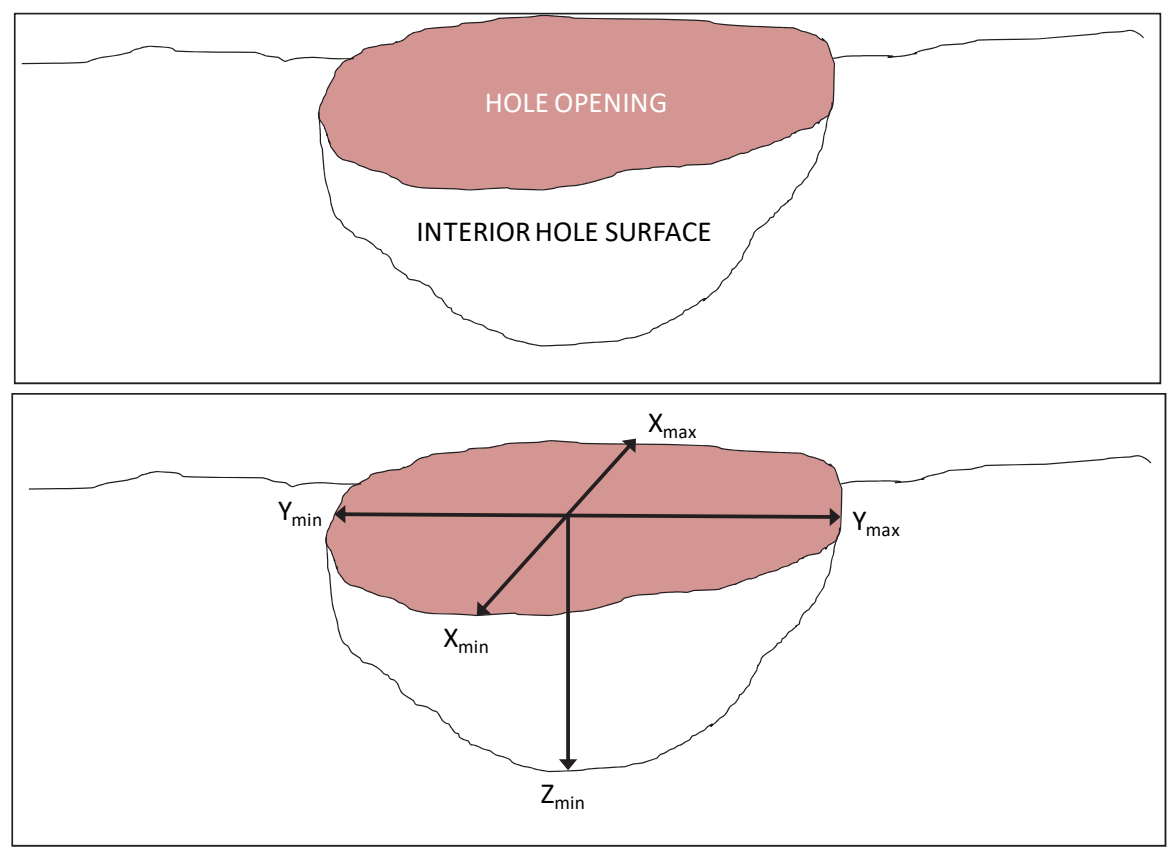

Each pixel $x$-coordinate, $y$-coordinate and z-coordinate data value in the point cloud is replaced with an updated pixel $\mathrm{x}$-coordinate data value $\mathrm{x}_{\mathrm{n}}$, updated pixel y-coordinate data value y'n and updated pixel z-coordinate data value $z^{\prime}$, respectively, using the equation:

$$
\left[\begin{array}{l}
x_{n}^{\prime} \\
y_{n}^{\prime} \\
z_{n}^{\prime}
\end{array}\right]=\left[\begin{array}{l}
x_{n} \\
y_{n} \\
z_{n}
\end{array}\right] *\left[\begin{array}{ccc}
1 & 0 & 0 \\
0 & \cos \theta_{x} & -\sin \theta_{x} \\
0 & \sin \theta_{x} & \cos \theta_{x}
\end{array}\right]
$$

where $\mathrm{x}_{\mathrm{n}}$ is the current pixel $\mathrm{x}$-coordinate data value in the point cloud data object, $y_{n}$ is the current pixel y-coordinate data value in the point cloud data object, $\mathrm{z}_{\mathrm{n}}$ is the current pixel z-coordinate data value in the point cloud data object and $n$ equals the number of pixels.

Next, the largest pixel $\mathrm{x}$-coordinate data value $\mathrm{xmax}_{\operatorname{man}}$ and the smallest pixel $\mathrm{x}$-coordinate data value $\mathrm{x}_{\mathrm{min}}$ are determined from the point cloud data object, along with the corresponding pixel z-coordinates, Zmax and $\mathrm{zxmin}$, respectively. The algorithm then calculates a y-axis angle of adjustment $\theta_{y}$ using the following equation:

$$
\theta_{y}=\tan ^{-1}\left(\frac{z_{x \max }-z_{x \min }}{x_{\max }-x_{\min }}\right)-\tan ^{-1}\left(\frac{1-1}{x_{\min }+3-x_{\min }}\right)
$$


Then each pixel $\mathrm{x}$-coordinate, $\mathrm{y}$-coordinate and $\mathrm{z}$-coordinate data value in the point cloud data object with an updated pixel $\mathrm{x}$-coordinate data value $\mathrm{x}_{\mathrm{n}}$, updated pixel $\mathrm{y}$-coordinate data value $\mathrm{y}_{\mathrm{n}}$ and updated pixel z-coordinate data value $z_{n}$, respectively, using the equation:

$$
\left[\begin{array}{l}
x_{n}^{\prime} \\
y_{n} \\
z_{n}
\end{array}\right]=\left[\begin{array}{l}
x_{n} \\
y_{n} \\
z_{n}
\end{array}\right] *\left[\begin{array}{ccc}
\cos \theta_{y} & 0 & -\sin \theta_{y} \\
0 & 1 & 0 \\
\sin \theta_{y} & 0 & \cos \theta_{y}
\end{array}\right]
$$

This completes the rotation of the point cloud into a plan view for the user. Small refinements in the angles $\theta_{\mathrm{x}}$ and $\theta_{\mathrm{y}}$ can be made by the user by selecting points on opposite sides of the hole to identify the level plane if not exactly determined in the autorotation calculations.

\subsubsection{Scaling the image}

The user can then crop out any superfluous imagery encompassing the hole of interest by creating a circular pattern around the excavated hole. These point cloud data are then removed from further calculation allowing the image on the screen to appear larger and more well-defined for the user to perform their analysis on. The user then needs to assign a dimension to the pixel space by identifying the length of the calibration object used in the images. This involves selecting two points with the cursor on a line bounding the object and inputting the distance value desired in the units desired for volume calculation (Figure 11).

This selection assigns data values for outer point $\mathrm{x}$-coordinate $\mathrm{x}_{0}$, outer point $\mathrm{y}$-coordinate $\mathrm{y}_{\mathrm{o}}$, inner point $\mathrm{x}$-coordinate $\mathrm{x}_{\mathrm{i}}$, inner point $\mathrm{y}$-coordinate $\mathrm{y}_{\mathrm{i}}$ and a scale value $\mathrm{S}$. Scale value $\mathrm{S}$ is a known quantity of desired dimensional units. For the calibration ring used in most of the experiments conducted with this method, the value is 15 inches being the distance between two opposing sides of the ring. 
Figure $11 \mathrm{a}, \mathrm{b}, \mathrm{c}$. Using the ERDC GUI to crop out data points outside the area of interest (a) and identifying the length of the reference scale (b) to obtain a more refined image for volume calculation (c).
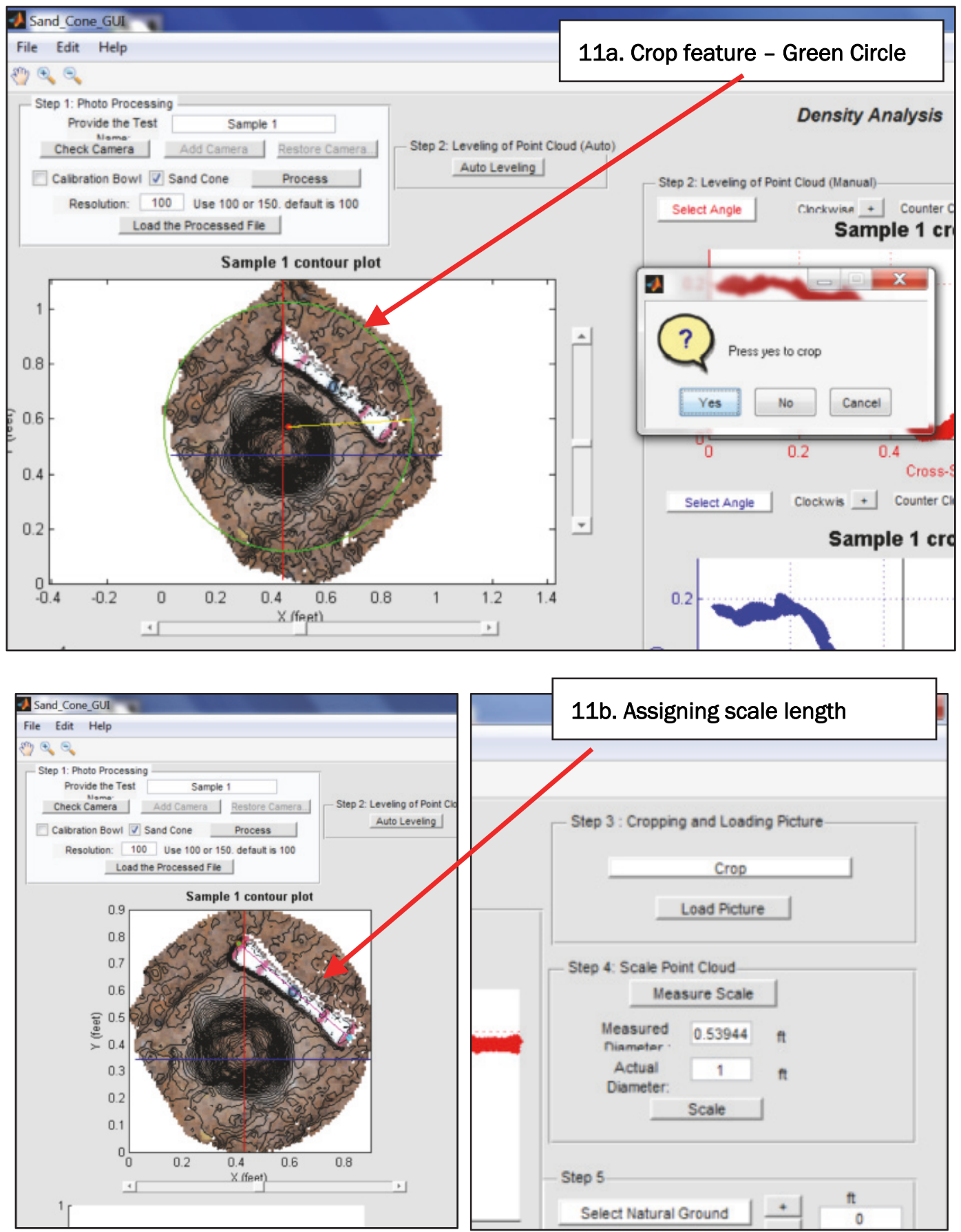


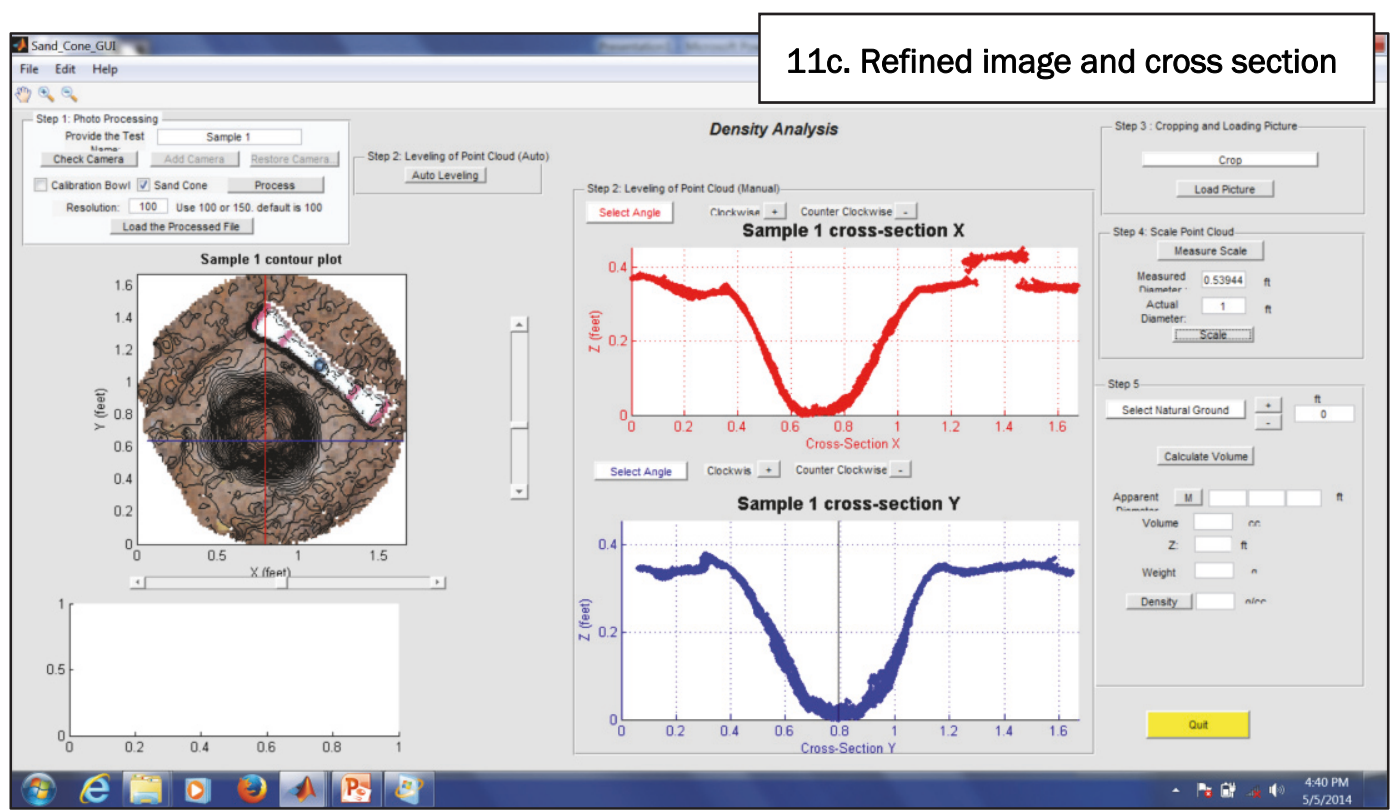

A coordinate distance $\mathrm{C}$ is calculated between an inner point and an outer point using the equation:

$$
C=\sqrt{\left(x_{o}-x_{i}\right)^{2}+\left(y_{o}-y_{i}\right)^{2}}
$$

And determines a scaling factor $\mathrm{F}_{\mathrm{s}}$ using the equation:

$$
F_{s}=S / C
$$

The point cloud data values for the pixel $\mathrm{x}$-coordinate, pixel y-coordinate, pixel z-coordinate are updated by multiplying each pixel $\mathrm{x}$-coordinate data value, pixel y-coordinate data value and pixel z-coordinate data value in the point cloud data object by scaling factor $F_{s}$. The point cloud now has real world dimensions and any calculations performed in this cloud space have meaning for determining volume.

\subsubsection{Determination of volume}

The software allows the user to determine the volume of the excavated hole downward from any $x-y$ plane cut along the z-axis. The software prompts the user to select two points, one on either side of the cross section (X or Y), to define the slope of a plane ideally laying along the original ground surface. The user can then use up and down arrows to move the visual representation of that plane along the z-axis through the visual representation of the excavation site and calibration object. The user adjusts the height until the ground plane intersects the perimeter of the excavation site (Figure 12). 
Figure 12. Using the ERDC GUI to obtain z-datum for volume estimation and utilization of contour lines to establish the top of the excavation.

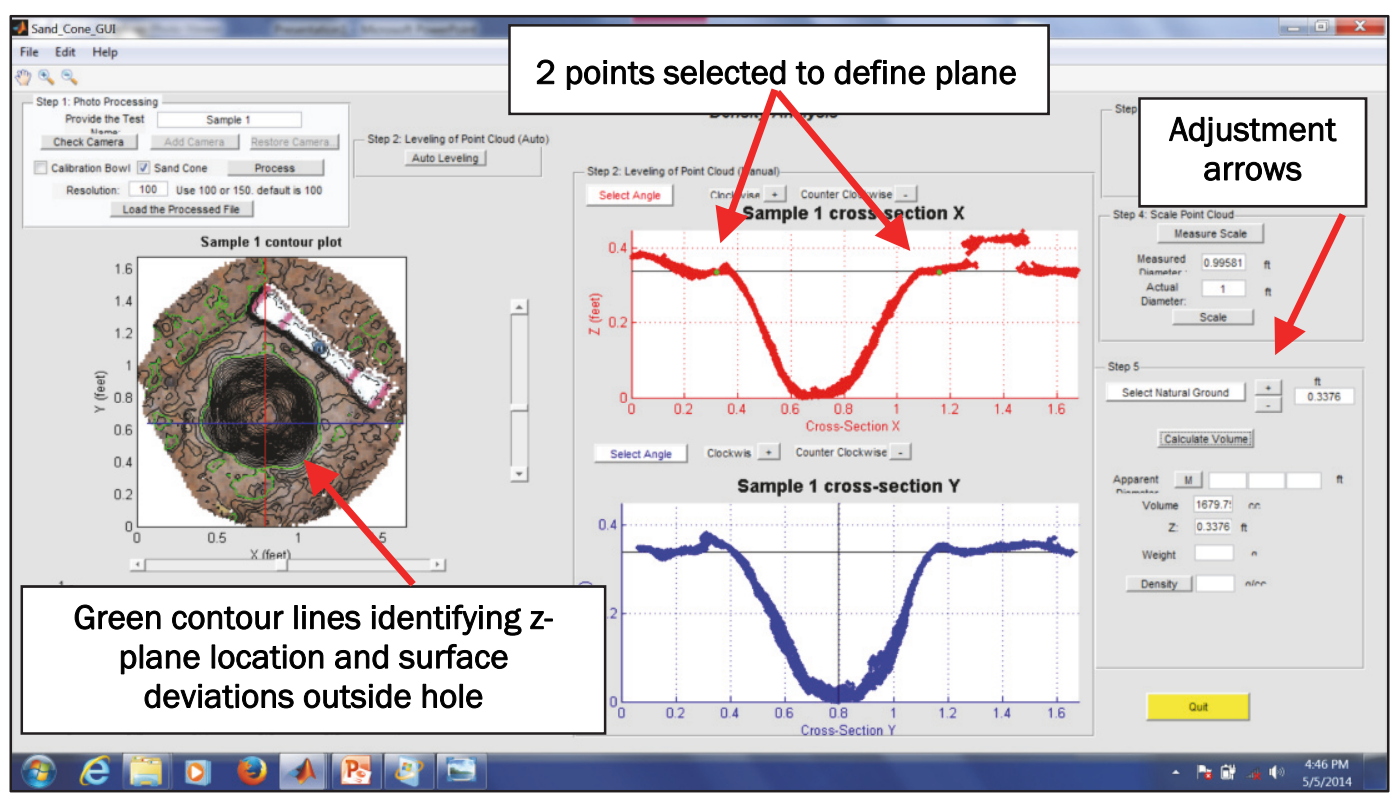

The $x-y$ plane selected by the user is color coded in green as a contour line extending around the perimeter of the excavated hole shown in the colored point cloud image. The user can also visualize where in relation to the lip of the hole they are on $\mathrm{x}$ - and $\mathrm{y}$ - direction cross-sectional plots. The user is to align the z-plane as closely to the actual lip of the excavated hole as possible while continuing to maintain a continuous contour around the hole perimeter. Due to undulations of the natural ground surface, other contour lines will become evident on the surface as shown in Figure 12. However the software is designed to only determine the volume of any area lying beneath the largest continuous contour line so as not to include other volumes associated with ground features not created by the excavation.

An illustration of the volume calculation begins with a representation of the excavated hole (Figure 13). When the user selects a given $x-y$ plane in the $\mathrm{z}$-axis, the software extracts the largest perimeter $\mathrm{x}$-coordinate data value $\mathrm{x}_{\mathrm{pmax}}$, the smallest perimeter $\mathrm{x}$-coordinate data value $\mathrm{x}_{\mathrm{pmin}}$, the largest perimeter $y$-coordinate data value $y_{p m a x}$, and the smallest perimeter $\mathrm{y}$-coordinate data value $\mathrm{y}_{\mathrm{pmin}}$ from the perimeter data object. 
Figure 13. Determination of extreme $X, Y, Z$ limits for volume calculation.

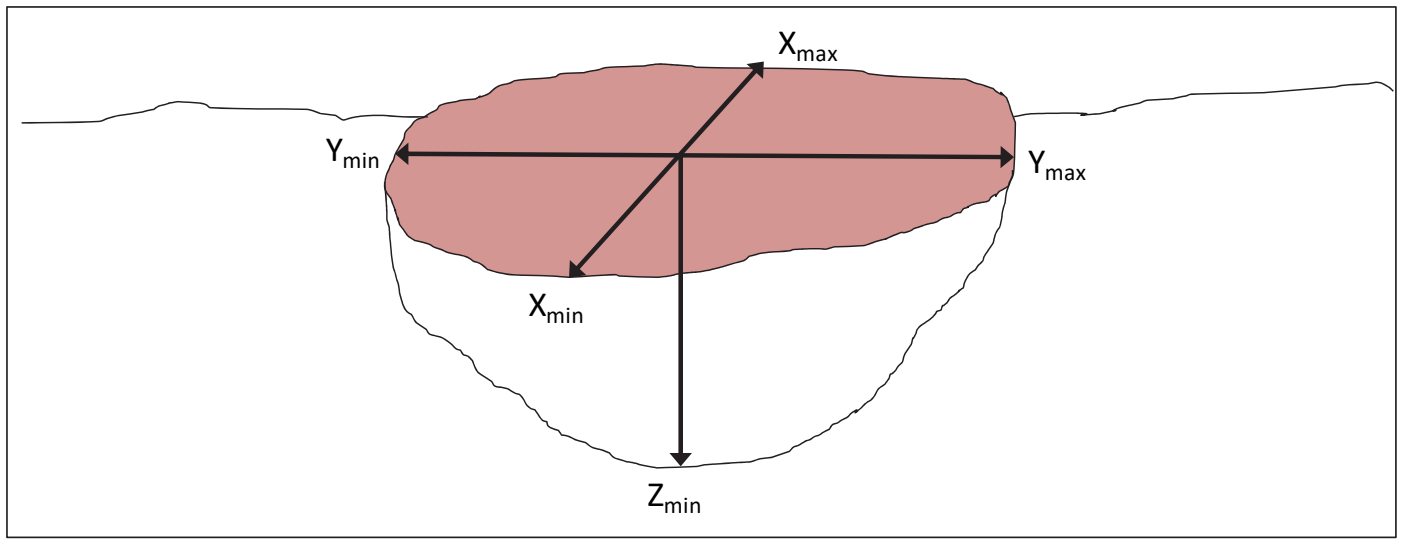

The software then generates an encompassing volumetric cube around the excavated hole (Figure 14) having outer boundaries defined by $\mathrm{x}_{\mathrm{pmax}}, \mathrm{X}_{\mathrm{pmin}}$, ypmax, $\mathrm{ypmin}, \mathrm{z}$-axis intersection point $\mathrm{zgp}$, and the smallest z-coordinate data value $\mathrm{Zmin}$ from the point cloud data object. Then the large volumetric cube is symmetrically divided into a cube grid comprising a plurality of sub-cubes having identical volume. The number of sub-cubes is preprogrammed and consists of a volume of one cubic pixel. This volume is then a function of the scaling parameter defining the length between pixels.

Figure 14. Creation of encompassing cubic volume around excavated hole and subdivision into one-cubic pixel cubes.

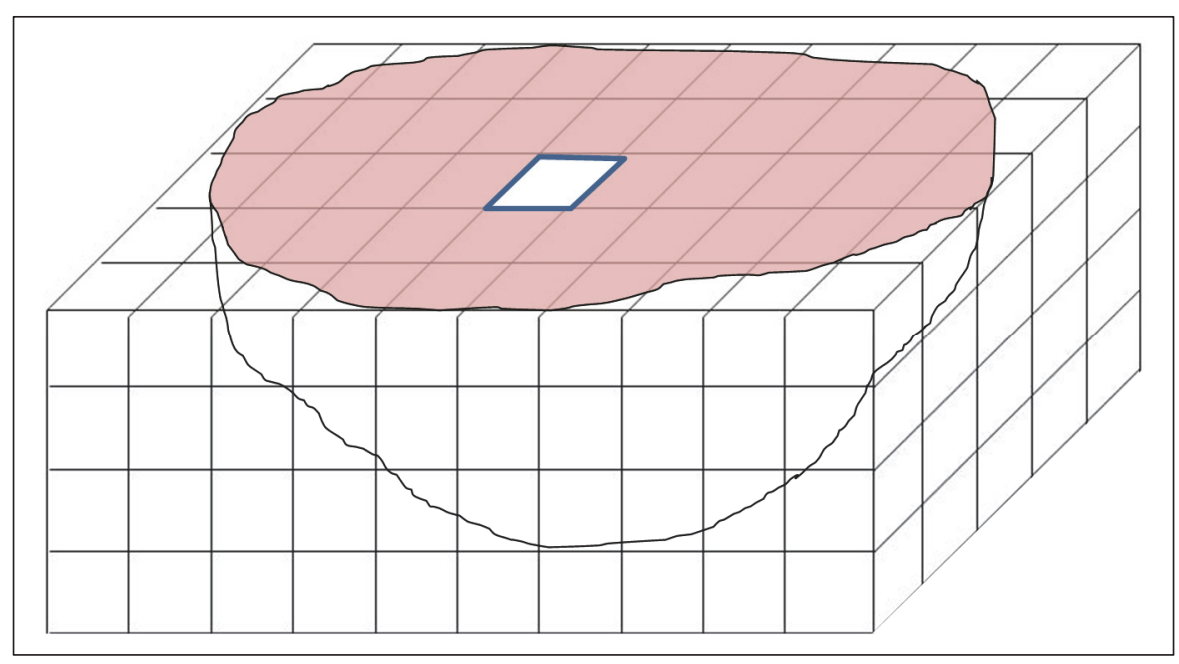

The software then identifies any sub-cubes located directly between the point cloud and the volumetric cube, as determined by the largest subcube perimeter (Figure 15). 
Figure 15. Eliminate cubes not associated with hole volume and identify partial volumes with cubes intersecting face of the hole.

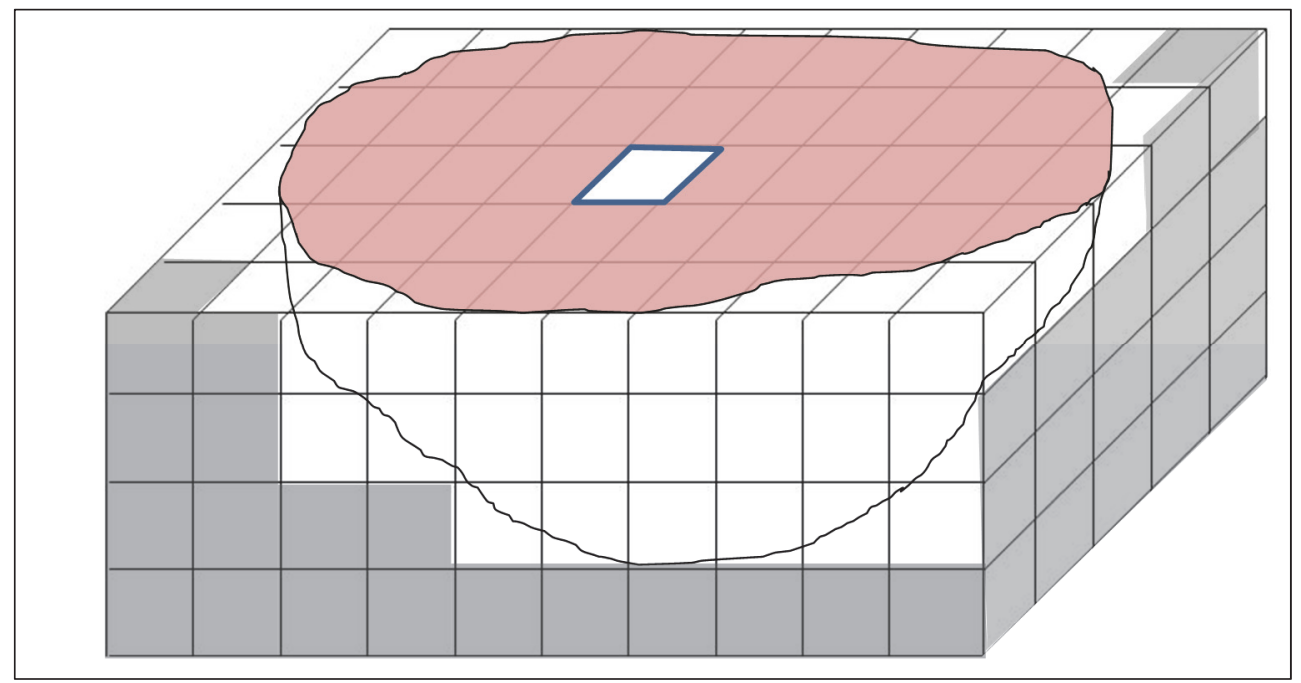

Finally, the remaining sub-cubes are summed taking in to account partial cube volumes of those sub-cubes that intersect the point cloud and the face of the excavated hole to calculate the excavated volume (Figure 16). The summation occurs in a summation of vertical columns, one sub-cube in area from the $x-y$ plane down along the z-axis to the intersection of the hole face. An alternative summation procedure provided in the software sums the cubes in a horizontal fashion to capture any voids that occur in an inverted position to the hole face that would be masked during a downward summation of cubes. A rationale for this would be the instance where a rock was extracted from the hole face creating a void like a miniature cave, which might be seen in the point cloud but creates a barrier to a summation of a continuous column of cubes from the surface downward.

Figure 16. Summation of subdivided cubes in columns around surface of the $x-y$ plane downward along the $z$-axis to the hole face.

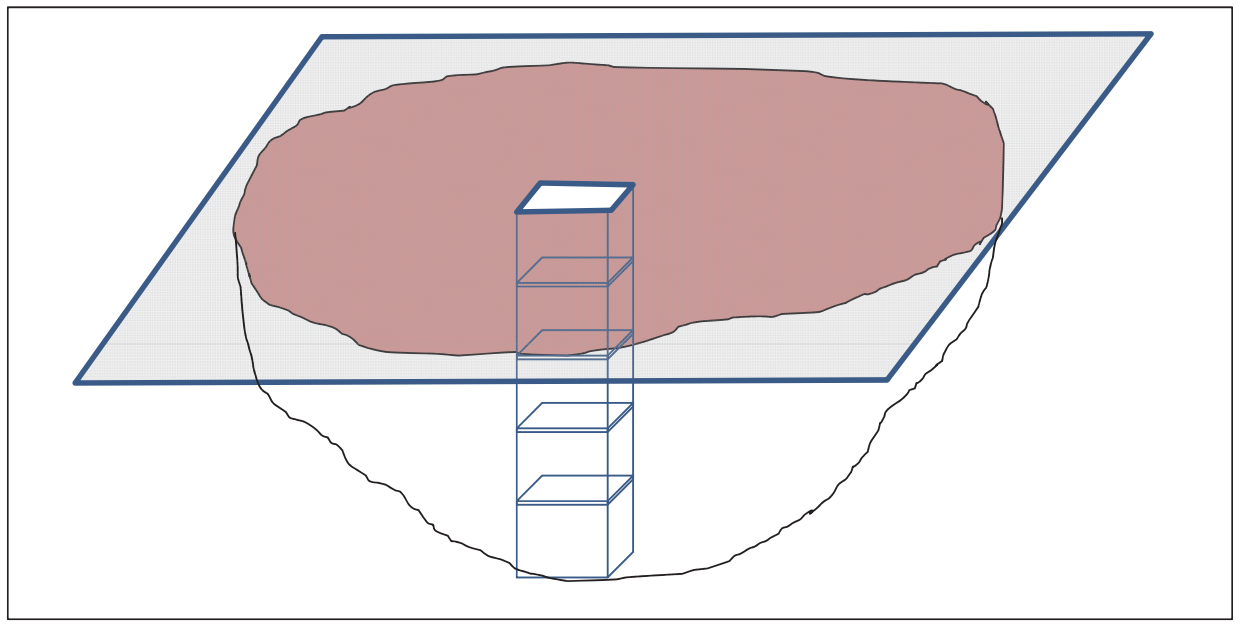


Once the calculations are complete, the user can enter the mass of soil removed from the excavated hole, and the software will compute the wet/bulk density of the soil by dividing the mass by the calculated volume. If the moisture content, w\%, is known, the user can enter that value as well, and the software will calculate the dry density of the soil by dividing the bulk density by $(1+\mathrm{w} \% / 100)$. The data are then saved in a variety of screenshots for later recall and data reporting (Figure 17).

Figure 17. Software output files from GUI for later reference.

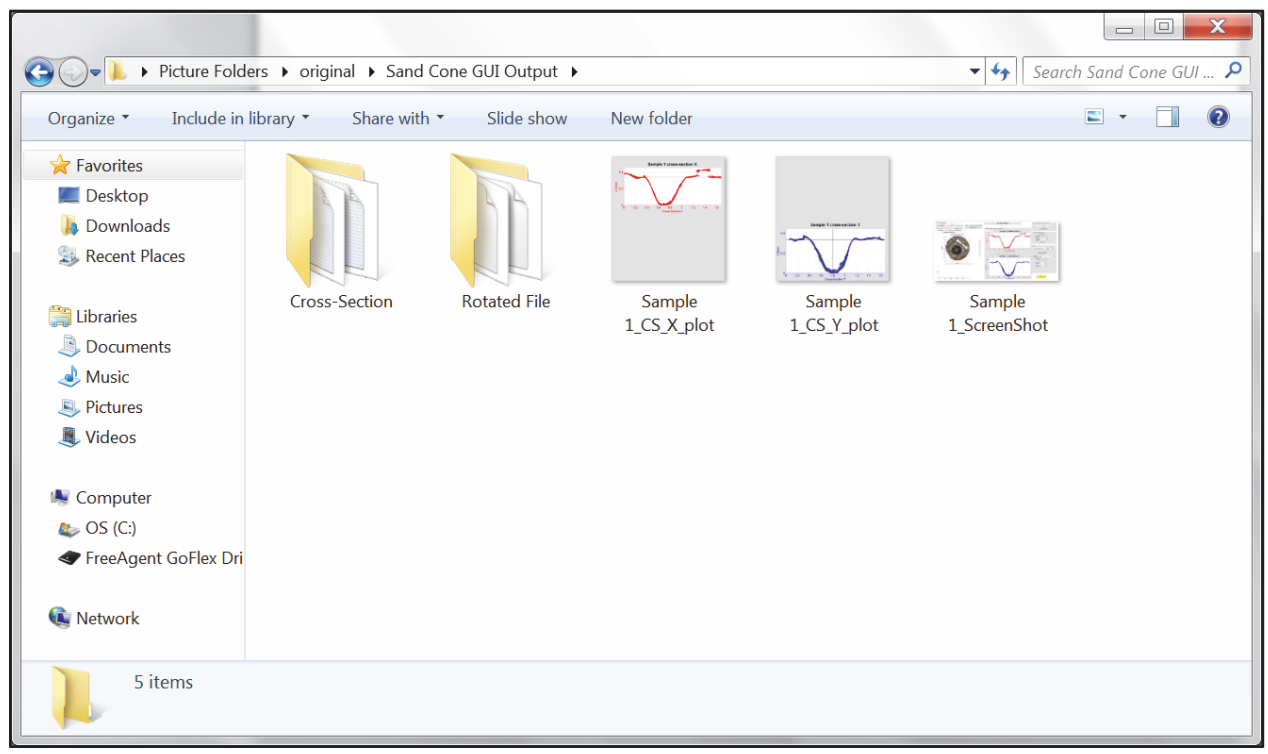

\subsection{Calibration}

In order to verify that the photogrammetric technique for capturing volume is accurate, a reference volume was constructed. This was necessary such that repeated attempts to image the hole using different camera settings, environmental conditions, and camera platforms should all return the same volume. Further this reference volume needed to resemble a hole excavated in the field, so that a sand cone test and a water volume test could be conducted to verify the hole volume in a manner similar to a field density test. The calibration platform was constructed to meet guidelines with the following attributes:

1. Sufficient areal dimensions to allow placement of a 15- or 16-in. diameter ring around opening to accommodate the reference scale used in the field experimentation

2. Removable dowels that can lock a sand cone plate into positions on the flat surface to perform a sand cone test 
3. A removable aluminum bowl that is designed to have a hemispherical shape throughout to minimize wall effects during photographing and resemble a field-excavated hole.

4. The aluminum bowl countersunk into the wooden platform for creation of a level surface; removable so the bowl can be weighed with water separate from the platform.

5. The aluminum bowl sandblasted, painted, and decorated with permanent ink in a randomized fashion to create a unique surface traceable by the structure from motion algorithm.

Figure 18 shows the platform that was built out from a wooden base. The base was painted a neutral reddish hue that has stark contrast to the red calibration ring. The dowel holes are visible where a sand cone plate can be centered on the aluminum bowl such that multiple sand cone tests can be conducted. The aluminum bowl rests in a routed lip that allows for a smooth surface across the top of the calibration platform.

Figure 18. Calibration platform with aluminum bowl and 15-in. diameter red ring for imaging (left) and close up view of aluminum bowl and texture (right).
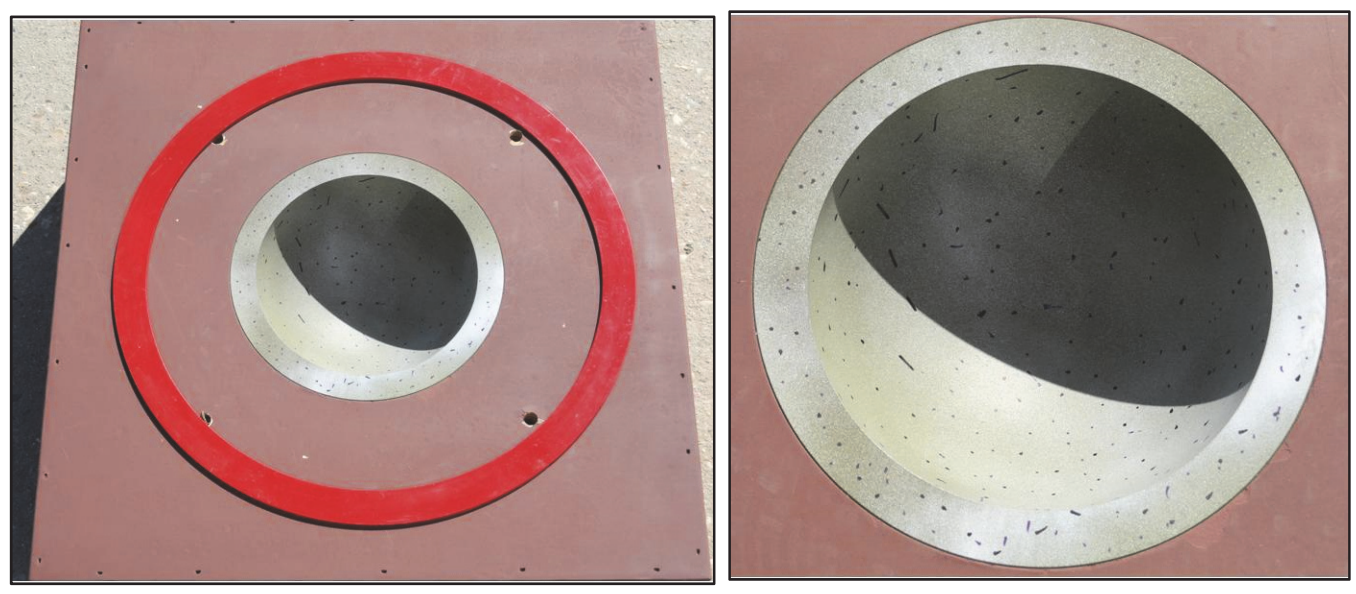

The volume of the aluminum bowl was calibrated using water by removing it from the platform and placing it directly on a large level balance accurate to 0.1g as shown in Figure 19. The bowl was filled with tap water adding a single drop of dishwashing liquid to remove surface tension of the water allowing for a level water surface. The weight of the bowl was recorded before and after filling three times and the average difference determined with results shown in Table 1 . Assuming the density of water as $1 \mathrm{~g} / \mathrm{cc}$, the volume of the bowl was directly proportional to the mass of the water it contained, resulting in a volume of $1105.8 \mathrm{cc}$. 
Figure 19. Water calibration of aluminum bowl insert, empty (left) and filled with water (right). Soap was added to create a level surface.
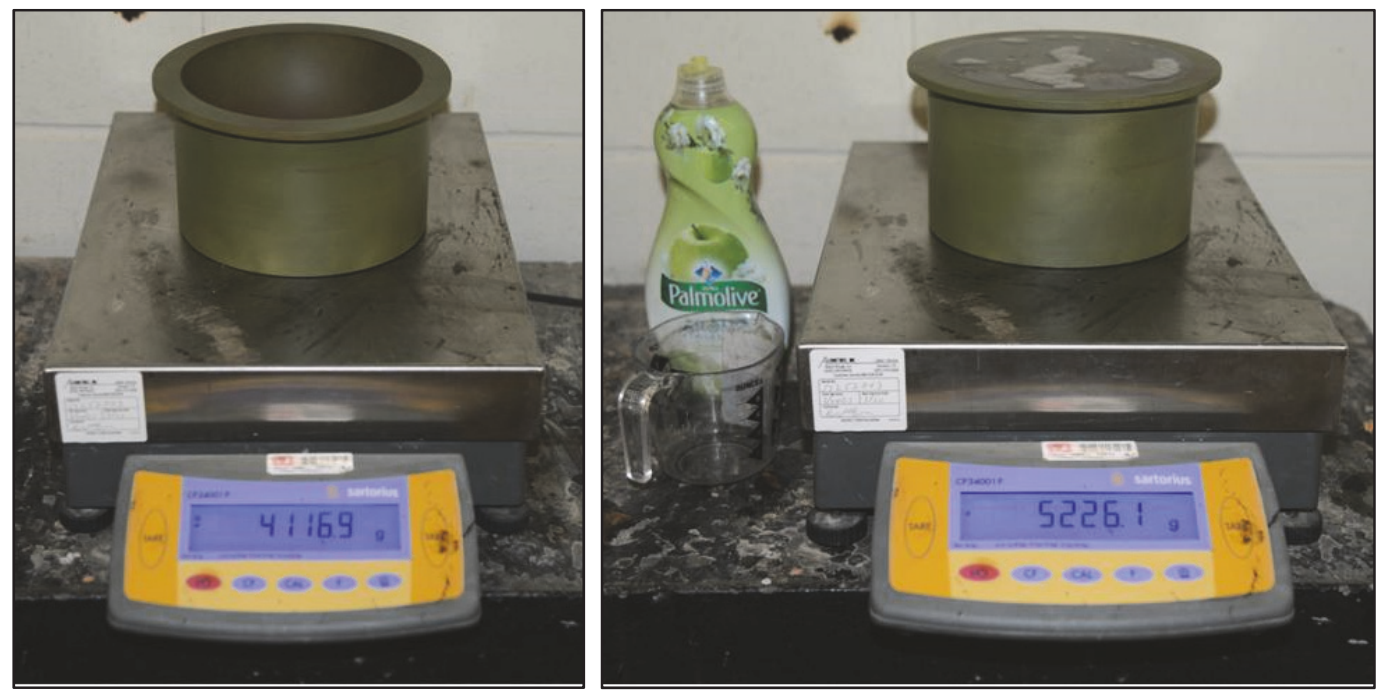

Table 1. Weighing trials of aluminum bowl with water added to determine hole volume.

\begin{tabular}{|c|r|r|r|}
\hline \multicolumn{4}{|c|}{ Weight of water in bowl (grams) } \\
\hline Trial & $\begin{array}{c}\text { Empty } \\
\text { Bowl }\end{array}$ & $\begin{array}{c}\text { Bowl with } \\
\text { Water }\end{array}$ & $\begin{array}{c}\text { Water in } \\
\text { Bowl }\end{array}$ \\
\hline 1 & 4118.5 & 5222.8 & 1104.3 \\
\hline 2 & 4118.5 & 5225.1 & 1106.6 \\
\hline 3 & 4118.5 & 5226 & 1107.5 \\
\hline 4 & 4118.5 & 5223.2 & 1104.7 \\
\hline & & Average $=$ & 1105.8 \\
\hline
\end{tabular}

A comparison to the water technique was obtained through use of the Sand Cone test method (ASTM 1556 2007b). In Figure 20, a completed sand cone test is shown mounted on the calibration platform. Note the wooden dowels holding the sand cone plate tightly in place during testing. The sand cone apparatus was calibrated using a level workbench surface and was very repeatable as shown in Table 2. A total of three sand cone measurements were made on the aluminum bowl with the plate affixed to the wooden dowels. Table 3 shows an average mold volume of $1103.8 \mathrm{cc}$ to compare to the water volume of $1105.8 \mathrm{cc}$, a differential of only $0.2 \%$ showing that both a water technique and sand cone technique are repeatable on a similar volume space and providing a definitive volume for comparison of the photogrammetric technique. 
Figure 20. Sand cone mounted on the calibration platform.

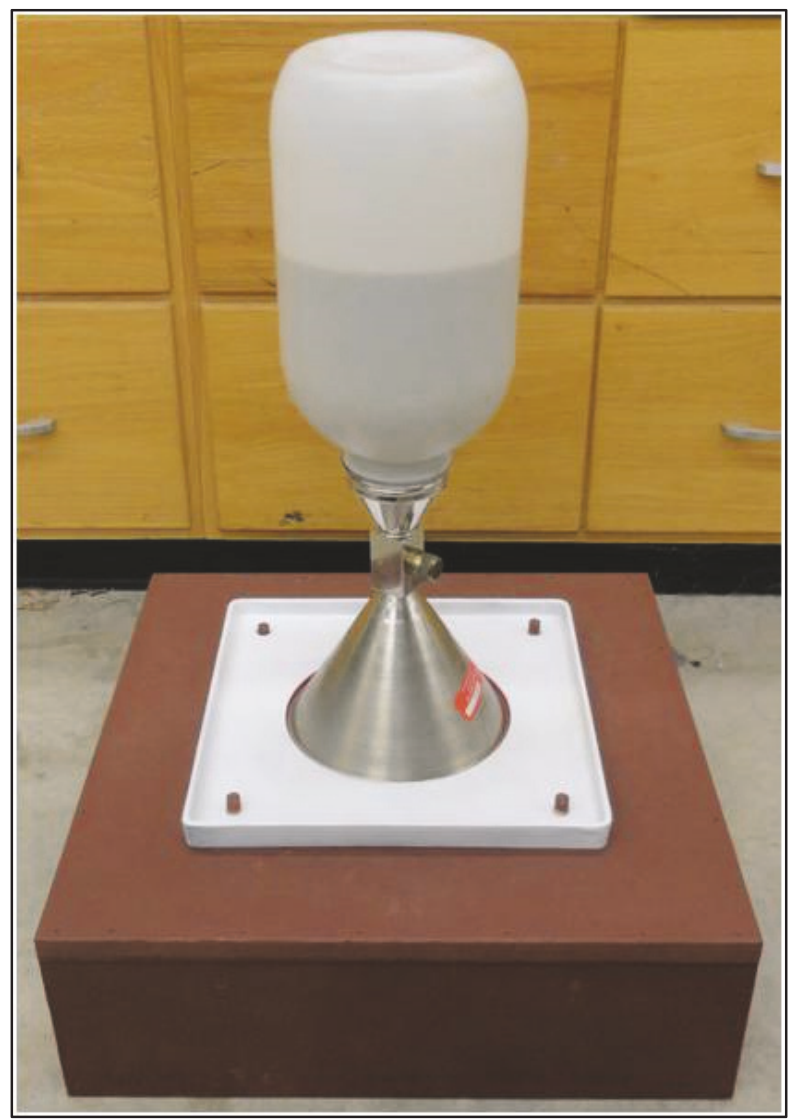

Table 2. Sand cone jug calibration prior to density measurement of calibration bowl.

\begin{tabular}{|c|r|r|r|r|r|}
\hline \multicolumn{7}{|c|}{ Sand Cone Calibration } \\
\hline Trial & $\begin{array}{c}\text { Empty Jug } \\
\text { (grams) }\end{array}$ & $\begin{array}{c}\text { Jug with } \\
\text { sand } \\
\text { (grams) }\end{array}$ & $\begin{array}{c}\text { Sand } \\
\text { (grams) }\end{array}$ & $\begin{array}{c}\text { Jug } \\
\text { Volume } \\
\text { (cc) }\end{array}$ & $\begin{array}{c}\text { Sand } \\
\text { density } \\
\text { (g/cc) }\end{array}$ \\
\hline 1 & 871 & 7189.3 & 6318.3 & 4037 & 1.565 \\
\hline 2 & 871 & 7193.3 & 6322.3 & 4037 & 1.566 \\
\hline 3 & 871 & 7184.2 & 6313.2 & 4037 & 1.564 \\
\hline 4 & 871 & 7170.5 & 6299.5 & 4037 & 1.560 \\
\hline 5 & 871 & 7169.4 & 6298.4 & 4037 & 1.560 \\
\hline 6 & 871 & 7184.9 & 6313.9 & 4037 & 1.564 \\
\hline & & & & Average $=$ & 1.563 \\
\hline
\end{tabular}


Table 3. Volume of calibration mold using the sand cone method.

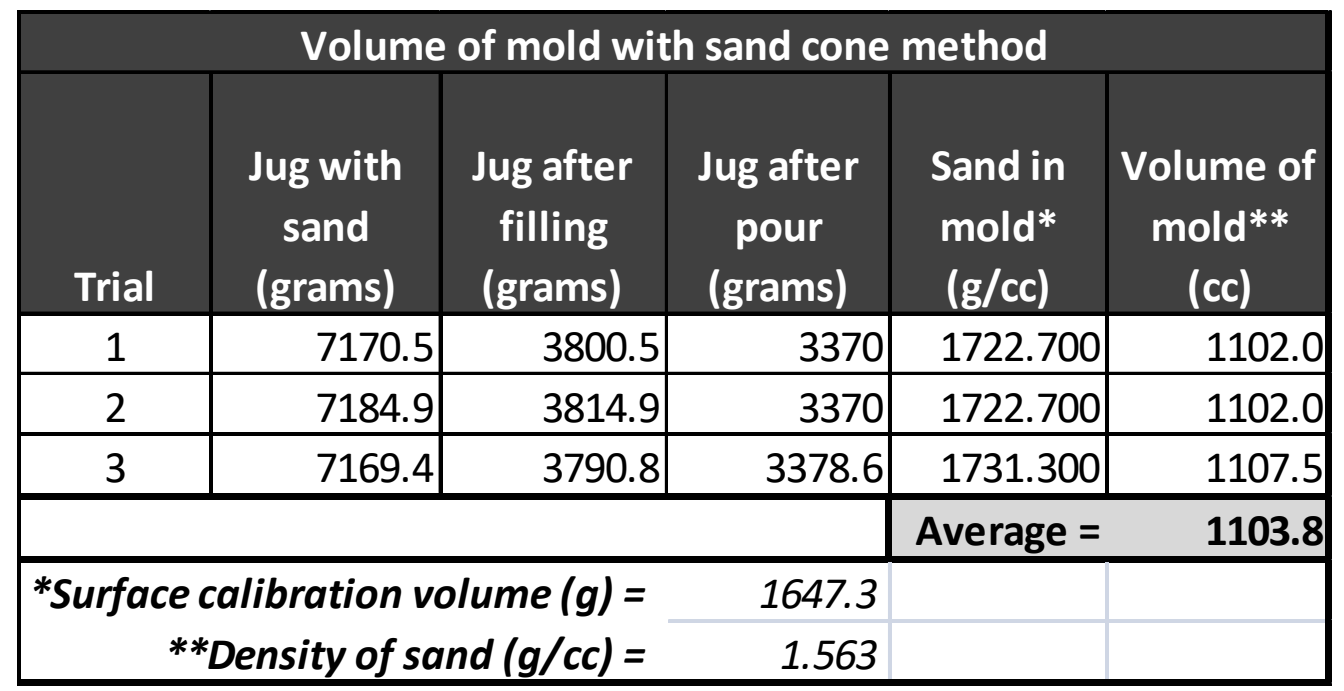

A series of photographs were taken of the aluminum bowl mounted in the wooden frame using the red calibration ring in a setup as shown in Figure 18. Three camera platforms were used for the validation of the photogrammetric technique (Figure 21):

- A Nikon D-80o, high resolution (36 megapixel) digital single lens reflux camera (SLR) with a 24-120mm zoom lens

- A Nikon D-40 low resolution digital SLR (6.1 megapixel) camera with 18-50mm zoom lens

- A Sony DSC-H70 point-and-shoot camera (16 megapixel) camera with 10x optical zoom

Figure 21. Cameras used in calibration experiment: Nikon D-800 (left), Nikon D-40 (center), Sony DSC-H70 (right).
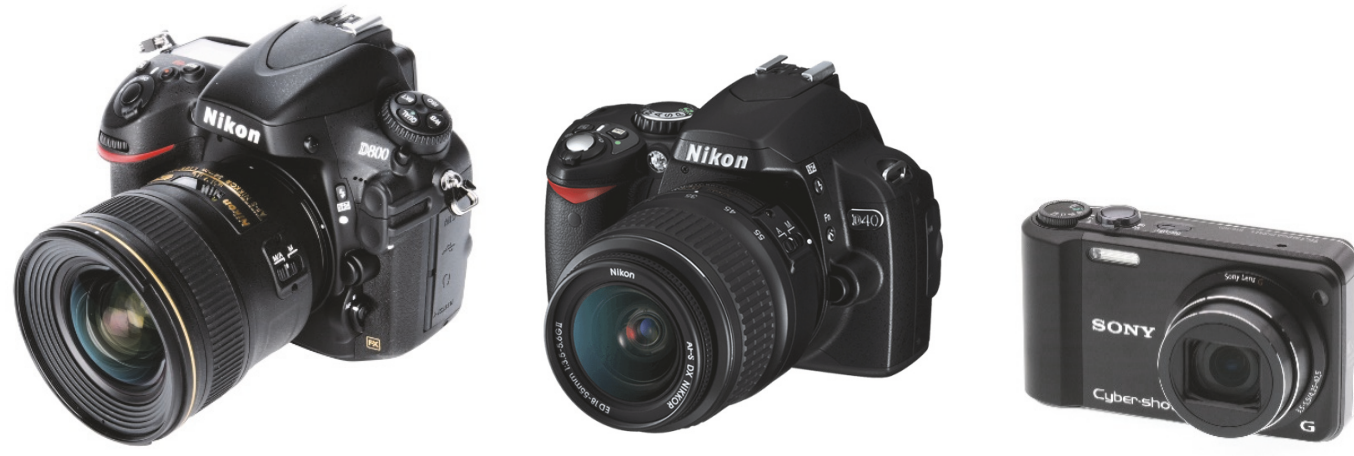

A series of 18 photographs were taken of the bowl with each camera device: 8 photographs around the perimeter capturing the red ring in each photograph, 8 photographs with zoom applied to the aluminum bowl, and 
2 overhead shots looking downward into the bowl. These follow the procedures outlined in Chapter 2.1. The photographs were then loaded onto the computer and the Matlab software run on each set of photos to determine the volumetric data provided in Table 4.

Table 4. Volume of calibration bowl using photogrammetric technique.

\begin{tabular}{|c|r|r|r|}
\hline \multicolumn{4}{|c|}{ Volume of hole (cc) } \\
\hline Trial & $\begin{array}{c}\text { Nikon } \\
\text { D-800 }\end{array}$ & $\begin{array}{c}\text { Sony DSC- } \\
\text { H70 }\end{array}$ & Nikon D-40 \\
\hline 1 & 1087.1 & 1098 & 1081.7 \\
\hline 2 & 1106.3 & 1106.9 & \\
\hline 3 & 1071 & 1122 & \\
\hline Average $=$ & $\mathbf{1 0 8 8 . 1}$ & $\mathbf{1 1 0 9 . 0}$ & $\mathbf{1 0 8 1 . 7}$ \\
\hline
\end{tabular}

Assuming an average total volume of the hole as $1104.8 \mathrm{cc}$, the Nikon D800 had an error of $1.6 \%$, the Sony an error of $0.3 \%$, and the Nikon D-40 an error of $2.2 \%$. It is not clear why the Sony performed the best; however, it was not influenced by optics of an adjustable lens attachment.

Irrespective of the lens influence, the high and medium megapixel cameras were able to capture the volume quite well using nothing more than optics. The low megapixel camera did not generate a fine enough point cloud and the coarseness reduced the number of sub-volume cubes, resulting in a less accurate total volume calculation.

\subsection{Summary}

The development of photogrammetric technique for capturing an accurate volume of hole excavated in soil typical of that found in the sand cone test was shown to be successful. The implementation of the software and the comparison of results to a reference volume that was validated using two volume replacement methods (sand cone and water replacement) show that with an error less than $2 \%$ of the total volume with accuracies within $0.05 \%$ of the reference volume based on camera type may provide a suitable substitute approach to measuring soil volume without a physical material to backfill the excavated hole. The next chapter will evaluate the performance of the technique in real soils as compared to the sand cone and nuclear density gauge using the same cameras as described in Section 2.3. 


\section{Experimental Procedures on Soil}

\subsection{Phase one: Initial development of technique}

Validation of the photogrammetric technique for determining the wet density of soil was approached in two phases. The first phase was using the technique wherever field experimentation was occurring for ERDC-based projects and comparing the results to either the sand cone or the nuclear density gauge reading. In most instances, however, the test sections evaluated were not designed explicitly for evaluating density, and therefore considerable variability in soil behavior was evident across the test sections. This phase helped refine the size and placement of the calibration object, the manner in which photographs were taken and the resolution required for good point cloud resolution. The second phase of validation was constructing test sections specifically for evaluating photogrammetry whereby replicates of the technique could be performed on a uniform material and compared to sand cone and nuclear gauge tests in a controlled environment.

Initial phase one evaluation involved performing the photogrammetry analysis on holes dug within the confines of a standard sand cone plate. Inaccuracies arose due to the presence of the vertical walls and shadowing caused by the tight confines of the sand cone plate causing missing data in the generated point cloud. Attempts were made to paint the sand cone plate white with a red ring painted around the inner lip to create greater contrast for the software to define the lip of the hole (Figure 5). However, the sand cone plate was abandoned as a reference scale and a circular ring was used as the calibration scale, allowing for holes to be dug in any manner of dimension and depth and a more parabolic shape to the hole to be created since no sand cone plate hindered excavation. This free-form digging allowed for much more accurate point cloud generation due to less shadowing and better imaging of the parabolic versus vertical face.

A summary of the data points collected during phase one of the study is presented in Table 5 using the Sony 16 megapixel camera. A discussion of the details of every particular data collection is not given as the intent of this data is to identify data trends to guide phase two testing. Phase two testing is to evaluate whether these data trends are systemic to the procedure or a function of the myriad of variables, which were evaluated during the development of the photogrammetric technique. 
Table 5. Data collected with Sony camera (2013 and 2014 software generations).

\begin{tabular}{|c|c|c|c|c|c|c|c|}
\hline Soil & Hole ID & $\begin{array}{l}\text { Wet Wt } \\
\text { Sampled } \\
\text { (grams) }\end{array}$ & $\begin{array}{c}\text { GUI } \\
\text { Volume } \\
\text { (cc) }\end{array}$ & $\begin{array}{c}\text { Calc Wet } \\
\text { Density } \\
\text { (pcf) }\end{array}$ & $\begin{array}{c}\text { NDG } \\
\text { Wet Dense } \\
\text { (pcf) }\end{array}$ & $\begin{array}{l}\text { Sand Cone } \\
\text { Wet Dense } \\
\text { (pcf) }\end{array}$ & $\begin{array}{c}\text { Water } \\
\text { Density } \\
\text { (pcf) }\end{array}$ \\
\hline \multirow{4}{*}{$\begin{array}{l}\text { Sandy Clay } \\
\text { Ft Polk Red Ring }\end{array}$} & 1 & \begin{tabular}{|l|}
2873 \\
\end{tabular} & 1385 & \begin{tabular}{|l|}
129.4 \\
\end{tabular} & 126.1 & & 120.0 \\
\hline & 2 & 3212 & 1663 & 120.5 & 122 & & 111.4 \\
\hline & 3 & 3136 & 1603 & 122.1 & 125 & & 118.5 \\
\hline & 4 & 3247 & 1596 & 127.0 & 124.1 & & 108.8 \\
\hline Gravelly Clay & 1 & 3131 & 1247 & 156.7 & 140.1 & & 150.5 \\
\hline \multirow[t]{3}{*}{ Ft Polk Red Ring } & 2 & 2594 & 1026 & 157.8 & 144.7 & & 155.6 \\
\hline & 3 & 3223 & & & 137.3 & & 128.6 \\
\hline & 4 & 2188 & 869 & 157.1 & 143 & & 138.5 \\
\hline \multirow{4}{*}{$\begin{array}{l}\text { Sandy Clay } \\
\text { Ft Polk Plate }\end{array}$} & 1 & 1898 & 819 & 144.6 & 132.2 & 133.4 & \\
\hline & 2 & 1770.5 & 832.5 & 132.7 & 124.1 & 120.2 & \\
\hline & 3 & 1763.5 & 826.9 & 133.1 & 128.1 & 132.4 & \\
\hline & 4 & 1667.5 & 801 & 129.9 & 130.2 & 133.7 & \\
\hline Gravelly Clay & 1 & 1807.5 & 1187 & 95.0 & 91.9 & 91.0 & \\
\hline \multirow[t]{3}{*}{ Ft Polk Plate } & 2 & 2137 & 1392 & 95.8 & 89.8 & 109.9 & \\
\hline & 3 & 1941 & 1291 & 93.8 & 91.0 & 85.5 & \\
\hline & 4 & 2467 & 1573 & 97.9 & 99.6 & 97.3 & \\
\hline \multirow{2}{*}{$\begin{array}{l}\text { Buckshot Clay } \\
\text { Hangar } 4\end{array}$} & 1 & 2617 & 1388.9 & 117.6 & 116.5 & & \\
\hline & 2 & 3605.4 & 1943.7 & 115.7 & 116.7 & & \\
\hline Limestone & 15 & 3842 & 1582 & 151.5 & 132.0 & 148.3 & \\
\hline \multirow[t]{2}{*}{ Hangar 4} & $2 \mathrm{~S}$ & 4107 & 1916 & 133.8 & 135.2 & 143.2 & \\
\hline & $3 N$ & 5474.5 & 2274 & 150.2 & 136.9 & 136.5 & \\
\hline \multirow{7}{*}{$\begin{array}{l}\text { Silt } \\
\text { Dugway }\end{array}$} & CW-1-10-L-UN 1 & 1350 & 768 & 109.7 & 98.8 & 103.4 & \\
\hline & CW-2-7-KCL 1-Pos 2 & 1706.5 & 976 & 109.1 & 106.8 & 105.1 & \\
\hline & CW-2-8-L-KCL 1-Pos 1 & 1595 & 1019 & 97.7 & 96.7 & 90.6 & \\
\hline & CW-2-9-KCLOPos 4 & 1400 & 892 & 97.9 & 102.7 & 99.0 & \\
\hline & CW-2-10-L-KCL 1-Pos 1 & 2020 & 1051 & 119.9 & 113.6 & 116.8 & \\
\hline & CW-2-11-L-KCL 1-Pos 2 & 1599 & 1021 & 97.7 & 98.0 & 94.5 & \\
\hline & CW-2-11-L-KCL 1-Pos 3 & 2007 & 1274 & 98.3 & 99.4 & 100.2 & \\
\hline Silty-Sand & CW-1-10-L-UN 1 & 2495 & 1148 & 135.6 & 129.3 & 133.8 & \\
\hline \multirow[t]{2}{*}{ Dugway } & CW-2-7-KCL 1-Pos 2 & 2260 & 1023 & 137.9 & 135.1 & 138.4 & \\
\hline & CW-2-8-L-KCL 1-Pos 1 & 2192.5 & 962 & 142.2 & 132.6 & 132.6 & \\
\hline \multirow{4}{*}{$\begin{array}{l}\text { Clay Gravel } \\
\text { Hangar } 4\end{array}$} & $1 \mathrm{~N}$ & 2813 & 1193 & 147.1 & 136.9 & 139.6 & \\
\hline & $2 \mathrm{~N}$ & 2606 & 1050 & 154.9 & 134.9 & 144.5 & \\
\hline & 15 & 2194.5 & 1051 & 130.3 & 132.2 & 137.2 & \\
\hline & $2 \mathrm{~S}$ & 3009.5 & 1486 & 126.4 & 135.4 & 136.7 & \\
\hline Calibration Bowl & Outdoor & 1105.8 & 1072 & 64.4 & 62.4 & 62.5 & 62.4 \\
\hline \multirow[t]{2}{*}{ Fly Ash* } & Hole 1 & 80.15 & 42.28 & 118.3 & 116.7 & 116.7 & \\
\hline & Hole 2 & 162.39 & 86.45 & 117.2 & 118.6 & 118.6 & \\
\hline
\end{tabular}

* Drive cylinder was used to collect comparison density and not sand cone or NDG

Table 6 illustrates the initial error discovered in the data processing. What is noticeable is a similar error seen between the sand cone-nuclear density gauge and the sand cone-photogrammetric technique. This suggests that the photogrammetric procedure is similar in response to the standard volume replacement technique. 
Table 6. Statistical summary of phase one evaluation of photogrammetric technique.

\begin{tabular}{|c|c|c|c|}
\hline & $\begin{array}{c}\text { NDG and } \\
\text { Photo }\end{array}$ & $\begin{array}{l}\text { SC and } \\
\text { Photo }\end{array}$ & $\begin{array}{c}\text { NDG and } \\
\text { SC }\end{array}$ \\
\hline Average density differential (pcf) & -4.5 & -2.2 & -2.2 \\
\hline Standard deviation (pcf) & 6.9 & 6.9 & 5.9 \\
\hline Coefficient of variation (\%) & 5.8 & 5.9 & 5.0 \\
\hline
\end{tabular}

In Figure 22, one-to-one comparisons are made between the wet density values measured among the sand cone, nuclear density gauge, and the photogrammetric method. What is noticeable is that deviations from the equality line occur at the higher wet density values ( $>130 \mathrm{pcf}$ ); those associated with the more coarse-grained materials. This error occurs because of the following:

- Complexity of properly imaging the surface covered with larger aggregates,

- Defining a smooth plane boundary at the top of the excavated hole caused by caving in of large particles and the lack of cohesion in the coarser-grained soils,

- Difficulty in identifying the side wall of the hole around protruding rocks, leaving holes in the point cloud.

This error is not noticed in the sand cone versus NDG plot, suggesting that when coarser-grained materials are being evaluated, a greater amount of care must be taken to capture the hole surface as accurately possible. Advances in the algorithms to define the hole surface from phase one to phase two help reduce the amount of error seen with these coarse-grained materials. 
Figure 22. Graphical comparison of wet density between sand cone, NDG, and photogrammetry.
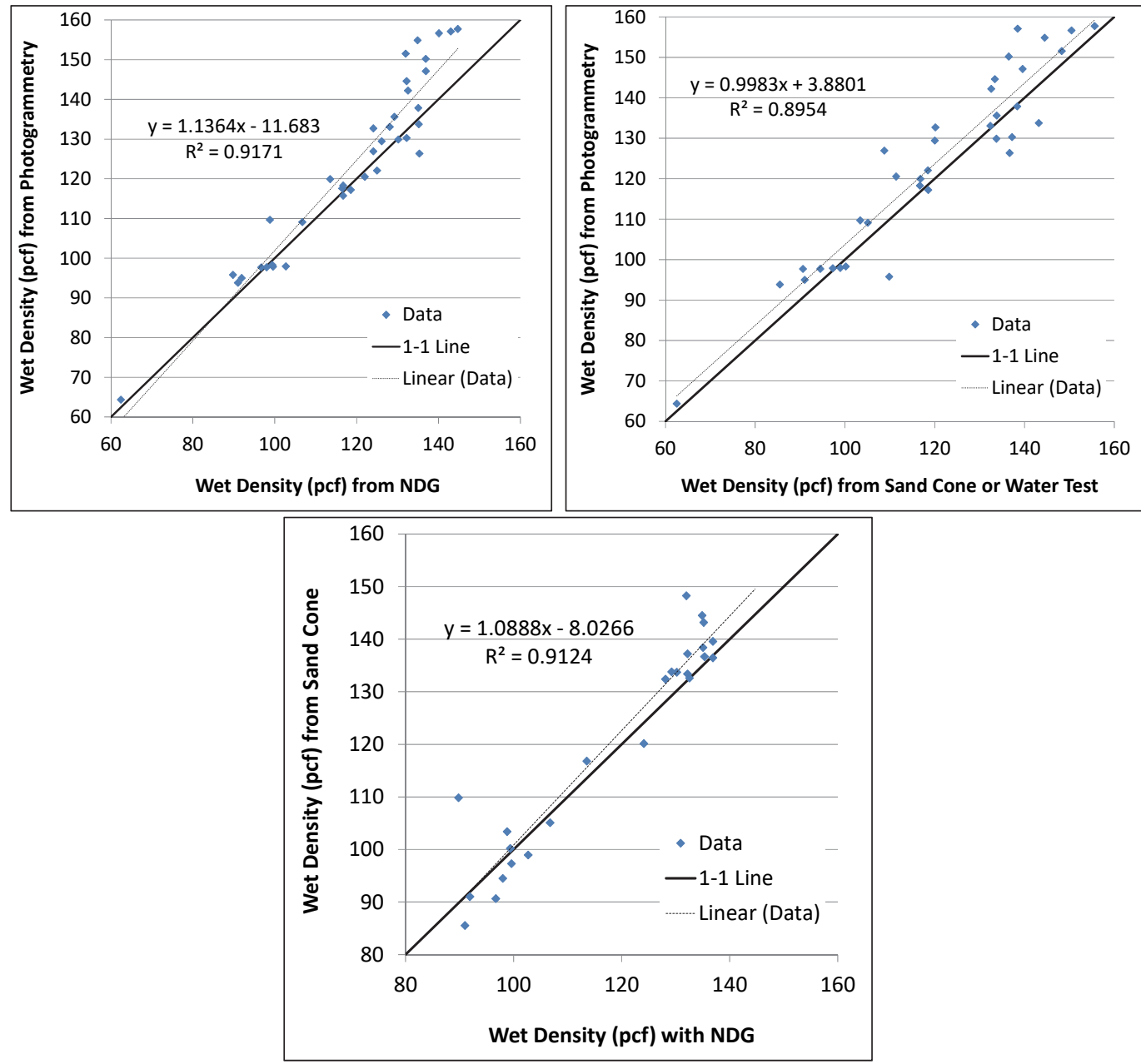

\subsection{Phase 2: Validation of technique on constructed test sections}

Six different soil types ranging from fine grained to coarse grained were used for this study in order to provide a wide range of soil properties for validating the effectiveness of the photogrammetry density method. The Unified Soil Classification System (USCS; ASTM 2011) soil types included high-plasticity clay (CH), low-plasticity clay (CL), clayey sand (SC), clayeysand with gravel (SC), blended clayey sand (SC), and crushed limestone (GW-GC).

Standard laboratory tests were performed at the ERDC Materials Testing Center (MTC) to determine basic geotechnical properties of the soils. Tests conducted on each soil included standard grain-size distribution (ASTM 2006) with hydrometer analysis (ASTM 2007a) for dissemination of silt and clay fractions, Atterberg limits (ASTM 2010b) including liquid limit (LL), plastic limit (PL), and plasticity index (PI), Unified Soil Classification 
(USCS; ASTM 2011), and modified proctor compaction (ASTM 2012) to determine optimum moisture content (OMC) and maximum dry density (MDD). Details of these test results are in Appendix A. A summary of these properties is shown in Table 7. The OMC was used to determine the two different moisture levels for compaction of each soil, and the MDD was used during construction to determine the different compaction levels for data collection.

Table 7. Soil properties.

\begin{tabular}{|c|c|c|c|c|c|c|c|c|c|c|c|}
\hline \multirow[b]{2}{*}{ Soil ID } & \multirow{2}{*}{$\begin{array}{l}\text { USCS } \\
\text { Classification }\end{array}$} & \multicolumn{3}{|c|}{ Atterberg Limits } & \multicolumn{3}{|c|}{$\begin{array}{c}\text { Grain size } \\
\text { (\% by weight) }\end{array}$} & \multirow[b]{2}{*}{$\mathrm{Cu}_{\mathrm{u}}$} & \multirow[b]{2}{*}{$\mathrm{C}_{\mathrm{c}}$} & \multirow{2}{*}{$\begin{array}{l}\text { MDD } \\
\text { (pcf) }\end{array}$} & \multirow{2}{*}{$\begin{array}{l}\text { OMC } \\
(\%)\end{array}$} \\
\hline & & LL & $\mathrm{PL}$ & PI & Fines & Sand & Gravel & & & & \\
\hline $\begin{array}{l}\text { High Plasticity } \\
\text { Clay }\end{array}$ & Clay $(\mathrm{CH})$ & 81 & 23 & 58 & 95.6 & 4.4 & 0 & - & - & 104.3 & 22.4 \\
\hline $\begin{array}{l}\text { Low Plasticity } \\
\text { Clay }\end{array}$ & Clay (CL) & 35 & 22 & 13 & 97.4 & 2.6 & 0 & - & - & 118.1 & 13.7 \\
\hline $\begin{array}{l}\text { Red Clayey } \\
\text { Sand }\end{array}$ & Clayey Sand (SC) & 19 & 13 & 6 & 34.5 & 65.4 & 0 & - & - & 119.8 & 12.5 \\
\hline Clay-Gravel & $\begin{array}{l}\text { Clayey Sand (SC), } \\
\text { with Gravel; }\end{array}$ & 25 & 13 & 12 & 14.7 & 46.4 & 38.9 & 1714 & 8.1 & 133.1 & 7.4 \\
\hline $\begin{array}{l}\text { Blended Clayey } \\
\text { Sand }\end{array}$ & Clayey Sand (SC) & 29 & 19 & 10 & 19.1 & 77.5 & 0 & 22.2 & 8.2 & 134.8 & 7.4 \\
\hline Limestone & $\begin{array}{l}\text { Gravel (GW-GC), } \\
\text { with Silty Clay } \\
\text { and Sand; }\end{array}$ & 20 & 14 & 6 & 5.7 & 21.6 & 72.7 & 24.4 & 2.4 & 145.7 & 4.7 \\
\hline
\end{tabular}

$\mathrm{C}_{\mathrm{u}}=$ Coefficient of uniformity

$\mathrm{C}_{\mathrm{c}}=$ Coefficient of curvature

\subsection{Description of test instruments for comparison}

In this study, the photogrammetric method was conducted alongside a series of other non-nuclear density devices to evaluate the feasibility of replacing the nuclear density gauge. The performance of the non-nuclear devices and their companion test plan are given in Berney and MejiasSantiago 2016. The list of instruments and methods that are relevant to the photogrammetric study is given in Table 8; the following sections describe each instrument or method in more detail.

Table 8. List of instruments used in this evaluation.

\begin{tabular}{|l|l|l|l|}
\hline Instrument & Standard Method & Description & Output \\
\hline & & & $\bullet$ Wet and Dry Density \\
Model 3430 & ASTM D6938 & Nuclear Moisture- & $\begin{array}{l}\bullet \% \text { Moisture Content } \\
\text { Roadreader }\end{array}$ \\
& & $\begin{array}{l}\text { DM } \\
\text { TM Voids }\end{array}$ \\
\hline Sand Cone & ASTM D1556 & Density Determination & $\bullet$ Wet Density \\
\hline
\end{tabular}




\begin{tabular}{|l|l|l|l|}
\hline Hot Plate & ASTM D4959 & Portable electric stove & $\bullet$ Moisture Content \\
\hline Laboratory Oven & ASTM D2216 & Reference standard & $\bullet$ Moisture Content \\
\hline Nikon D800 & N/A & Photogrammetric & $\bullet$ Wet density \\
\hline
\end{tabular}

\subsubsection{Nuclear moisture-density gauge}

The Troxler Model 3430 Roadreader ${ }^{\mathrm{TM}}$ nuclear moisture-density gauge, shown in Figure 23, uses the interaction of gamma radiation with matter to measure density through direct transmission or backscatter. It determines the density of a material by counting the number of photons emitted by a cesium-137 source that are read by the detector tubes in the gauge base. In direct transmission, the source rod extends through the base of the gauge into a pre-drilled hole to position the source at the desired depth, a maximum of 12 in. deep. Photons from the source travel through the material in the test area, collide with electrons present in the material, and reach the photon detectors in the gauge. During a backscatter measurement, the source is lowered near the surface of the test material in the same plane as the photon detectors. The gamma photons that enter the test material must be scattered at least once to reach the detectors in the gauge. Photons emitted from the source penetrate the test material, and the scattered photons are measured by the detectors. A backscatter reading measures material from the surface to a depth of approximately 4 in. (Troxler Electronic Laboratories Inc. 2007).

A material with a high density increases the number of collisions between the gamma photons and the electrons present in the material. Therefore, the number of photons reaching the detector tubes is reduced. Hence, the lower the number of photons reaching the detector tubes, the higher the material density. The opposite is true for material with a lower density; fewer collisions occur between the gamma photons and electrons present in the material. More photons will reach the detector tubes, increasing the density count. A microprocessor in the gauge converts these counts into a density reading (Troxler Electronic Laboratories Inc. 2007). 
Figure 23. Nuclear moisture-density gauge.

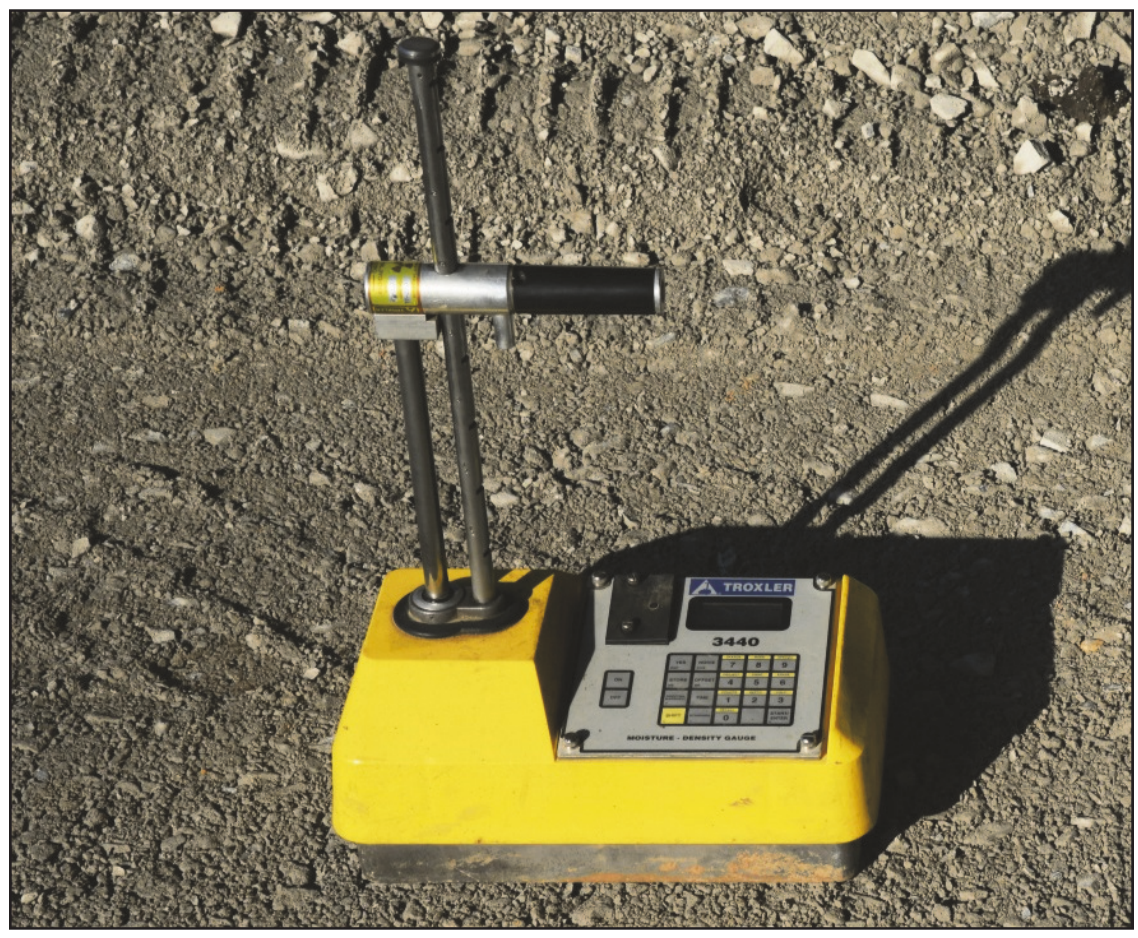

The moisture determination occurs in much the same way as the backscatter density reading. The Americium-241: Beryllium source is located inside of the gauge base. Fast neutrons from this source enter the test material and are slowed by collisions with hydrogen atoms present in the material. The helium 3 detector in the gauge base counts the number of thermalized (slowed) neutrons. This number (known as the moisture count) is directly related to the amount of moisture in the tested area (Troxler Electronic Laboratories Inc. 2007). The NDG was used according to ASTM D6938 (ASTM 2010c) with a rod driven 6 in. into the ground to obtain moisture content and wet density.

\subsubsection{Sand cone}

The sand cone test was used in this study as the reference standard for comparing the effectiveness of the photogrammetric method in measuring in-place soil density. The sand cone density test is a volume replacement test that determines the wet density of a soil. Density is determined by the quotient of soil mass removed from a hole divided by the volume of the hole. The volume of the hole created is indirectly measured by the mass of sand used to fill the hole, with the assumption that the sand fills the hole with a known, uniform density (Sebesta et al. 2006). 
The sand cone replacement test was conducted according to ASTM D1556 (2007b). Clay was used to seal the inner ring of the sand cone plate to minimize sand grains being trapped beneath the plate. A \#20-\#30 grade Ottawa sand was used as the uniform sand. Three sand cone devices were used during testing to expedite the process. Each sand cone bottle was water- and sand-calibrated prior to the start of the exercise, but no further calibration checks were conducted after the testing began. A field scale accurate to $\pm 0.5 \mathrm{~g}$ determined the mass of soil and sand. A surface calibration was performed on every hole dug to account for surface variability at each test location. Holes were dug with a diameter slightly smaller than the ring and a depth of at least 3 in. for all fine-grained soils and up to 4 in. or more for granular materials to produce a representative sample volume. The sand cone density device and accessories are shown in Figure 24.

Figure 24. Sand cone density apparatus and accessories.

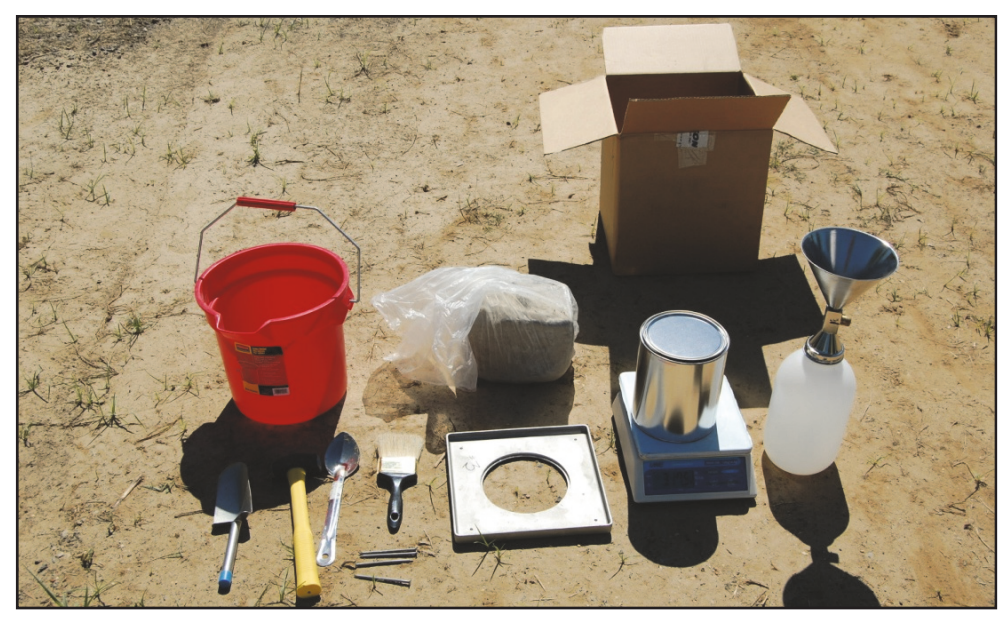

\subsubsection{Hot plate}

In this study, the hot plate method was used as a rapid tool for measuring moisture content in the field to compute dry density as a companion tool to the sand cone and the photogrammetry methods' wet-density-only determination. The hot plate method consisted of an electric portable stove (Waring model SB30 1300 Watt single burner) that applied direct heat to the soil (Figure 25). An aluminum specimen container (pan) was initially weighed empty, and then it was weighed with the soil sample before and during heating of the sample. The stove was set in a high heat mode, and the sample container was placed on the stove similar to a conventional stovetop. The soil sample was stirred while heating to expedite the drying process. The specimen container was removed from the heat and weighed at frequent intervals ( 1 to $5 \mathrm{~min}$.) that depended on 
the initial moisture of the soil. The heating and weighing process was repeated until a change in soil mass of less than one percent occurred during a 1-min. interval. At that point, the moisture content was calculated. Data were monitored using the ERDC Rapid Soil Analysis Kit software (Berney and Wahl 2008) converted to an Android App running on a Motorola Xoom Tablet to provide real time computation of moisture content and change detection during the drying process.

Figure 25. Hot plate, scale, and accessories used to determine soil moisture content.

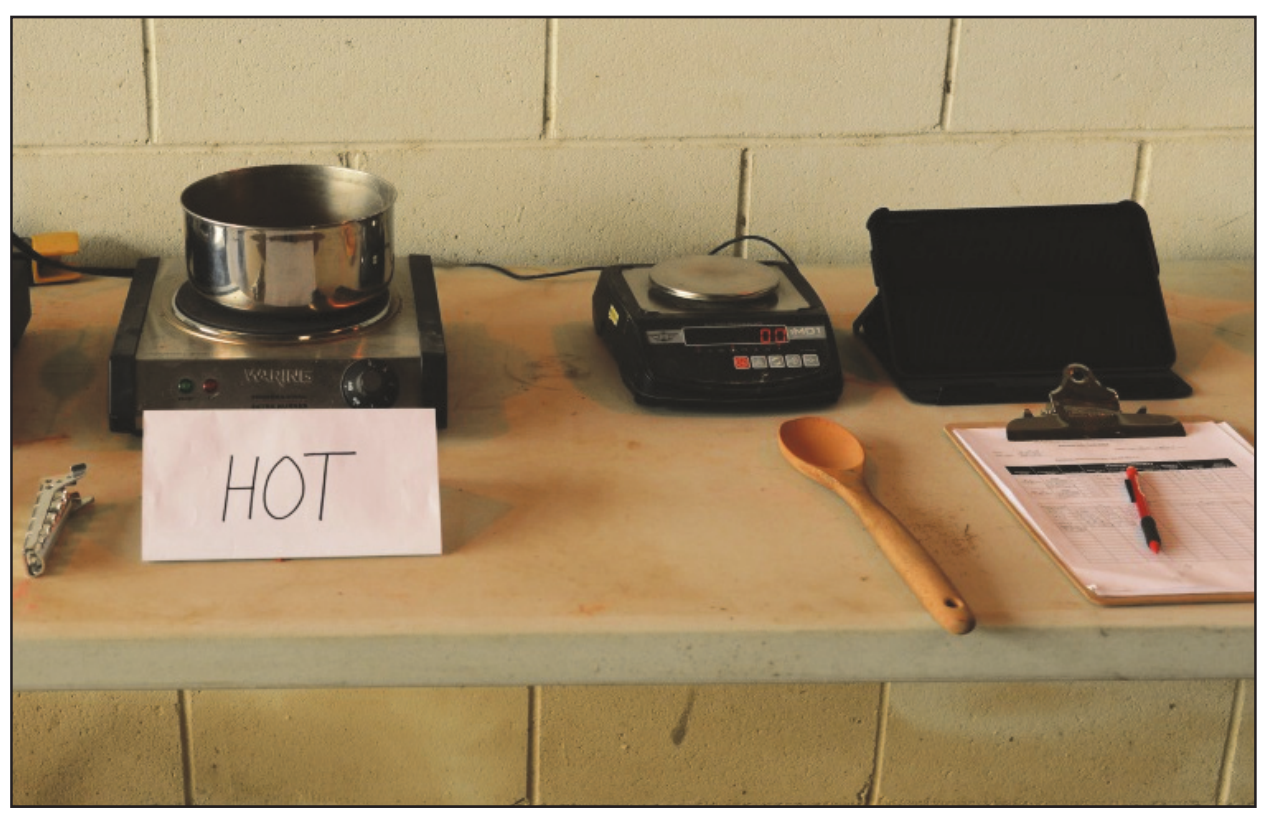

\subsubsection{Laboratory oven}

Drying of the soil using the laboratory oven test was the reference standard for comparing the effectiveness of the hot plate in measuring soil moisture content. The oven temperatures and controls were set to $230^{\circ} \mathrm{F} \pm 9^{\circ} \mathrm{F}$ and the samples were heated overnight (minimum $15 \mathrm{hr}$ ) according to ASTM 2216 (ASTM 2010a).

\subsubsection{Camera - Nikon D800}

The camera selected for the study was the Nikon D8oo camera using a 25-105 mm zoom lens as described in Chapter 2. This a 36 megapixel, fullframe CCD sensor that represented the best imaging platform for both resolution and speed from which to calculate excavated hole volumes. A series of 16 to 18 photographs was taken of each hole as per the guidance given in Chapter 2. Following image collection, the memory card was removed from the camera and downloaded onto a laptop computer that 
contained the Matlab software to calculate the hole volume. A $10 \mathrm{~kg} \pm 1 \mathrm{~g}$ balance was used to weigh the soil removed from the hole for input into the software. The soil moisture content obtained from the hot plate analysis of soil excavated from the hole was input into the software to determine dry density. This value was used to simulate the data likely to be available in the field as an oven-dried moisture would not be feasible in an up-tempo construction scenario.

\subsection{Construction of soil test section}

A total of 12 test strips were constructed at ERDC under a large covered hangar to help protect the soils from the elements. Each soil was prepared to the desired moisture as listed in Table 9 by letting it air-dry or by wetting it using a hydro-seeder depending on the current moisture content of the soil at the time of preparation. A skid steer or front-end loader was used to mix the soil to distribute the moisture more consistently. Some of the soils, especially the $\mathrm{CH}$, required the use of a tiller to loosen the soil, expose more surface area, and allow for more uniform moisture distribution. For test strip construction purposes only, constant monitoring of the soil moisture content was performed by using the standard laboratory microwave oven (ASTM 2008). Once the soil was at the desired moisture content, it was placed in the test section in two lifts using a dump truck and a skid steer (Figure 26).

Table 9. Moisture levels used to prepare each soil for testing.

\begin{tabular}{|c|l|c|c|c|}
\hline & & \multirow{2}{*}{$\begin{array}{c}\text { Moisture Content at } \\
\text { Test Strip }\end{array}$} & Soil ID & \multicolumn{2}{|c|}{ Compaction Level Tested } \\
\cline { 5 - 5 } & time of testing (\%) & Low & High \\
\hline 1 & High-Plasticity Clay & 26.5 & & $\mathrm{X}$ \\
\hline 2 & High-Plasticity Clay & 33.7 & & $\mathrm{X}$ \\
\hline 3 & Clay-Gravel & 8.6 & $\mathrm{X}$ & $\mathrm{X}$ \\
\hline 4 & Limestone & 3.2 & $\mathrm{X}$ & $\mathrm{X}$ \\
\hline 5 & Limestone & 4.9 & $\mathrm{X}$ & $\mathrm{X}$ \\
\hline 6 & Clay-Gravel & 6.2 & $\mathrm{X}$ & $\mathrm{X}$ \\
\hline 7 & Blended Clayey Sand & 7.9 & $\mathrm{X}$ & $\mathrm{X}$ \\
\hline 8 & Red Clayey Sand & 10.5 & $\mathrm{X}$ & $\mathrm{X}$ \\
\hline 9 & Low-Plasticity Clay & 19.7 & $\mathrm{X}$ & $\mathrm{X}$ \\
\hline 10 & Red Clayey Sand & 16.0 & $\mathrm{X}$ & $\mathrm{X}$ \\
\hline 11 & Blended Clayey Sand & 5.0 & $\mathrm{X}$ & $\mathrm{X}$ \\
\hline 12 & Low-Plasticity Clay & 12.7 & $\mathrm{X}$ & $\mathrm{X}$ \\
\hline
\end{tabular}


Figure 26. Placing soil to build a testbed using a) dump truck and b) skid steer.
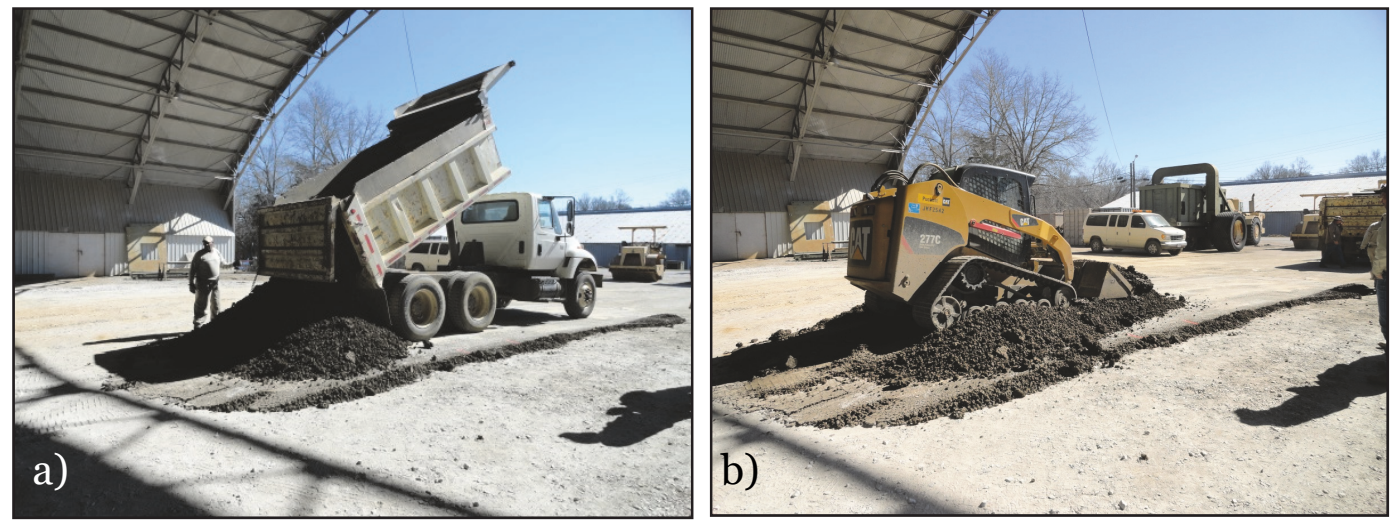

For each test strip, the first lift placed was approximately two roller widths $(10 \mathrm{ft})$ across to provide a wide enough base to create a top layer at least $8 \mathrm{ft}$ across. The test items were constructed in two 6-in.-thick compacted lifts such that the final test section was 12-in. thick to provide a suitable thickness of uniform soil above the natural subgrade to ensure that the response of each instrument was not influenced by the subgrade layer's properties. The test items were considered ready for testing when the second lift was at the specified compaction level.

The clay gravel, limestone, blended clayey sand, low-plasticity clay, and red clayey sand were compacted using a Caterpillar CS433E 7-ton vibratory smooth drum roller (Figure 27a). The high-plasticity clay was compacted using an Ingram 35-ton rubber tire compactor (Figure 27b). In order to maintain a smooth surface, the finer-grained soils when compacted on the wet side of optimum required placement of a plastic sheet over the test section during the compaction process to prevent adherence of the soil to the roller drum (Figure 28).

Figure 27. Soil compaction equipment: a) smooth drum roller and b) rubber tire compactor.
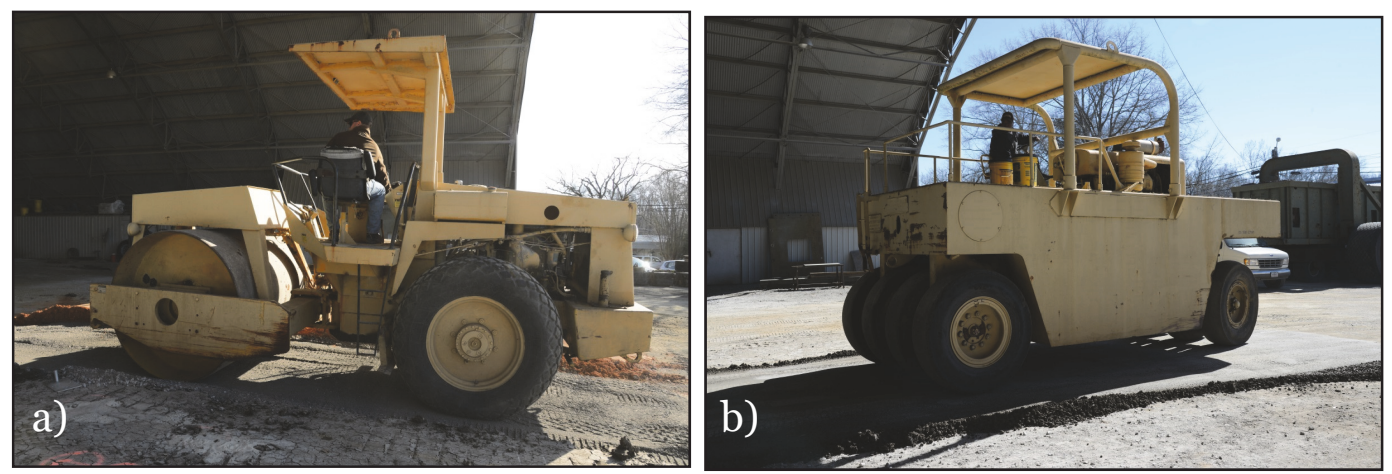
Figure 28. Use of plastic sheet on test strip to prevent soil adhering to the drum.

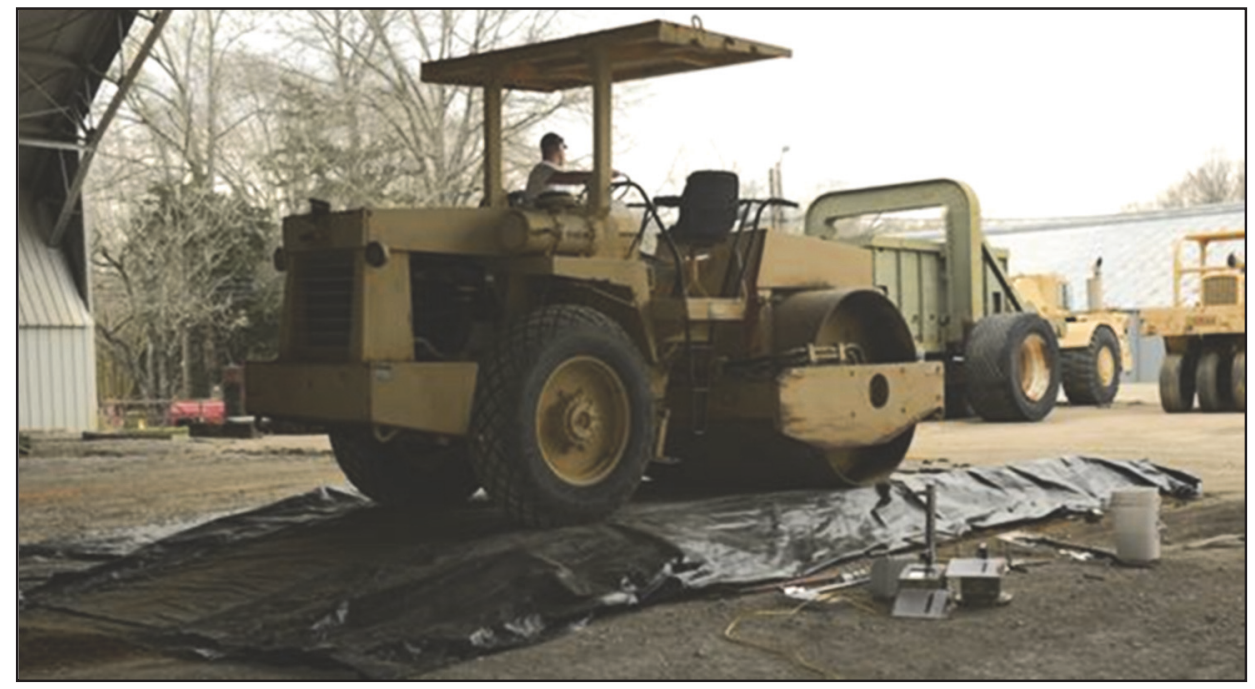

During the compaction of the first 6-in. lift, NDG readings were obtained after each roller pass or after a series of passes to determine the number of roller passes required to achieve low- and high-compaction levels. This varied for each soil and moisture level.

\subsection{Test procedures}

The NDG was calibrated each test day prior to use as per ASTM D6938 (ASTM 2010c). This ensured that radiation counts were within the proper limits. The NDG was then used for the remainder of the test day without subsequent calibration. Testing was conducted as compaction progressed. Density and moisture content measurements were obtained with the NDG at two different compaction levels (low and high). Only the high-plasticity clay was tested at one level of compaction. The number of roller coverages required for completing each compaction level varied with soil type and moisture condition. One coverage of the roller consisted of one pass down the test strip and one pass going back.

Figure 29 shows typical test layouts for each test strip. Each test strip was divided into three test areas. Each test strip was compacted to a low density, tested and then compacted further to a high density and tested again in new locations. At each compaction level, i.e., low (L) and high (H), a reading of the NDG was obtained in each of the three test areas (R1, R2, and R3) along with one sand cone and one photogrammetry hole (Figure 30) for a total of three readings per soil per compaction effort. The NDG was tested at a depth of 6 in., and readings were obtained in two directions around the hole 
at approximately 90 degrees from each other. Digging of the sand cone hole was accomplished using a metal spoon and chisel. The confined space of the sand cone plate typically resulted in a smaller hole than the photogrammetry technique (Figure 31). Some excavations for the photogrammetry technique used a sharpshooter shovel in addition to a spoon and chisel to expedite the process and produce the more concave hole shape that provides better imaging. The soil sample excavated from each sand cone hole had its moisture measured based on the standard oven procedure. Each soil sample excavated for the photogrammetry technique had its moisture determined using the hot plate. An example of a finished section of test items for the limestone material is shown in Figure 32.

Figure 29. Typical test item layout.

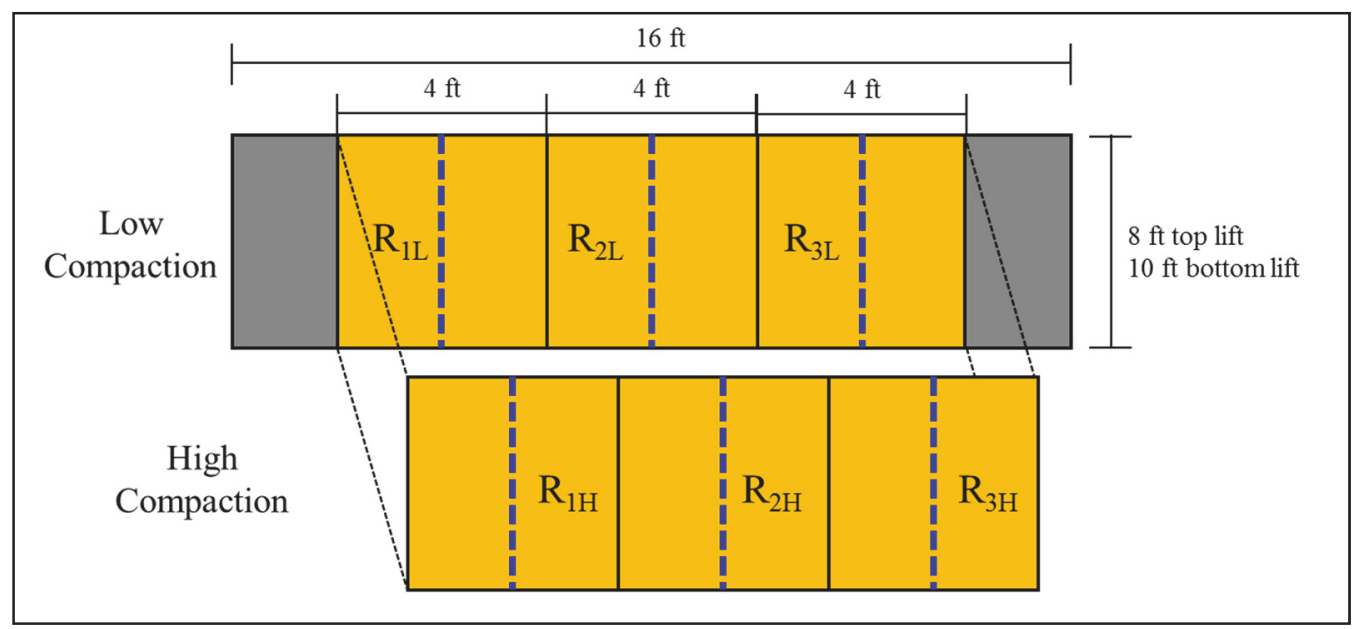

Figure 30. Testing of sand cone density and photogrammetry technique inside red ring. Sharpshooter shovel was used for some photogrammetry excavations.

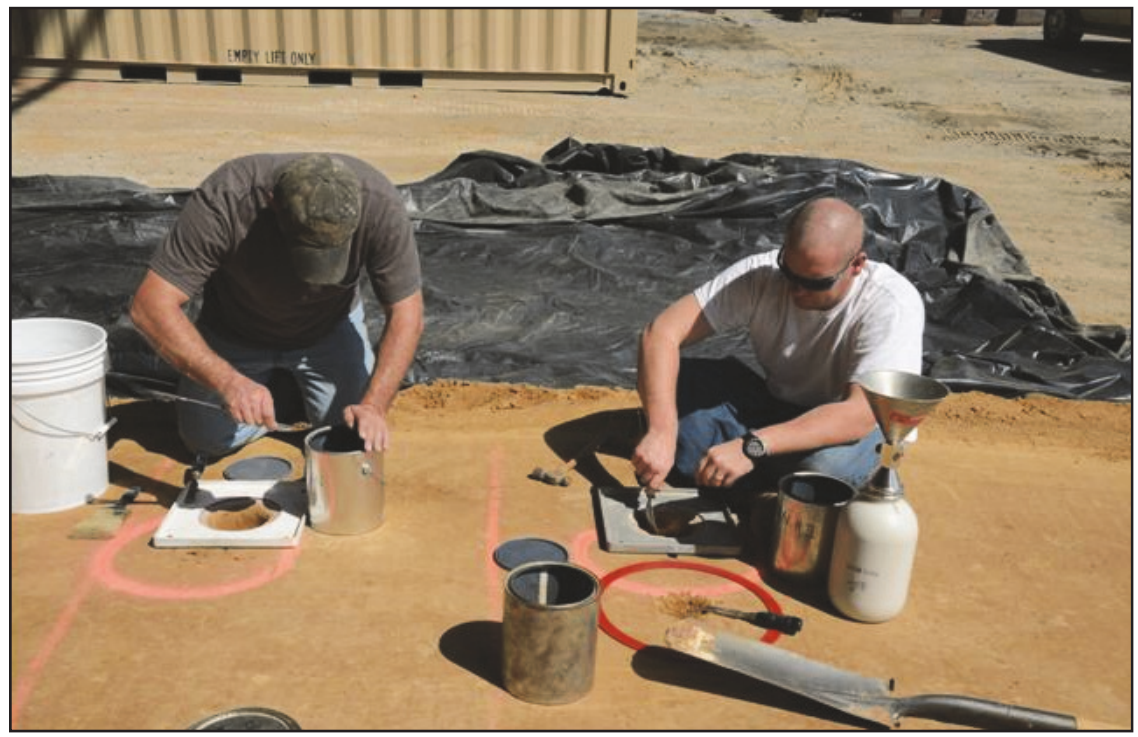


Figure 31. Example of sand cone versus photogrammetry holes. Note the photogrammetry technique is more conducive to a larger excavation
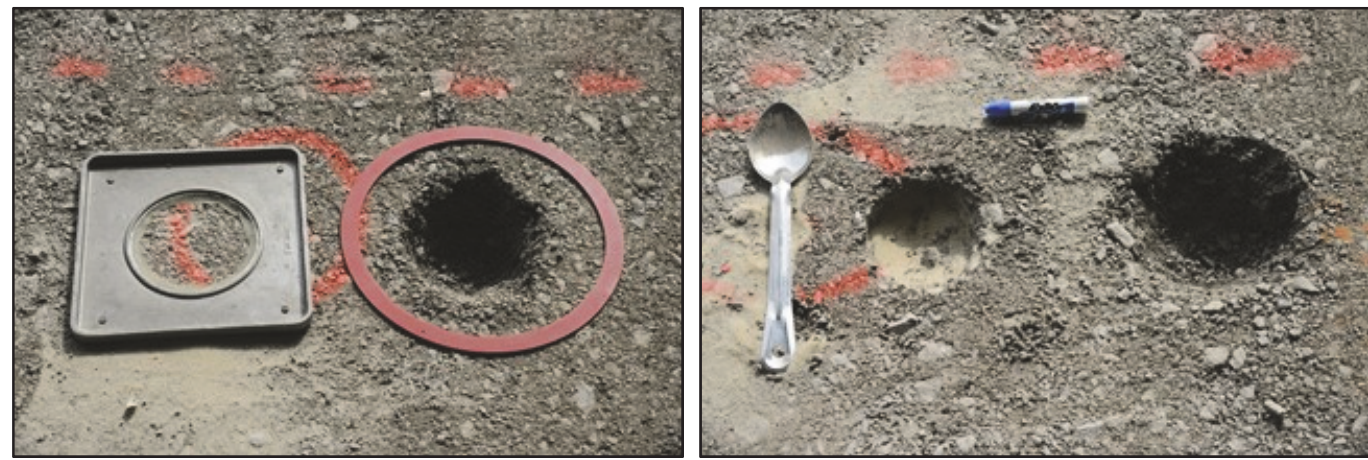

Figure 32. 12 post-test locations of sand cone and photogrammetry samples on Limestone test section for both low and high compaction efforts.

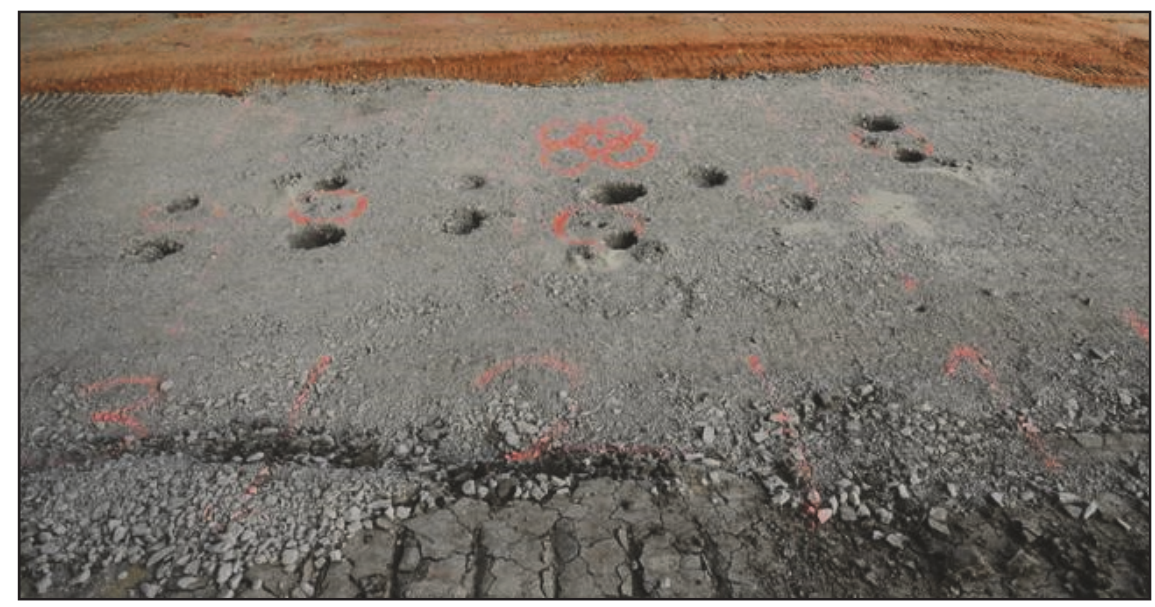

\subsection{Image examples}

To illustrate the image resolution obtained with photogrammetry for each of the soil types studied, the following set of figures displays a pair of far and near digital images for each soil classification, followed by the point cloud analysis image developed from the Matlab analysis. These figures illustrate how texture and size of the hole play a role in the accuracy of the volume calculation shown in Chapter 4. Fine-grained soils display a much cleaner point cloud with less pixilation or white space where data could not be found. Further, less error is found within the fine-grained holes owing to a smoother surface and less aggregate protruding from the wall face. Identifying the lip of the hole is also cleaner with the finer-grained soils than with coarser aggregate having a rougher surface texture. The exception to this observation is the $\mathrm{CH}$ material that, owing to its dark color, created difficulty in capturing detail within the hole if the lighting was not optimal. 
Figure 33. CH-High plasticity clay soil excavation
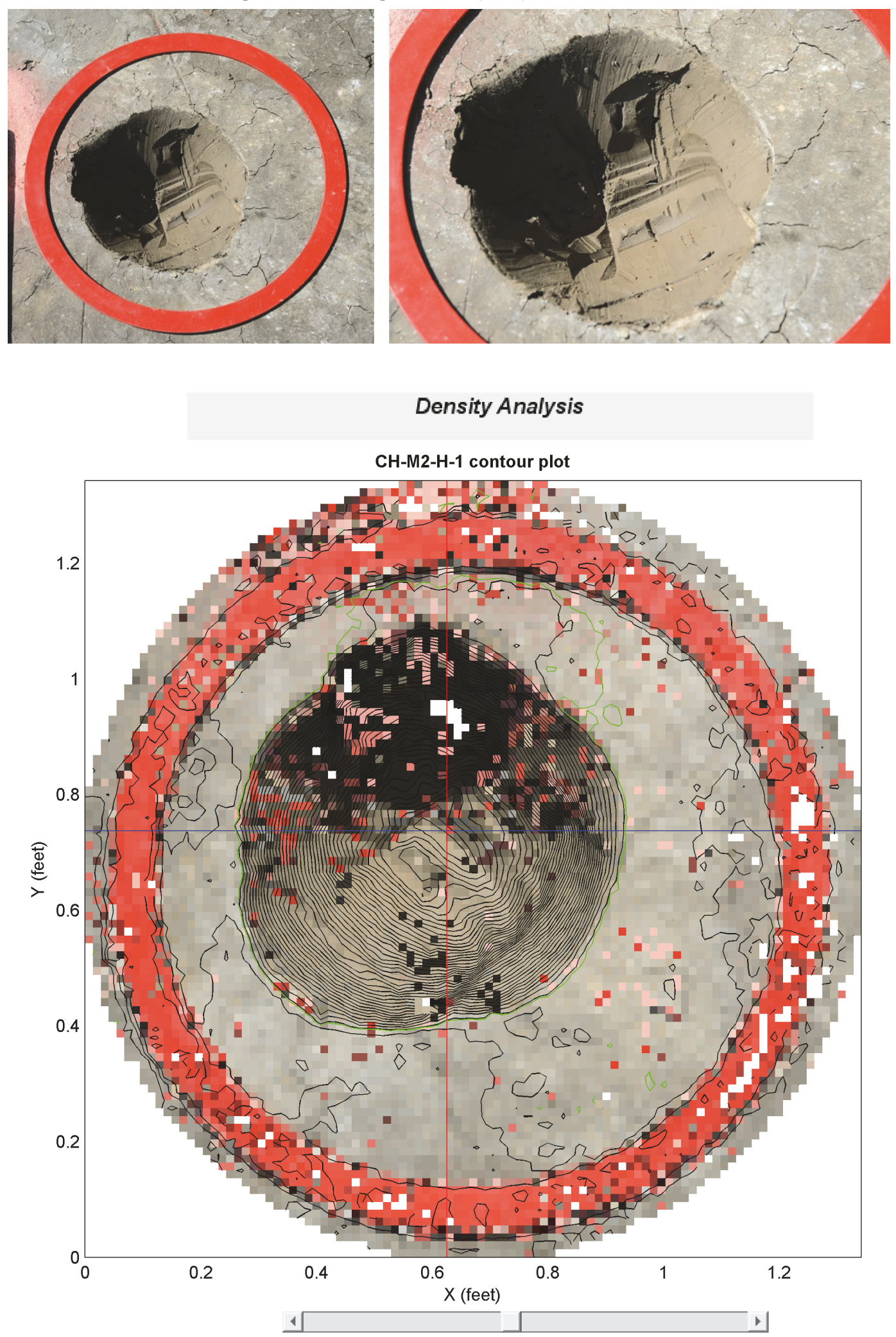
Figure 34. SC-Clayey sand with gravel soil excavation.

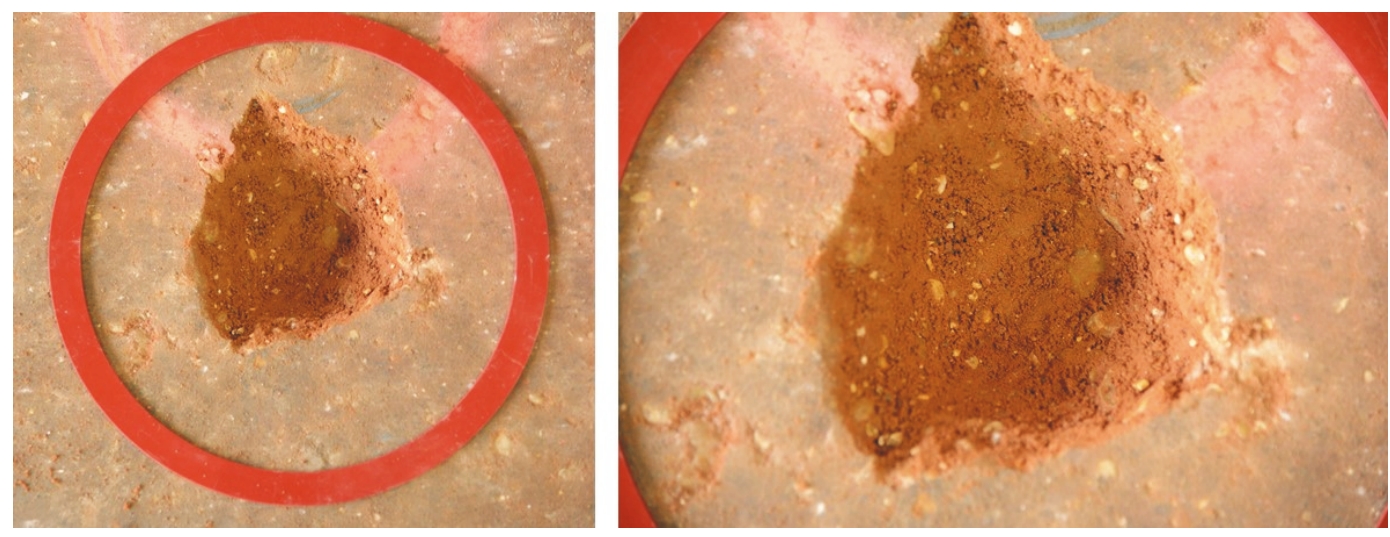

\section{Density Analysis}

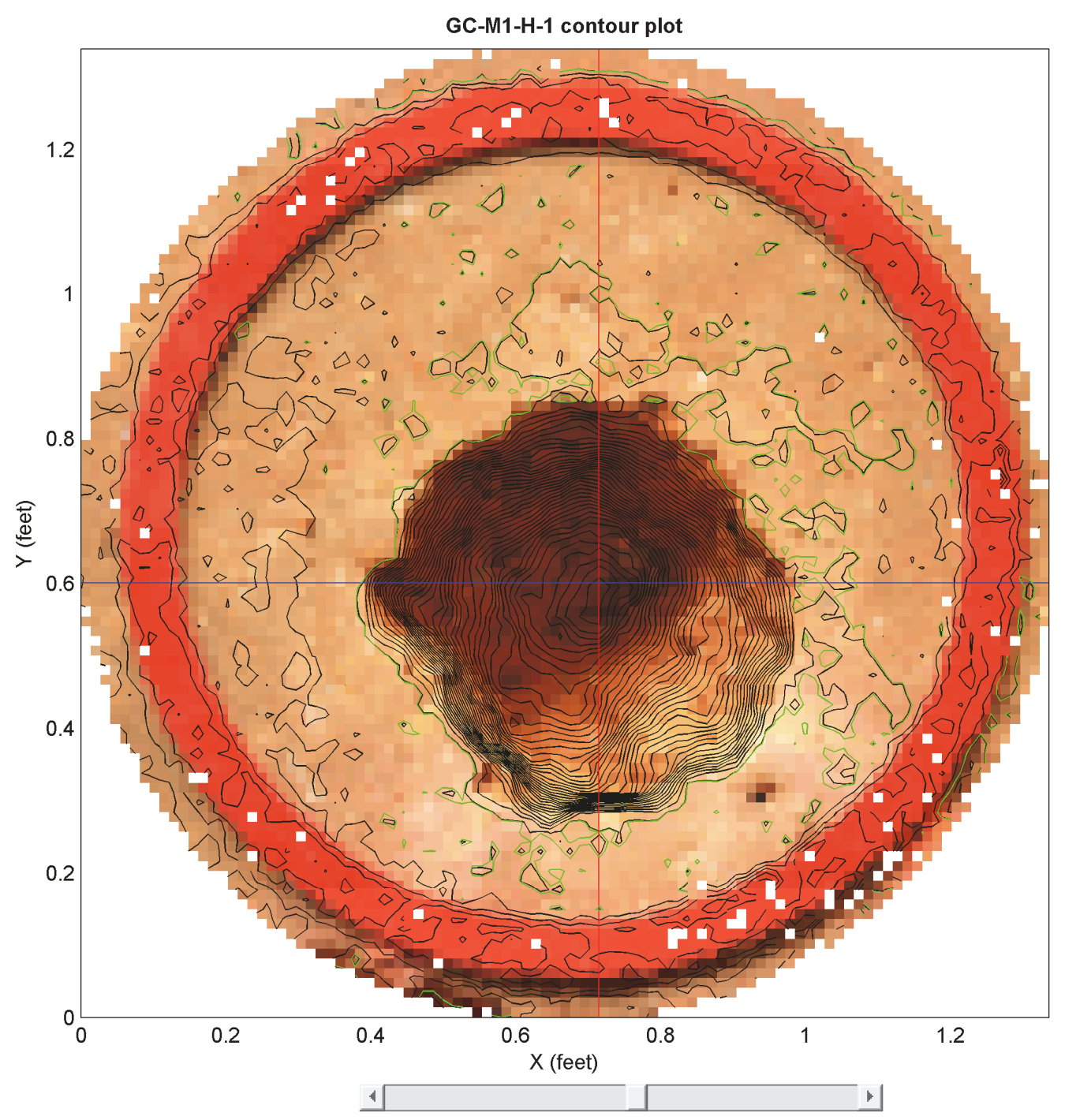


Figure 35. CL-Low plasticity clay soil excavation.
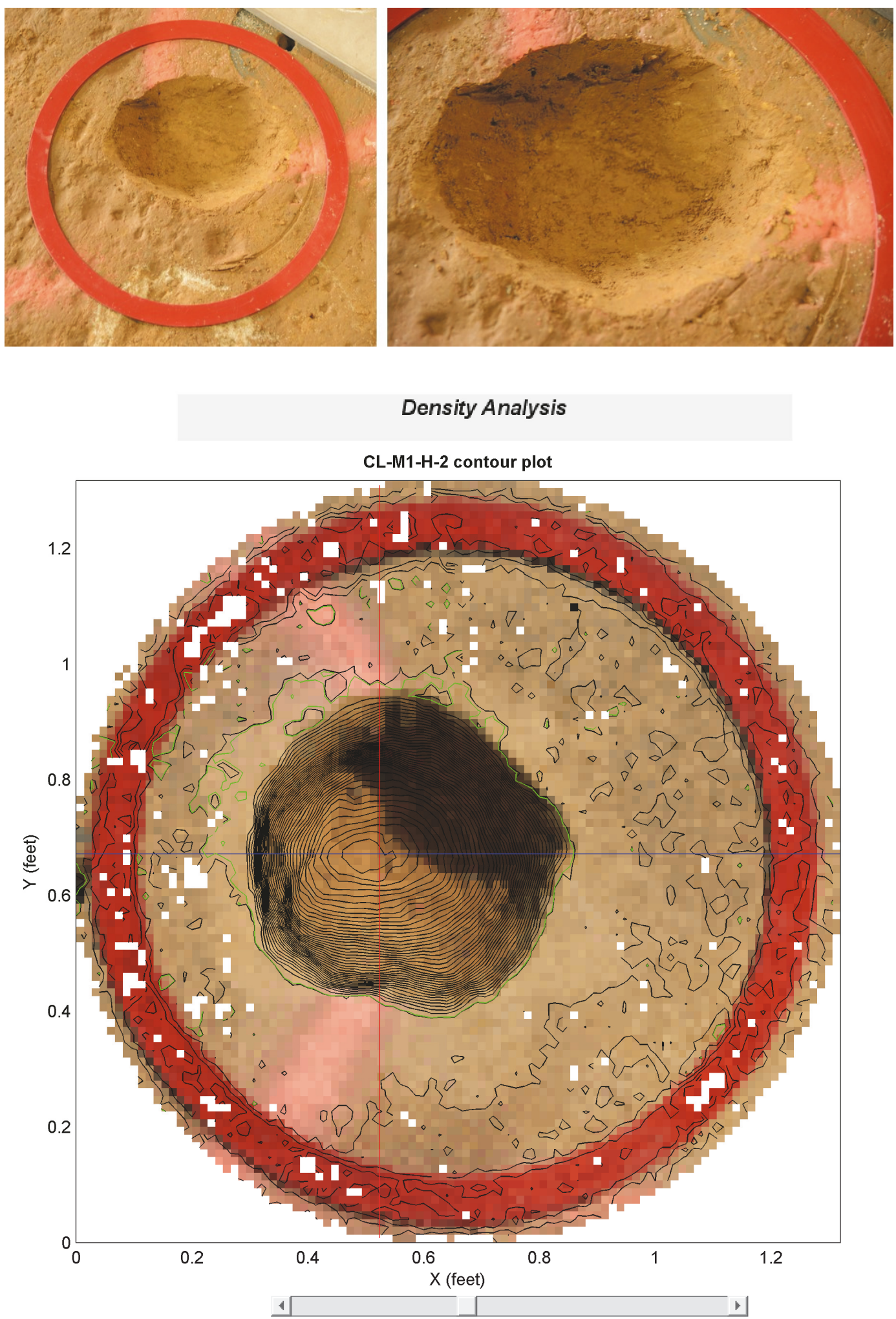
Figure 36. GW-GC-Gravel with silty clay and sand soil excavation.
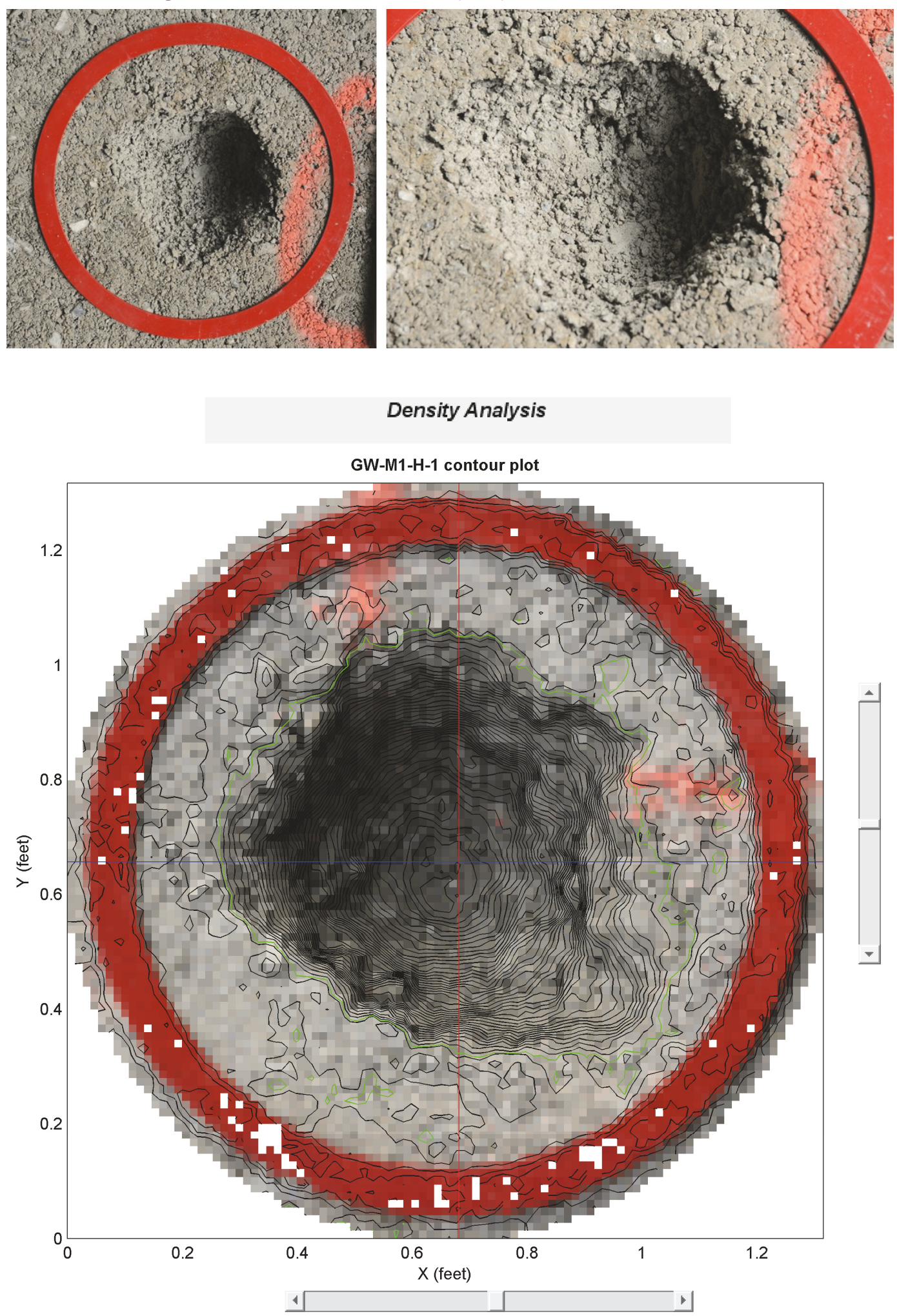
Figure 37. SC-Red clayey sand soil excavation.
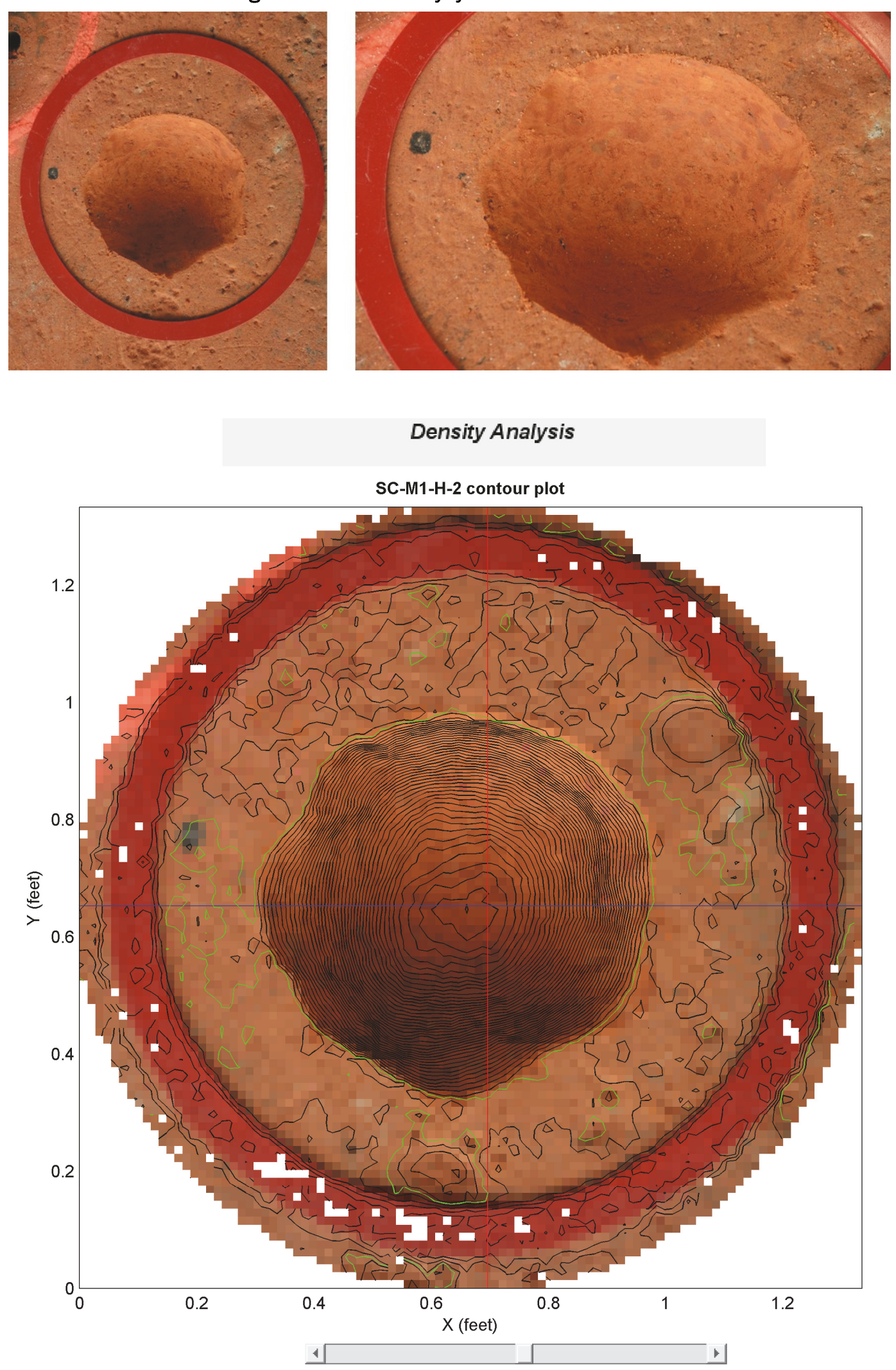
Figure 38. SC-Blended clayey sand soil excavation.

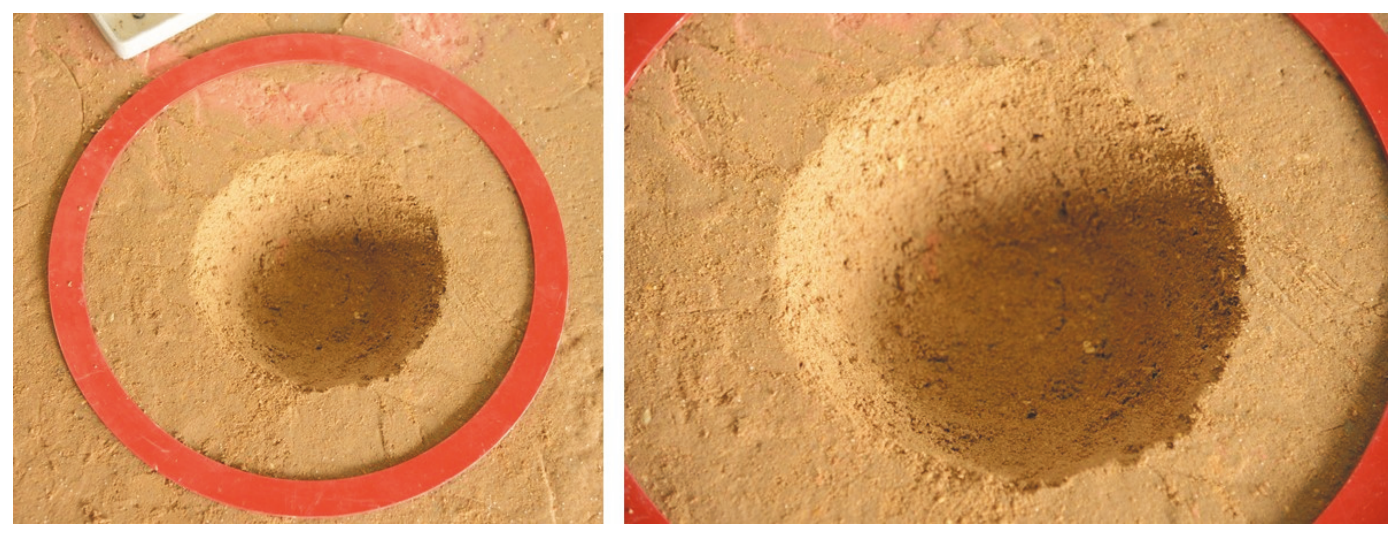

Density Analysis

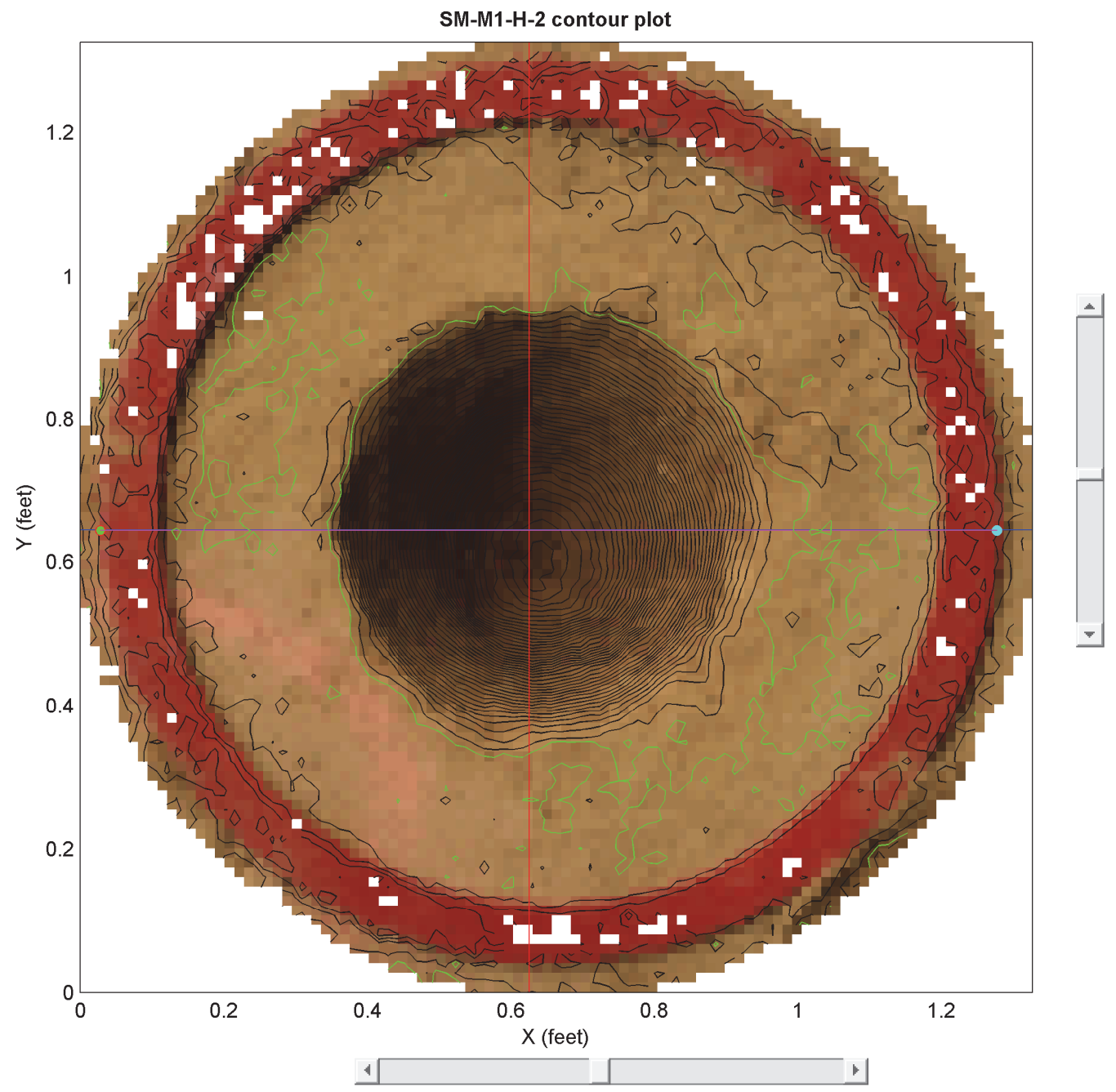




\section{Data Analysis and Results}

\subsection{Soil test section}

\subsubsection{Range of soil conditions evaluated}

To provide a means of assessing the photogrammetry technique over a range of moisture contents and densities typical of a field construction, each of the six soil types was tested at a high and low moisture along with a high and low density. Attention was paid to ensure that moisture values were near the $\mathrm{OMC}$ for all soils except for $\mathrm{CH}$ clay, which has inherent constructability problems at dry moisture contents. For all other soils, the relative density ranged from average values of $82 \%$ to $96 \%$ of modified MDD for the high-low comparison and an average moisture content range of $1.8 \%$ below OMC to $3.4 \%$ above OMC (Table 10). These ranges are considered typical of most horizontal construction activities and therefore provide a good evaluation of how the devices will capture the necessary data for quality control. Figure 39 illustrates the data points collected during the full scale test section construction with respect to the modified proctor density curve.

Table 10. Range of relative density and moisture content achieved during construction.

\begin{tabular}{|c|c|c|c|c|c|c|c|}
\hline \multicolumn{3}{|c|}{ USCS } & \multicolumn{3}{|c|}{ Dry density range } & \multicolumn{2}{|c|}{ Moisture range } \\
\hline Soil ID & Classification & MDD & OMC & Max & Min & Low & High \\
\hline High plasticity clay & $\mathrm{CH}$ & 104.3 & 22.4 & $94 \%$ & $82 \%$ & -4.3 & 13.76 \\
\hline Clay Gravel & SC w/gravel & 133.1 & 7.4 & $97 \%$ & $89 \%$ & 0.7 & 3.44 \\
\hline Limestone & GW-GC & 145.7 & 4.7 & $99 \%$ & $82 \%$ & 1.61 & 0.33 \\
\hline Low plasticity clay & $\mathrm{CL}$ & 118.1 & 13.7 & $98 \%$ & $73 \%$ & 1.3 & 6.7 \\
\hline Blended sandy clay & Blended SC & 134.8 & 7.4 & $97 \%$ & $87 \%$ & 2.7 & 0.8 \\
\hline Red clayey sand & Red-SC & 119.8 & 12.5 & $94 \%$ & $83 \%$ & 2.5 & 5.5 \\
\hline & & & verages: & $96 \%$ & $82 \%$ & 1.8 & 3.4 \\
\hline
\end{tabular}


Figure 39. Moisture-density range tested for each soil type. Note: $M 1$ are samples tested at the lowest moisture content, M2 are samples tested at the highest moisture content.
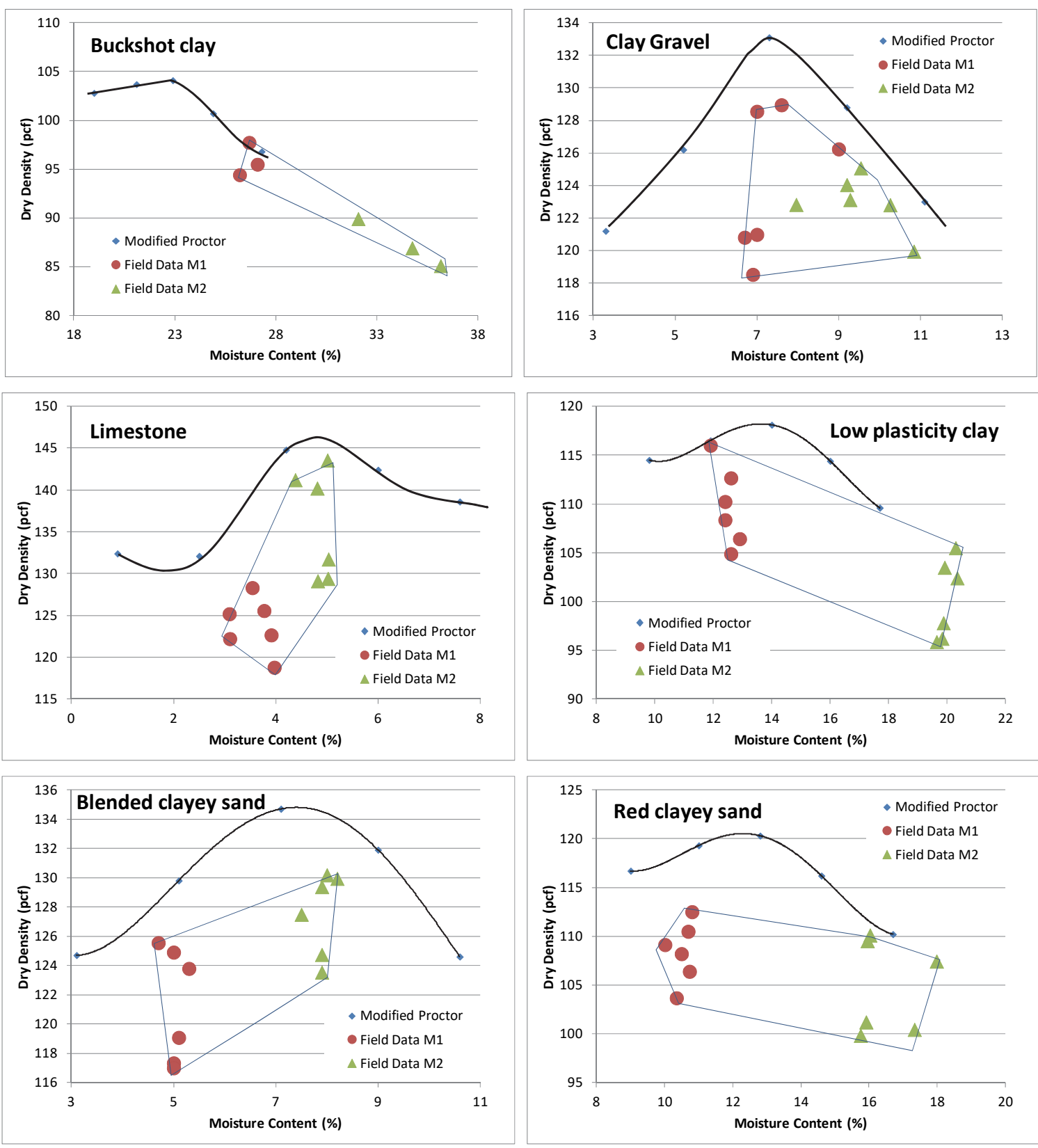

\subsubsection{Hot plate moisture correlation to laboratory oven-dried procedure}

Because the photogrammetry technique along with the sand cone method provides only a measure of wet density, some method must be employed in the field to obtain a moisture content to allow dry density determination. A previous study by Berney et al. (2013) identified a number of alternatives to measure field moisture content without the use of a conventional oven or NDG. The open-flame burner was determined to be the most accurate technique of all those tested, being superior even to the NDG. At the time 
of the study, the hot plate method was not tested, but independent studies at ERDC suggest it can be used as a reliable alternative since it is very similar in function to the open-flame burner. For each test location used for determining sand cone density, a separate soil sample was obtained and split between the oven and a hot plate to provide a one-to-one comparison of moisture content. The hot plate soil sample was dried until less than a $1 \%$ change in overall soil mass occurred, and the oven-dried soil was dried according to ASTM (2008) as outlined in Chapter 2.

A comparison of moisture contents across all soil samples tested is shown in Figure 40 with a resultant coefficient of determination of $99 \%$. This indicates that for soils of both high and low moisture contents, proper use of the hot plate can yield moisture content values with accuracy exceeding that of the NDG. These results compare favorably with the accuracy of the open-flame burner. Therefore, the hot plate system can be used as a rapid field technique to obtain moisture readings and, therefore, the moisture content measured for each hole prepared for the photogrammetry method was based on the hot plate method.

Figure 40. Comparison of hot plate versus oven-dried moisture content techniques.

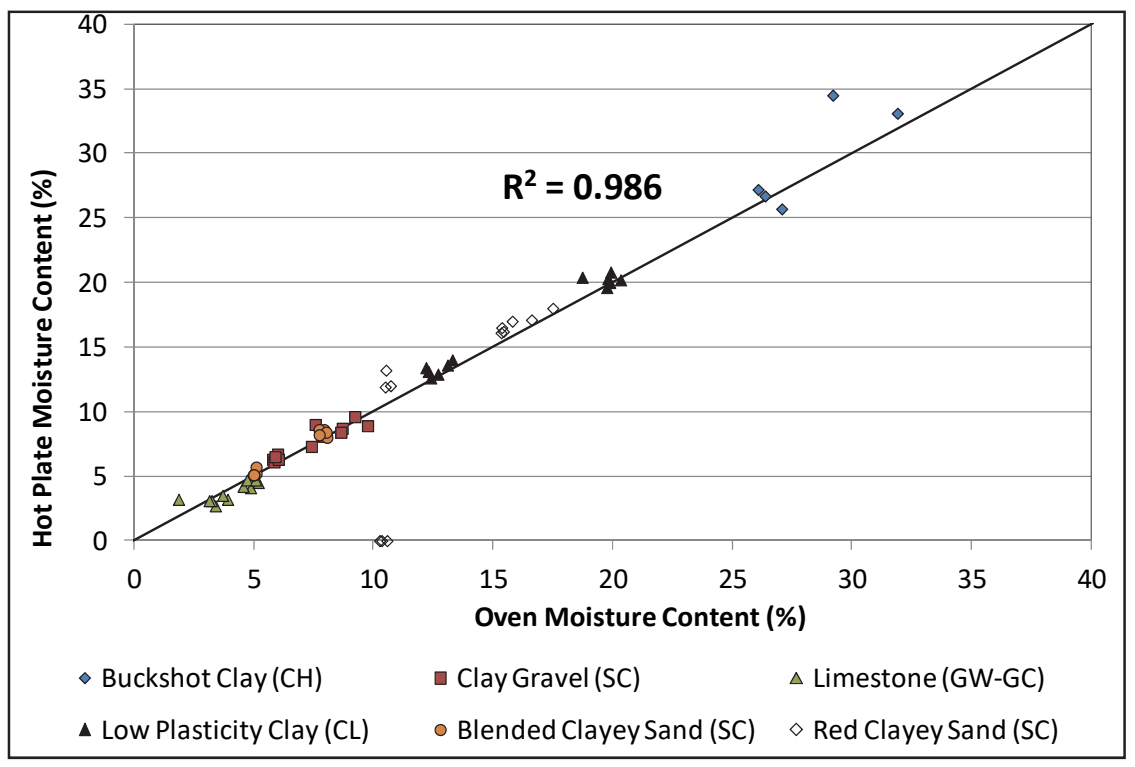




\subsection{Data comparisons}

\subsubsection{Sand cone versus nuclear density gauge}

To determine whether the photogrammetry method is a suitable replacement technique for the sand cone or NDG, a relative measure of accuracy between the sand cone and nuclear gauge techniques must be determined. For this purpose wet and dry density determined from the sand cone method and the hot plate moisture were compared to the NDG. Figure 41 and Figure 42 illustrate that a one-to-one comparison of sand cone to the NDG for wet density and dry density returned $\mathrm{R}^{2}$ values of $87 \%$ and 95\%, respectively. This sets the baseline comparison values for the correlations obtained with the photogrammetry method. Detail data collection information for all the tests used in the analysis are given in Appendix B.

Figure 41. Comparison of wet density between Sand Cone and NDG.

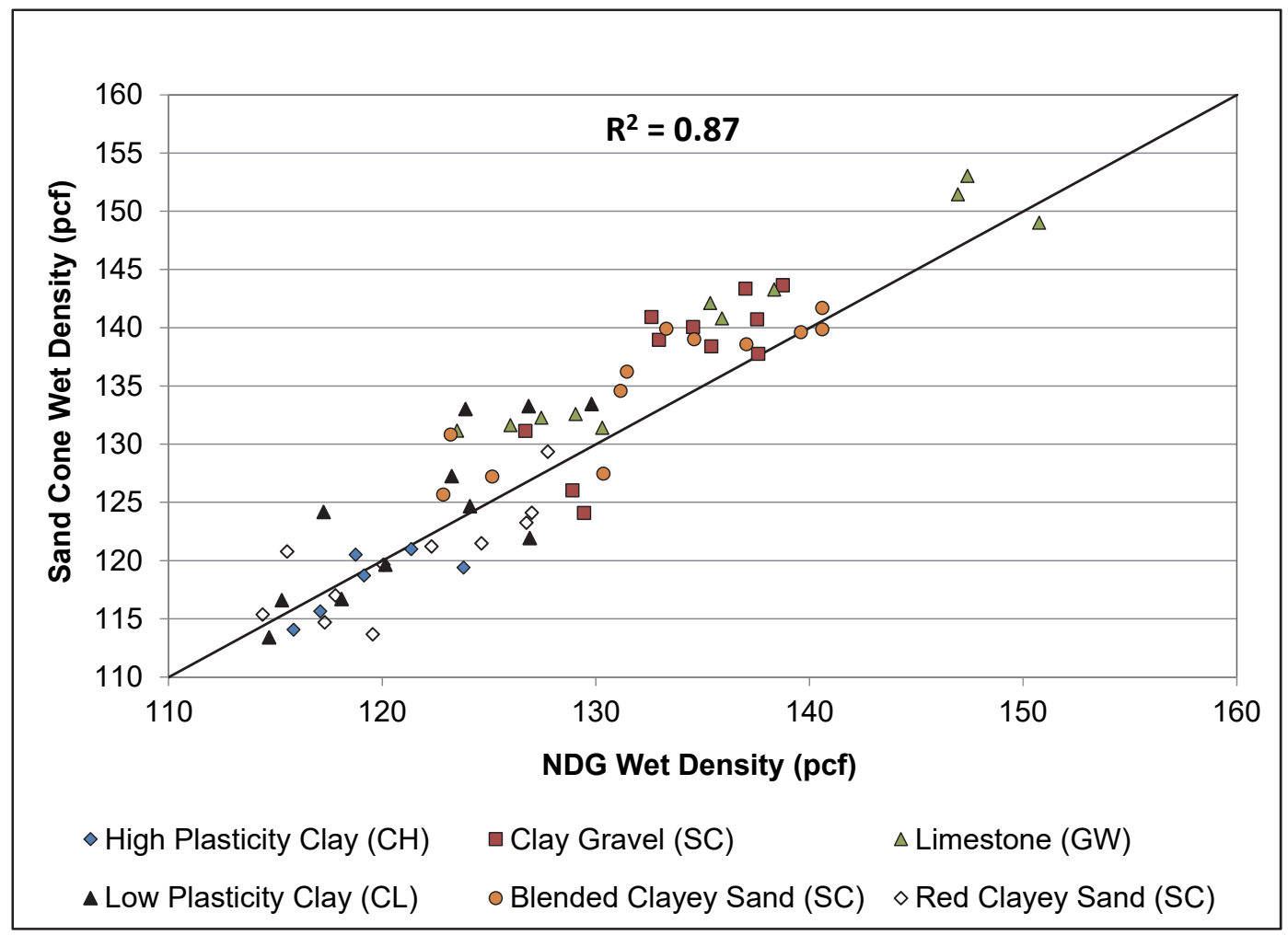


Figure 42. Comparison of dry density between Sand Cone and NDG.

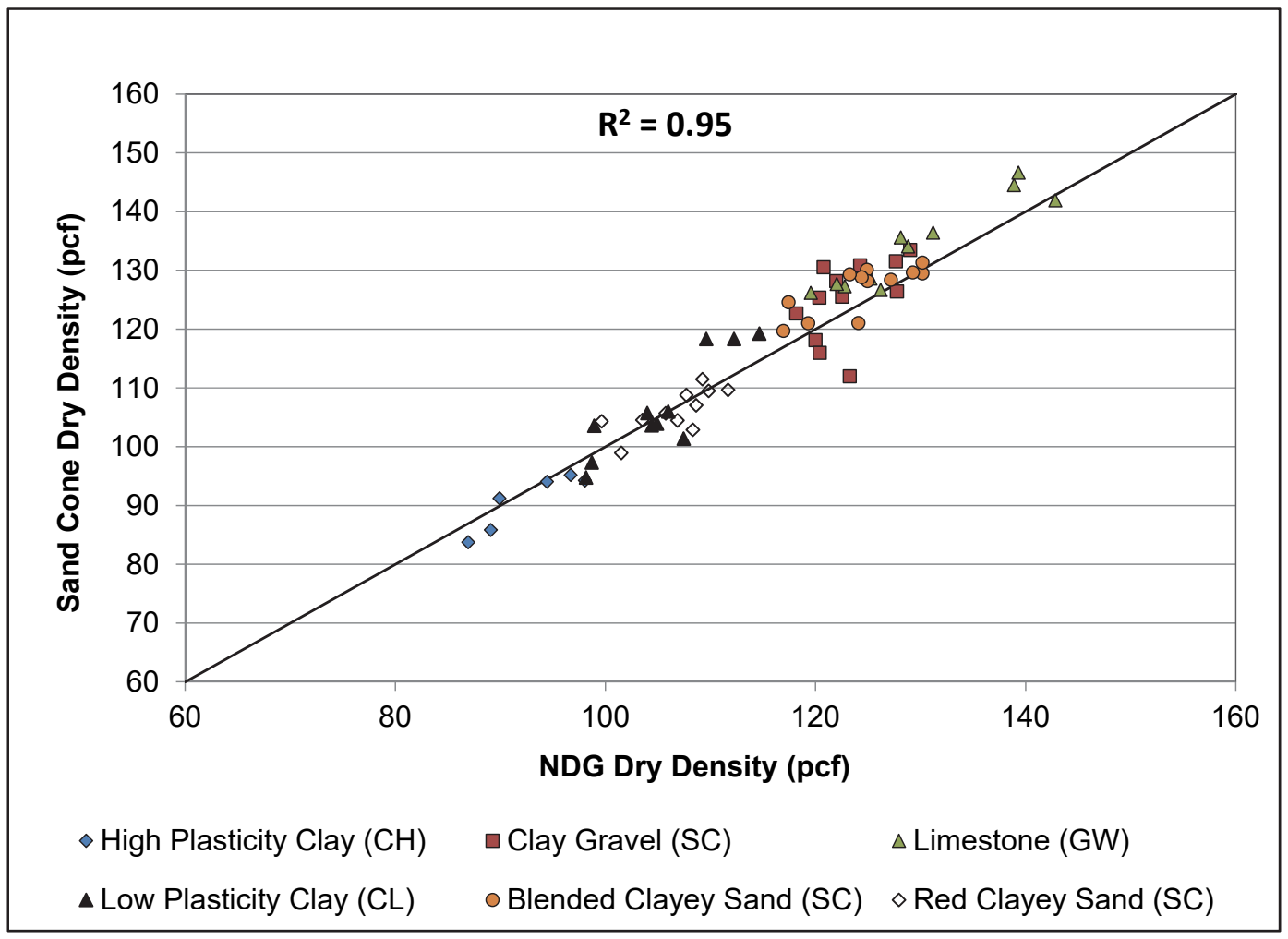

\subsubsection{Photogrammetry correlations to NDG and sand cone - cumulative}

Direct comparisons between wet and dry density determined from the photogrammetric method to either the NDG or the sand cone for all soils tested in the study are shown in Figure 43 and Figure 44 (NDG) and Figure 45 and Figure 46 (sand cone). The $\mathrm{R}^{2}$ value for the wet density is $81 \%$ and $76 \%$ for the NDG and sand cone respectively compared to the $87 \%$ reference value. The $\mathrm{R}^{2}$ value for the dry density is $92 \%$ and $89 \%$ for the NDG and sand cone respectively compared to the $95 \%$ reference value. Based on this evaluation, the field response of the photogrammetric method is slightly less accurate than the sand cone method. Integration of the moisture content improves the accuracy of the technique as shown by the increase in correlation for the dry density comparisons. 
Figure 43. Comparison wet density between NDG and photogrammetry method.

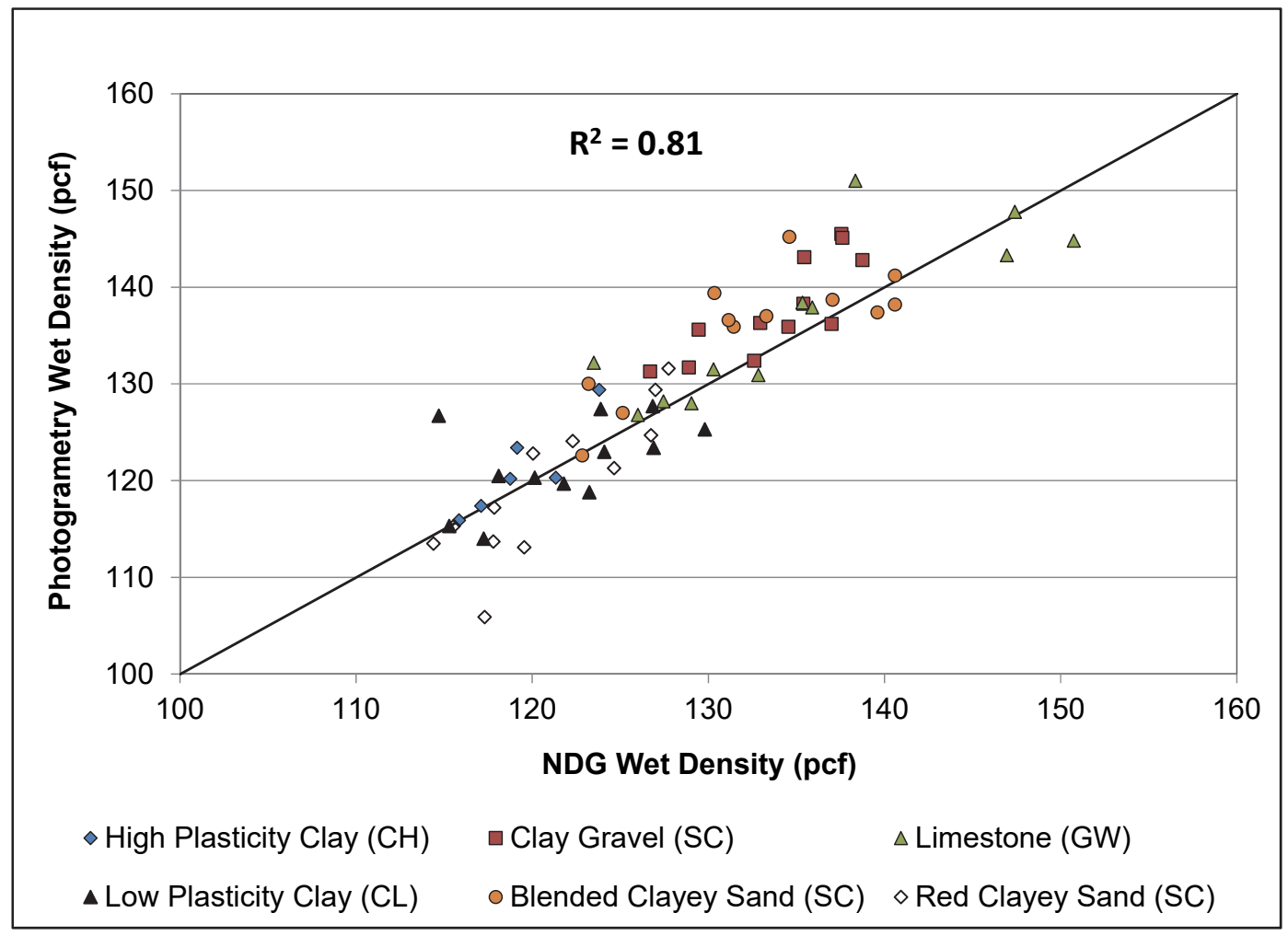

Figure 44. Comparison of dry density between NDG and photogrammetry method.

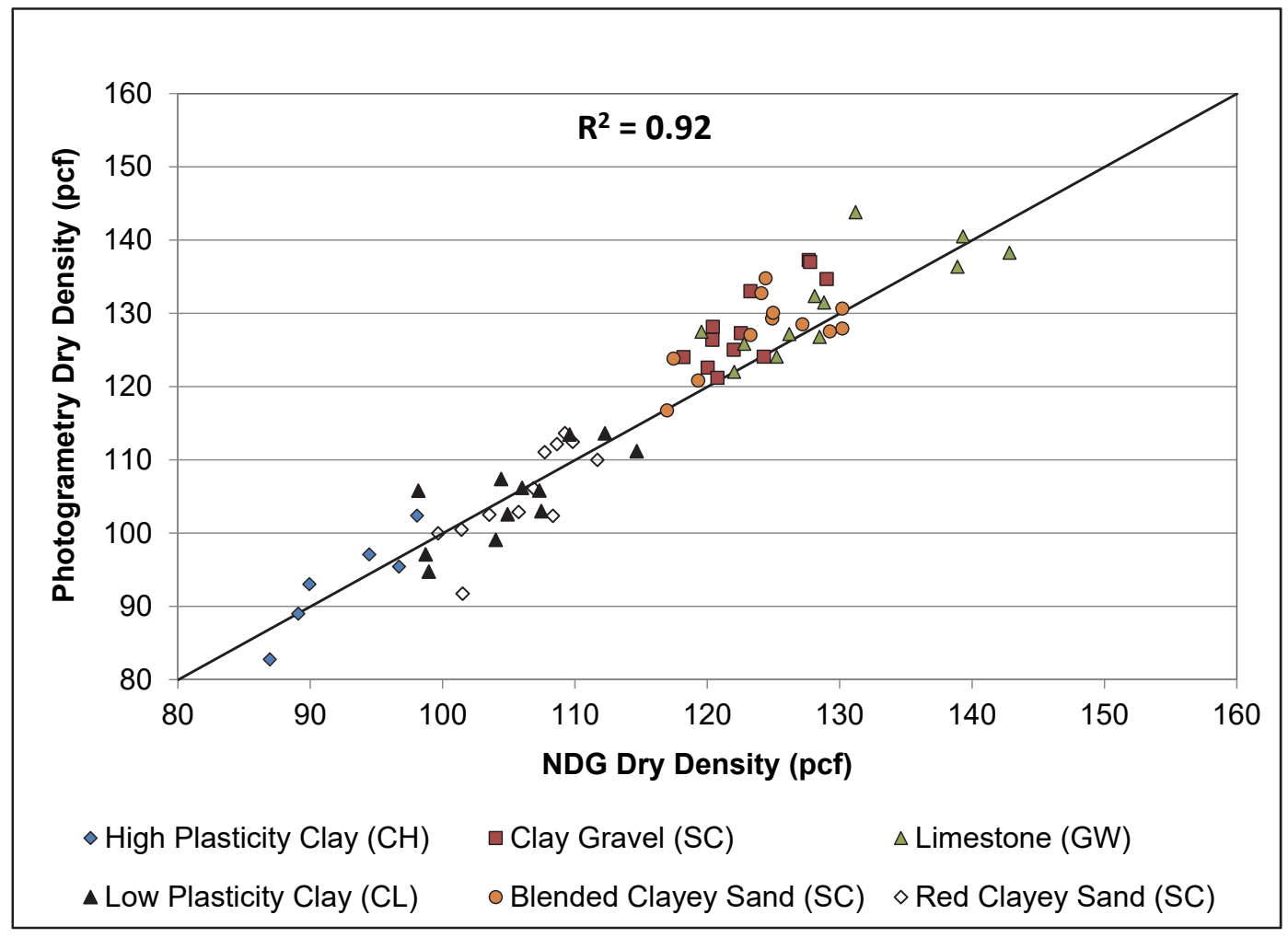


Figure 45. Comparison wet density between sand cone and photogrammetry method.

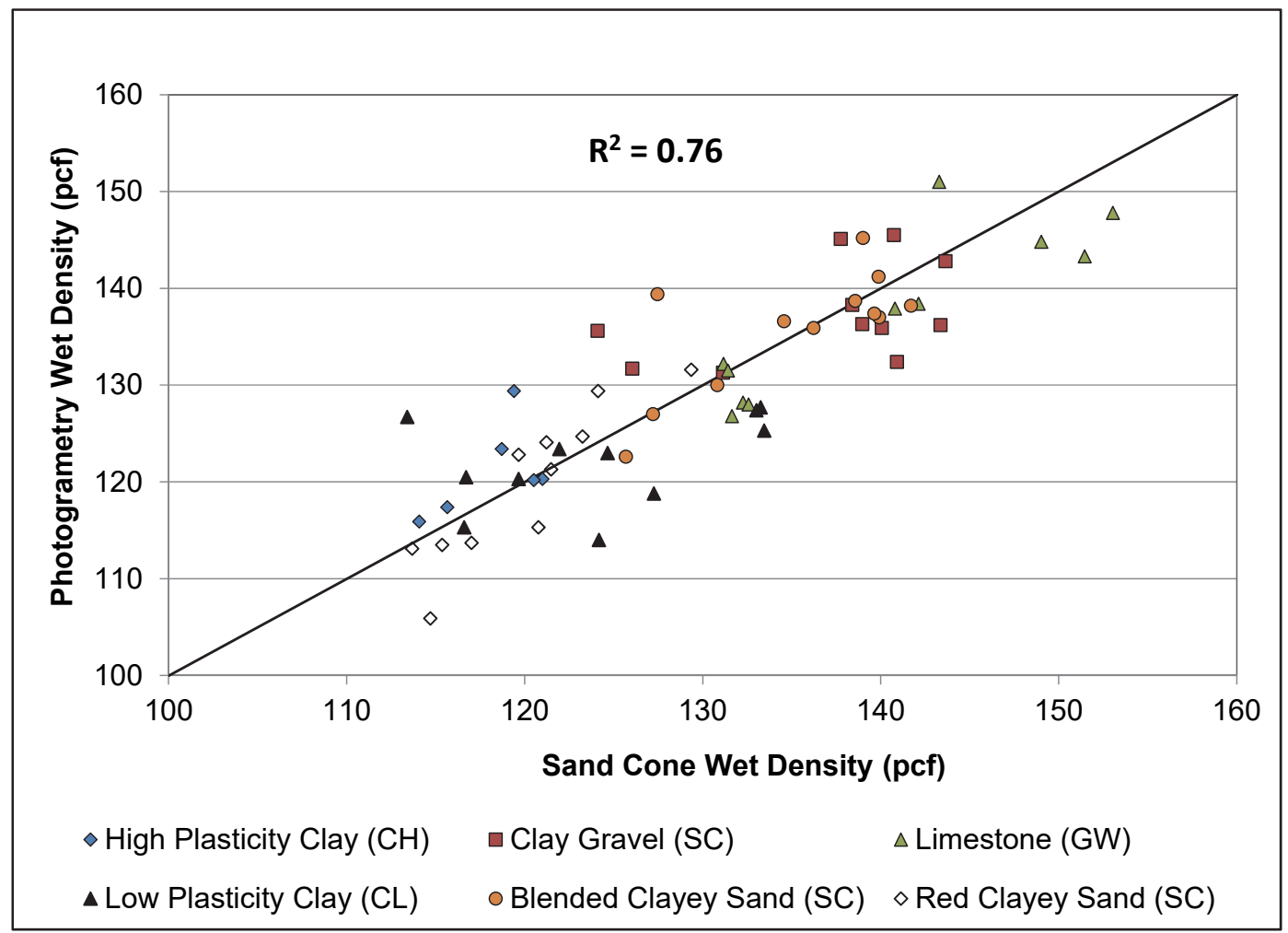

Figure 46 . Comparison dry density between sand cone and photogrammetry method.

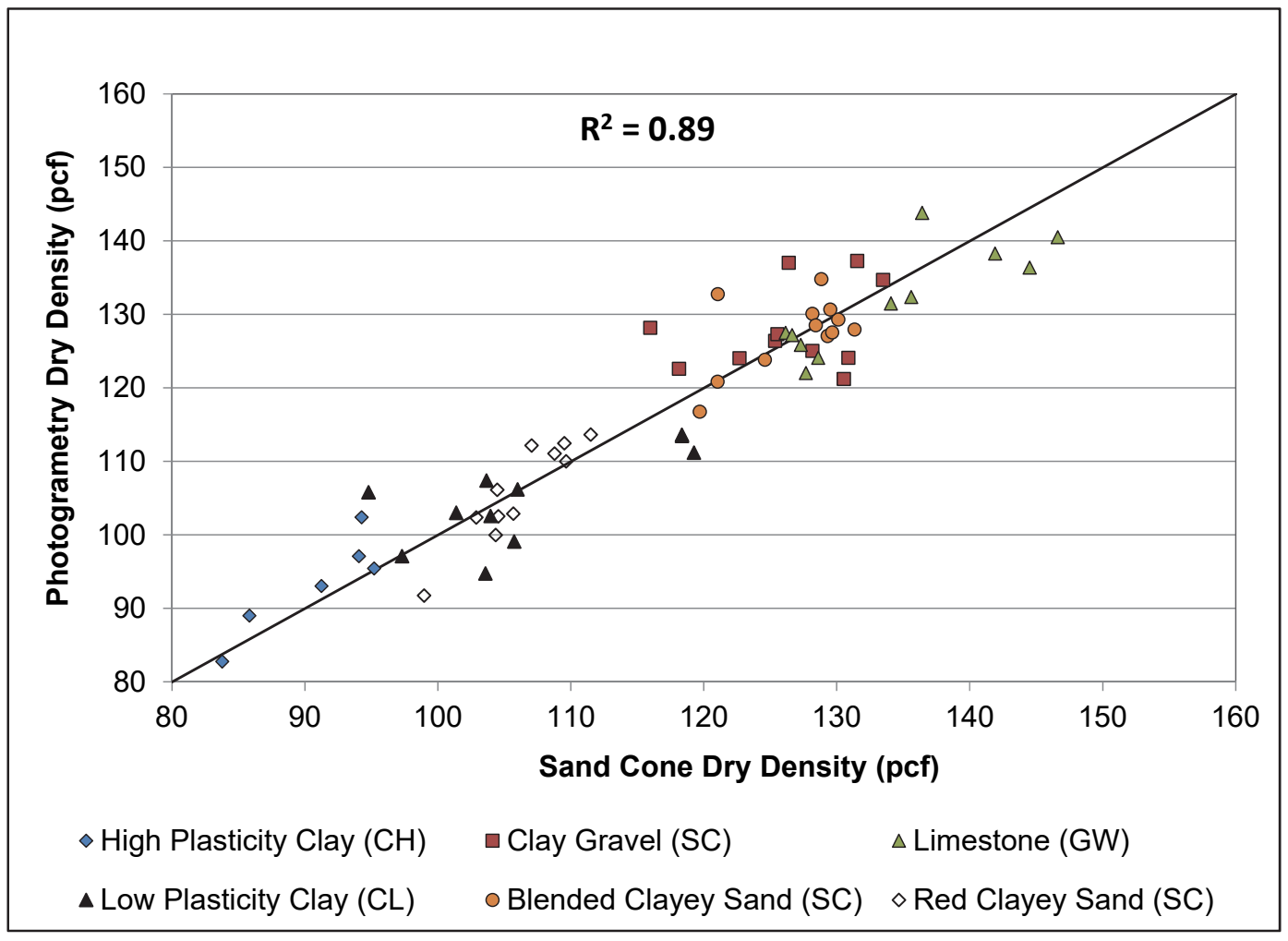




\subsubsection{Photogrammetry correlations to NDG and sand cone - soil type}

Each of the previous figures shows general correlations considering all the soils together, which cover a broad range of wet and dry density response. These correlations illustrate that the technique is able to discern density variations between soil types but do not indicate the variability seen within each soil type, which is represented by the scatter in the plots for each soil classification. Table 11 shows the correlation between methods by individual soil type to show for which soils the technique functions best. The data representations are shown in Figure 47. The correlation values are reduced from those of the combined data set, indicating less reliability when considering a single soil type. Figure 47 shows that there was typically one photogrammetry value that was considerably greater (greater than 2 standard deviations) in density (too small a volume measured with the software), suggesting that the image was difficult to process or data was not measured correctly. Table 12 shows the revised correlations with those individual points removed from each data set, producing a dramatic increase in the relationship.

Table 11. Correlation of determination between photogrammetry method and NDG and sand cone method for each soil type tested.

\begin{tabular}{|c|c|c|c|c|}
\hline & \multicolumn{2}{|c|}{ Wet Density } & \multicolumn{2}{|c|}{ Dry Density } \\
\hline & Sand & NDG & Sand & NDG \\
\hline $\mathrm{CH}$ & 0.32 & 0.79 & 0.82 & 0.84 \\
\hline SC w/Grav & 0.22 & 0.68 & 0.11 & 0.72 \\
\hline GW-GC & 0.77 & 0.69 & 0.69 & 0.61 \\
\hline $\mathrm{CL}$ & 0.17 & 0.27 & 0.52 & 0.60 \\
\hline Blended SC & 0.54 & 0.61 & 0.32 & 0.43 \\
\hline Red SC & 0.68 & 0.72 & 0.67 & 0.66 \\
\hline
\end{tabular}

Table 12. Correlation of determination between photogrammetry method and NDG and sand cone method for each soil type tested with outliers removed.

\begin{tabular}{|c|c|c|c|c|}
\hline & \multicolumn{2}{|c|}{ Wet Density } & \multicolumn{2}{|c|}{ Dry Density } \\
\hline & Sand & NDG & Sand & NDG \\
\hline $\mathrm{CH}$ & 0.32 & 0.79 & 0.82 & 0.84 \\
\hline GC & 0.77 & 0.72 & 0.71 & 0.77 \\
\hline GW & 0.93 & 0.87 & 0.88 & 0.83 \\
\hline $\mathrm{CL}$ & 0.48 & 0.67 & 0.70 & 0.79 \\
\hline SM & 0.81 & 0.71 & 0.71 & 0.53 \\
\hline SC & 0.71 & 0.75 & 0.63 & 0.65 \\
\hline
\end{tabular}


Figure 47. Wet density comparisons between photogrammetry and NDG and sand cone with outliers noted in circles.
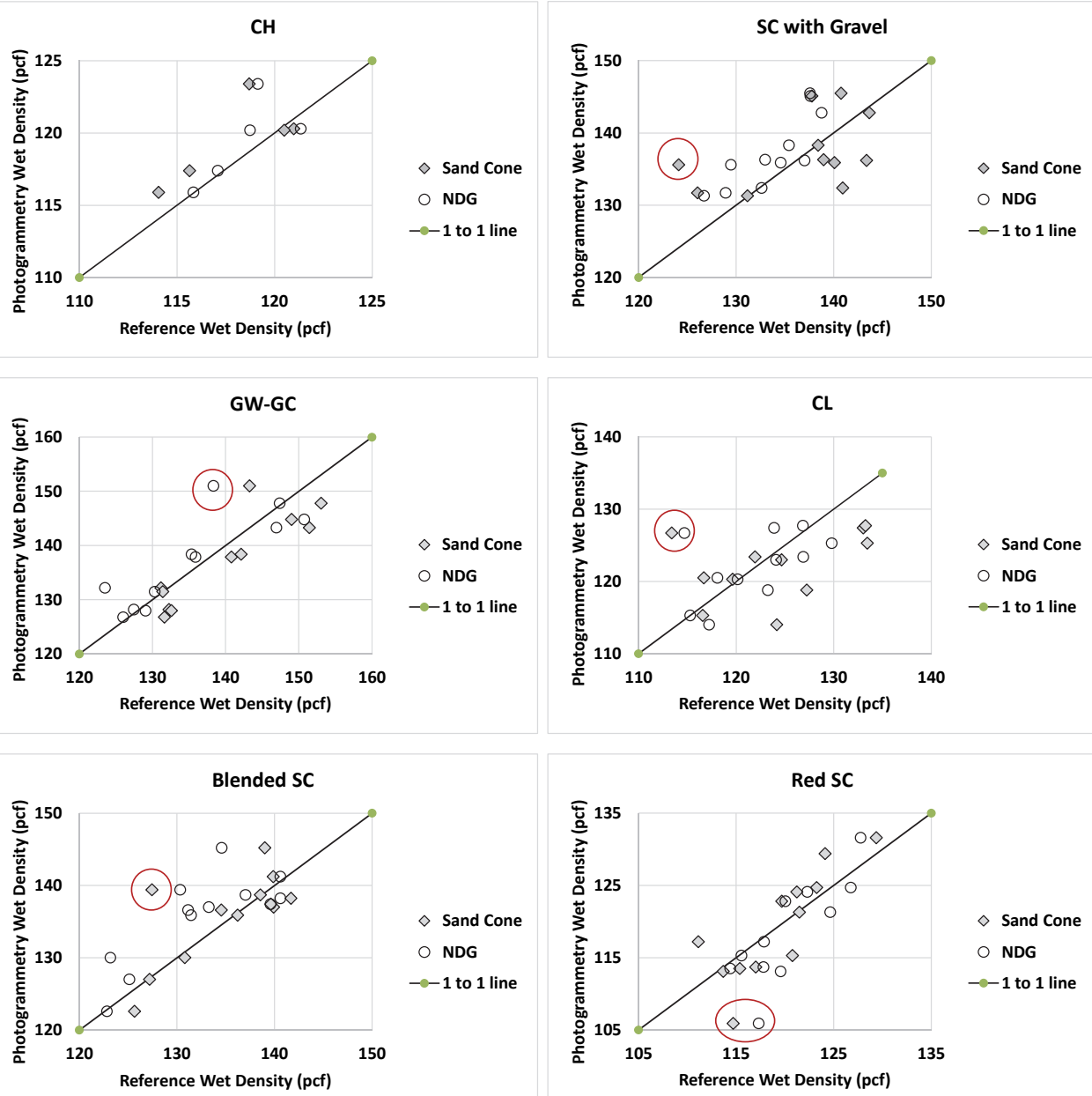

Based on soil type, the finer-grained CL and SC soils tended to have a poorer correlation whereas it was anticipated that coarser-grained soils would exhibit this trend. The rough surface texture and angular particles of the coarser soils should make it difficult to resolve small cavities in the excavated hole and an accurate z-plane from which to calculate the hole, volume; however, in this study, these soils correlated the best. A possible solution would be to conduct a series of photographs before and after excavation to establish a better z-plane from which to base the volume calculations.

The statistical results of the phase two validation study are shown in Table 13 and Table 14 (with outliers removed) as a direct comparison to the initial phase one data collection events in Table 6 . The more carefully constructed test sections and uniform application of the photogrammetric technique improved the variability slightly from phase one with the correlation with the NDG still being the best. 
Table 13. Statistical summary of phase two evaluation of photogrammetric technique.

\begin{tabular}{|r|c|c|c|}
\hline & \multicolumn{2}{|c}{ NDG and } & \multicolumn{2}{c|}{ SC and } & \multicolumn{2}{c|}{ NDG and } \\
& Photo & Photo & SC \\
\hline Average Density Differential (pcf) & -1.5 & 0.3 & -1.7 \\
\hline Standard Deviation (pcf) & 4.5 & 5.2 & 3.9 \\
\hline Coefficient of Variation (\%) & 3.5 & 4.0 & 3.1 \\
\hline
\end{tabular}

Table 14. Statistical summary of phase two evaluation of photogrammetric technique with outliers removed.

\begin{tabular}{|r|c|c|c|}
\hline & \multicolumn{2}{c}{$\begin{array}{c}\text { NDG and } \\
\text { Photo }\end{array}$} & \multicolumn{2}{c|}{ SC and } & \multicolumn{2}{c|}{ NDG and } \\
& Photo & SC \\
\hline Average Density Differential (pcf) & -1.1 & 0.6 & -1.4 \\
\hline Standard Deviation (pcf) & 3.6 & 4.3 & 3.8 \\
\hline Coefficient of Variation (\%) & 2.8 & 3.3 & 3.0 \\
\hline
\end{tabular}

\subsection{Data summary}

While the data demonstrates that there can be good success using the photogrammetry method, it is concerning that outliers exist to such a magnitude that a missed value could prove detrimental in a field quality control setting. Outliers can obviously occur in any field testing exercise, but it was found that outliers existed within almost all soil types tested yielding too small a volume of the excavated hole. Further, soil conditions that were hypothesized to be ideal for determining volume represented the most variable conditions. The research has demonstrated that the photogrammetry technique has merit, but further research is needed to identify methods to reduce the possibility of outliers. 


\section{Conclusions and Recommendations}

\subsection{Conclusions}

This research effort sought to apply the principles of photogrammetry to obtain the volume of a hole excavated in the ground from a series of photographs taken with a digital camera. The research considered the development of algorithms that enable a rapid means to process threedimensional digital point clouds to obtain accurate volumes of small holes. Using a uniquely designed calibration platform to ensure its sufficiency, the photogrammetric technique was validated through a series of data collection efforts across multiple test sites representing a wide range of compacted soils and a comparison made between the NDG and sand cone test for accuracy and expediency. The goal was to present a stand-alone digital platform that can detect volumes of small holes dug for the purpose of quality control of soil density with the accuracy of the sand cone and the expediency of the NDG. The key findings are as follows:

\subsubsection{Devices}

- It was determined that a higher mega-pixel camera achieves a better point cloud and, therefore, a more accurate rendering of the surface of an excavated hole which, in turn, creates a more accurate volume calculation.

- It is not necessary that the higher mega-pixel camera (16 mp or higher) be a single lens-reflux or a simple point-and-shoot camera so long as it has a high optical mega-pixel value.

\subsubsection{Accuracy}

- Using the calibration apparatus constructed for this research, it was determined that the calculated hole volume was between $0.3 \%$ and $1.6 \%$ of the reference (water) volume using various high mega-pixels cameras.

- Using the sand cone method on the same apparatus yielded an accuracy of $0.2 \%$ with repeated tests. This suggests that the photogrammetry method has the potential to provide a reasonable estimate of the sand cone method. 


\subsubsection{Soil response}

When tested on a series of soils using uncontrolled test sections and varying image scales for calculating scale the $\mathrm{R}^{2}$ value was

- Wet Density: 92\% and 90\% relative to NDG and sand cone respectively, compared to a $91 \%$ between the NDG and sand cone

When tested on a controlled test section using multiple replicates on similar material, the $\mathrm{R}^{2}$ value was

- Wet Density: $81 \%$ and $76 \%$ relative to the NDG and sand cone respectively, compared to an $87 \%$ between the NDG and sand cone

- Dry Density: 92\% and 89\% relative to the NDG and sand cone respectively, compared to a $95 \%$ between the NDG and sand cone

The variability can be attributed to a smaller soil data set in the second study where soils that cause difficulty in imaging magnify the error versus dispersion of error over a wider range of soil types. Outlying data points greater than 2 standard deviations beyond the mean error were found in all but the $\mathrm{CH}$ soil type, which also resulted in lower correlations and was especially evident in correlations within specific soil types. Further research is required to minimize outliers of this type to improve the accuracy and confidence in the photogrammetry technique.

\subsection{Areas for future study}

The photogrammetry technique provides a leap forward in technology to replace the use of the sand cone method in identifying hole volume more accurately and with a minimum of logistics. However, accuracy can be an issue, especially with outliers since the method of determining volume has a great human input when performing the software analysis. Alternative ways to automate the analysis to minimize operator error and better methods to collect the point cloud data are needed. Suggestions for these alternatives are as follows:

\subsubsection{Hardware advancements in point cloud collection}

The advent of flash LiDAR (Light and Distance Ranging) cameras offers the ability to take a single photograph to resolve a dense scaled point cloud minimizing errors associated with stitching multiple photos, manually 
scaling the image, and accounting for poor lighting conditions. However, these flash LiDAR cameras are prohibitively expensive as of this writing, but are likely to become standard equipment in the future. As well, the advent of stereo camera systems with dual lenses and onboard cloud rendering software can also create rapid, accurate point clouds from very few images minimizing the same issues as before but for a much cheaper price. It is suggested that either of these imaging platforms be explored in the future to establish their sufficiency in reducing error.

\subsubsection{Use of pre- and post-imaging}

Another technique to minimize error in volume calculation is to take a series of photographs before and after excavation and use algorithms that subtract one point cloud from the other. This will allow for any surface changes that may be missed with the current technique. This also removes the burden of the user defining a level surface as the surface condition no longer matters since change detection is all that is required. The drawback to this approach is the time to collect a second set of imagery and produce a second point cloud. The hardware advancements discussed previously could remedy this and provide a better volume estimate as well.

\subsubsection{New processing techniques}

The ERDC is pursuing the use of volumetric filling algorithms in threedimensional point clouds for identifying the presence of rutting and depressions within pavement surfaces. These same tools could be applied to identifying the volumetric extent of the excavated holes eliminating the need for defining a level surface. These algorithms could be applied to data already collected to see if more consistent volumes could be obtained with less user input. 


\section{References}

American Society for Testing and Materials (ASTM) International. 2006. Standard test method for sieve analysis of fine and coarse aggregates. Designation C 136. West Conshohocken, PA: American Society for Testing and Materials International.

. 2007a. Standard test method for particle-size analysis of soils. Designation D 422-63. West Conshohocken, PA: American Society for Testing and Materials International.

2007b. Standard test method for density and unit weight of soil in place by sand cone method. Designation D 1556-07. West Conshohocken, PA: American Society for Testing and Materials International.

2007c. Determination of water (moisture) content of soil by direct heating. Designation D 4959-07. West Conshohocken, PA: American Society for Testing and Materials International.

2008. Standard test methods for determination of water (moisture) content of the soil by the microwave oven heating. Designation D 4643-08. West

Conshohocken, PA: American Society for Testing and Materials International.

2010a. Standard test methods for laboratory determination of water (moisture) content of soil and rock by mass. Designation D 2216-10. West Conshohocken, PA: American Society for Testing and Materials International.

.2010b. Standard test methods for liquid limit, plastic limit, and plasticity index of soils. Designation D 4318. West Conshohocken, PA: American Society for Testing and Materials International.

2010c. West Conshohocken, PA. Standard test method for in-place density and water content of soil and soil-aggregate by nuclear methods (shallow depth). Designation D 6938-10. West Conshohocken, PA: American Society for Testing and Materials International.

2011. Standard practice for classification of soils for engineering purposes (unified soil classification system). Designation D 2487. West Conshohocken, PA: American Society for Testing and Materials International.

2012. Standard test methods for laboratory compaction characteristics of soil using modified effort. Designation D 1557. West Conshohocken, PA: American Society for Testing and Materials International.

Berney IV, E. S., and Wahl, R. E. 2008. A rapid soils analysis kit. ERDC/GSL TR-o8-3. Vicksburg, MS: U.S. Army Engineer Research and Development Center.

Berney IV, E. S., J. D. Kyzar and L. O. Oyelami. 2011. Device comparison for determining field soil moisture content. ERDC/GSL TR-11-42. Vicksburg, MS: U.S. Army Engineer Research and Development Center. 
Berney IV, E. S., M. Mejías-Santiago, and J. D. Kyzar. 2013. Non-nuclear alternatives to monitoring moisture-density response in soils. ERDC/GSL TR-13-6. Vicksburg, MS: U.S. Army Engineer Research and Development Center.

Berney IV, E. S., Mejías-Santiago, M., and J. Beasley. 2014. Validation tests of a nonnuclear combined asphalt and soil density gauge. ERDC/GSL TR-14-10. Vicksburg, MS: U.S. Army Engineer Research and Development Center.

Berney IV, E. S., and M. Mejias-Santiago. 2016. Validation testing of non-nuclear alternatives to measuring soil density. ERDC TR-16-28. Vicksburg, MS: U.S. Army Engineer Research and Development Center.

Ehrgott, J. Jr., D. Rickman, J. Payne, W. Myers, Jr., C. Thomas, M. Adley, J. Windham, E. Berney, T. Waddell, T. C. Pratt, D. P. Danko, R. L. Talbott, Jr., W. McNeal, Jr. and C. W. Crowder. 2016. An introduction to the CALDERA forensic crater analysis program. ERDC TR-16-9. Vicksburg, MS: U.S. Army Engineer Research and Development Center.

Matlab. 2012. MATLAB and statistics toolbox release. Natick, MA: The MathWorks, Inc.

Sebesta, S., C. Estakhri, T. Scullion, and W. Liu. 2006. New technologies for evaluating flexible pavement construction: Year 1 report. FHWA/TX-06/0-4774-1. College Station, TX: Texas Department of Transportation.

Troxler Electronic Laboratories Inc. 2016. Application Brief: Troxler Model 3430 Roadreader ${ }^{\mathrm{TM}}$ Nuclear Moisture Density Gauge. Research Triangle Park, NC: Troxler Electronic Laboratories Inc.

Troxler Electronic Laboratories Inc. 2007. Troxler Models 3400-4640 Basic Gauge Operations Manual. http://www.troxlerlabs.com/Portals/0/Troxler\%20Documents/other1\%28basic\%29.pdf 


\section{Appendix A: Soil Characterization Data}

\section{A.1 Clay Gravel}

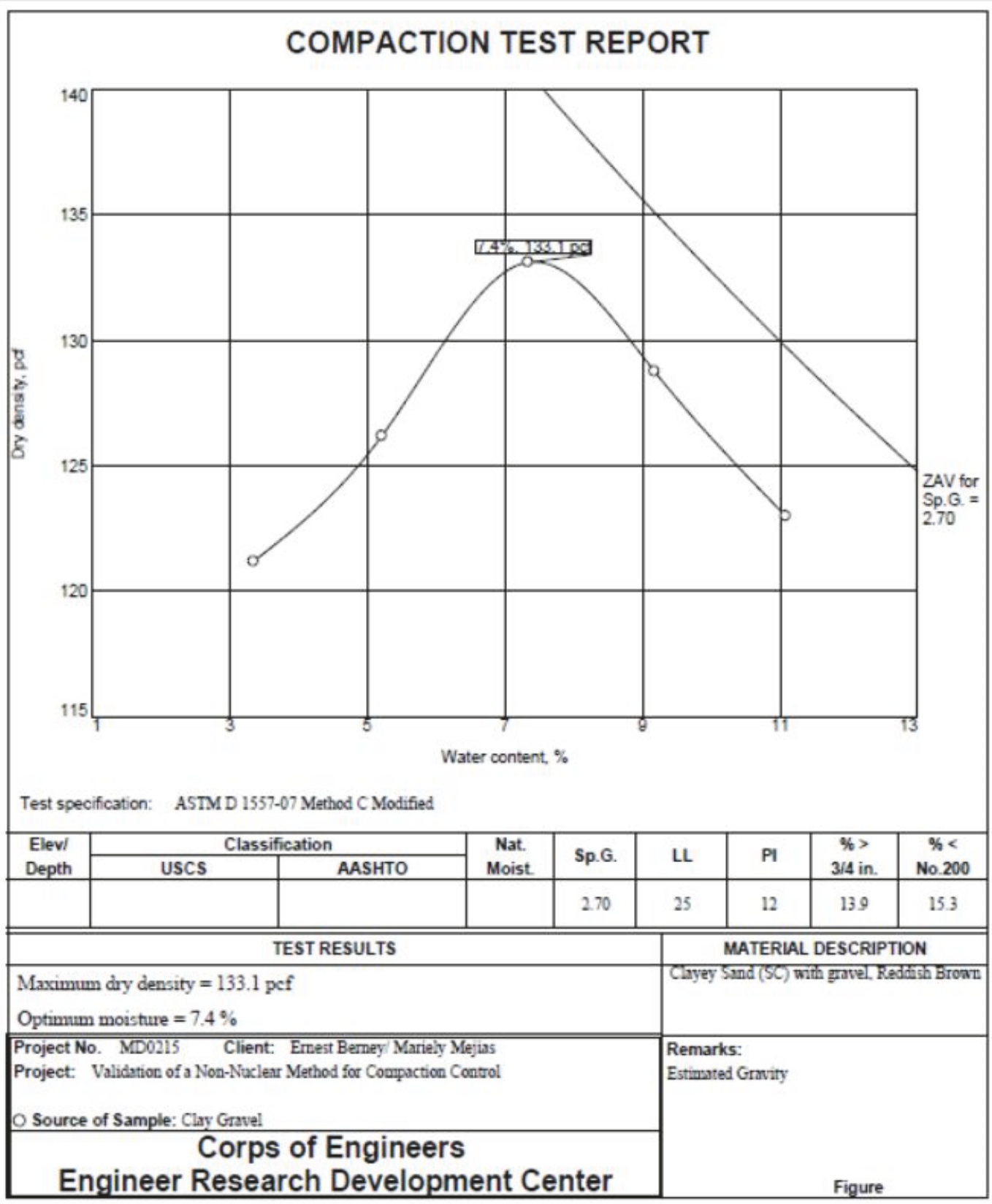




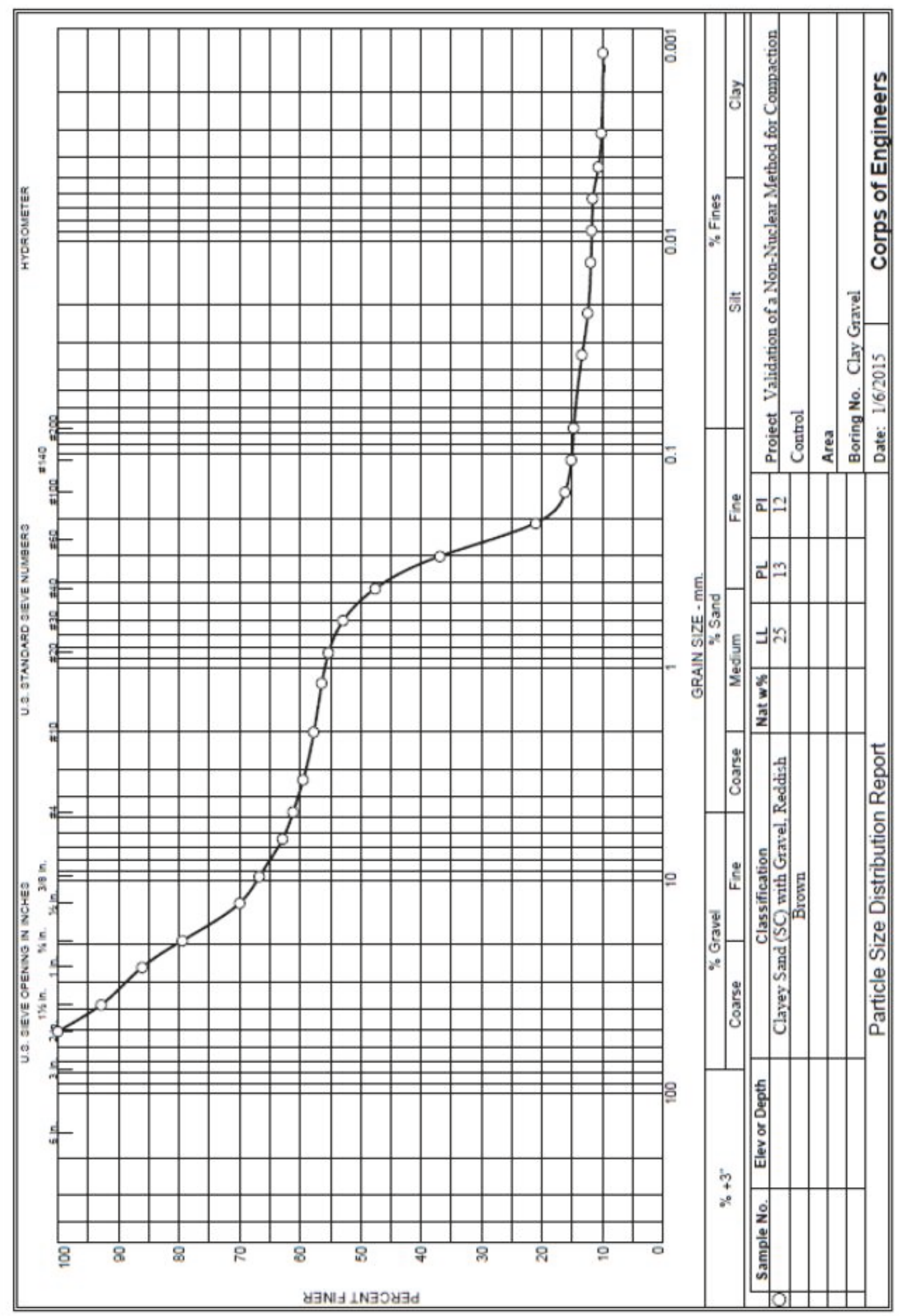




\section{A.2 Limestone}

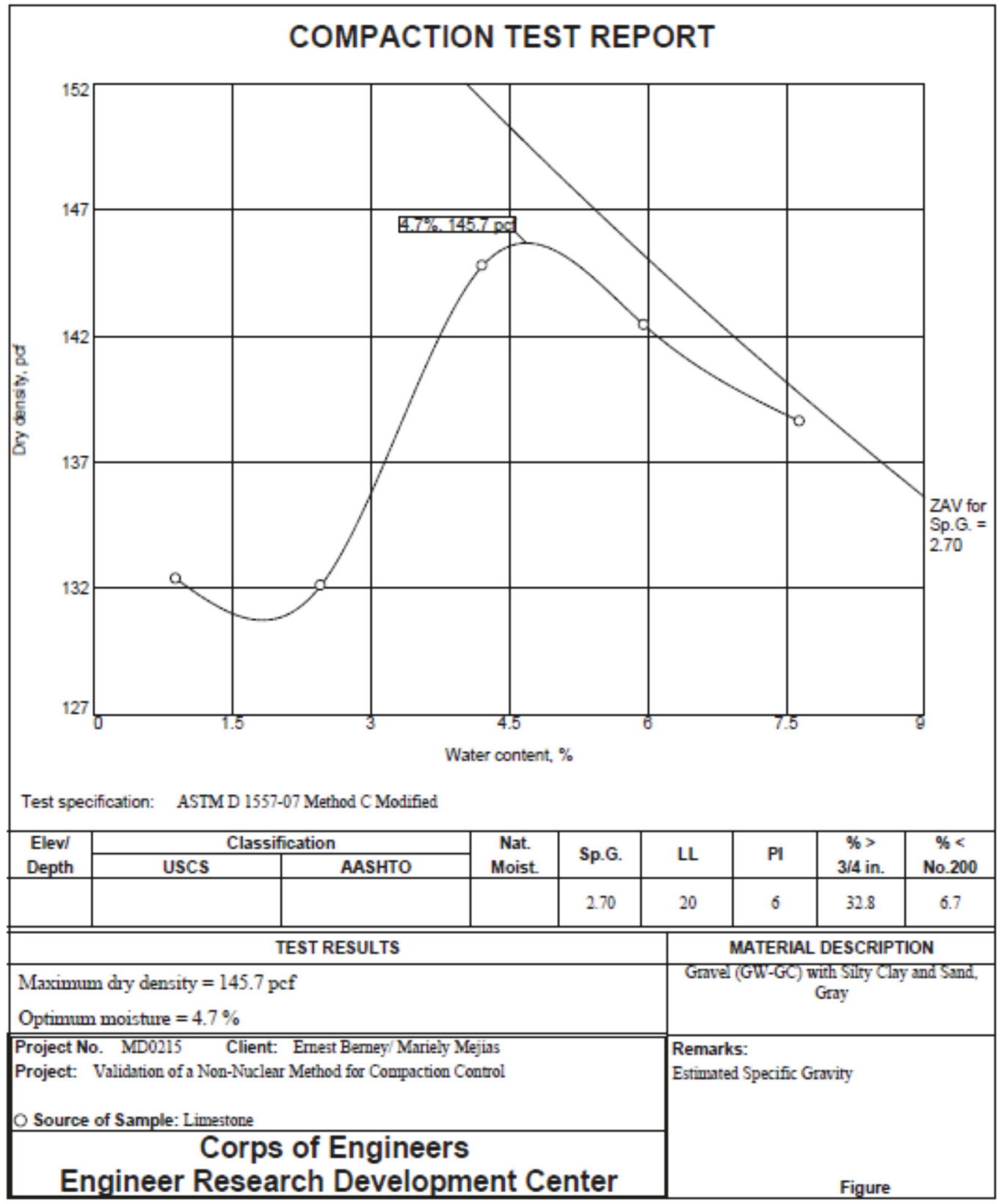




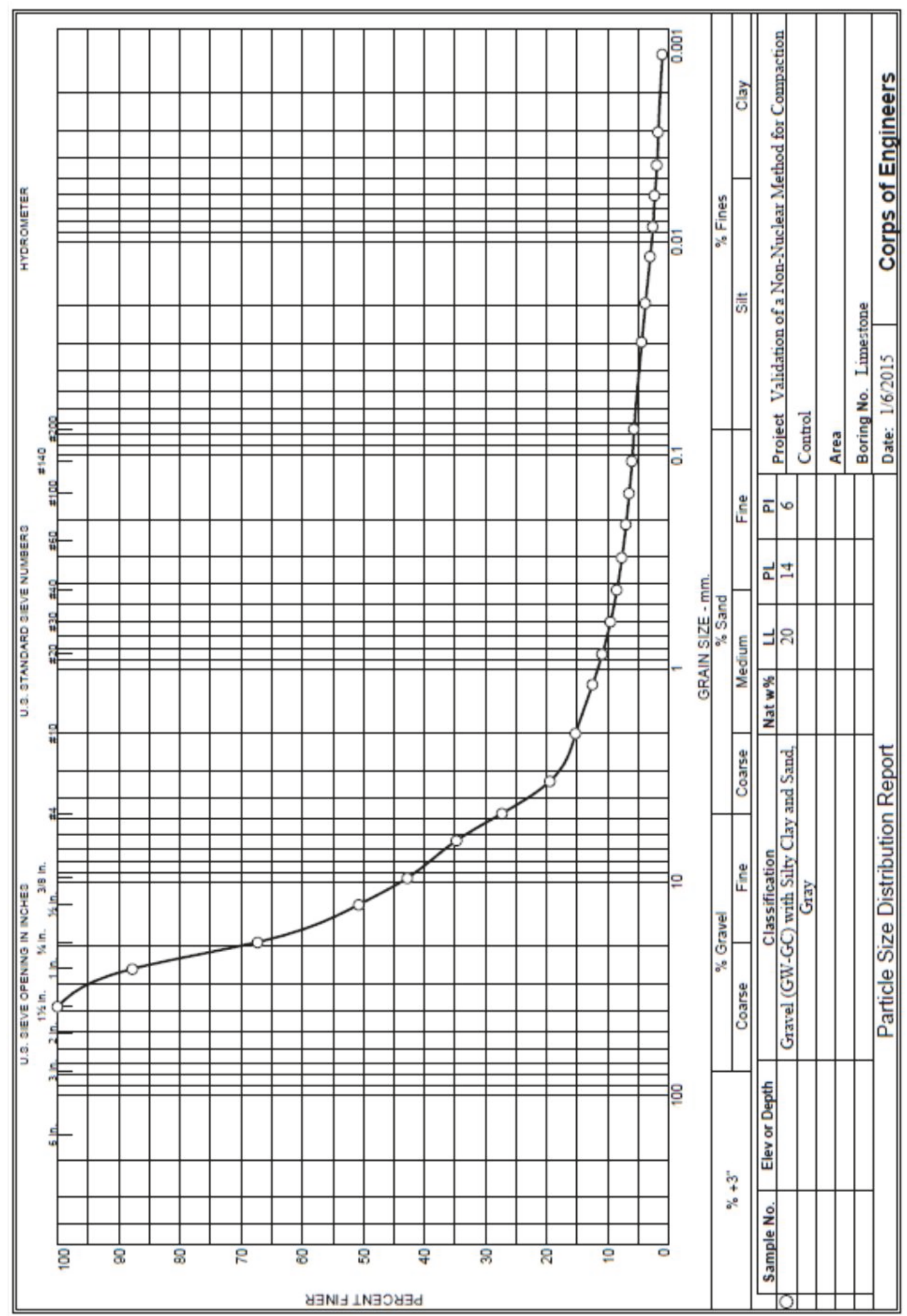




\section{A.3 Red Clayey Sand}

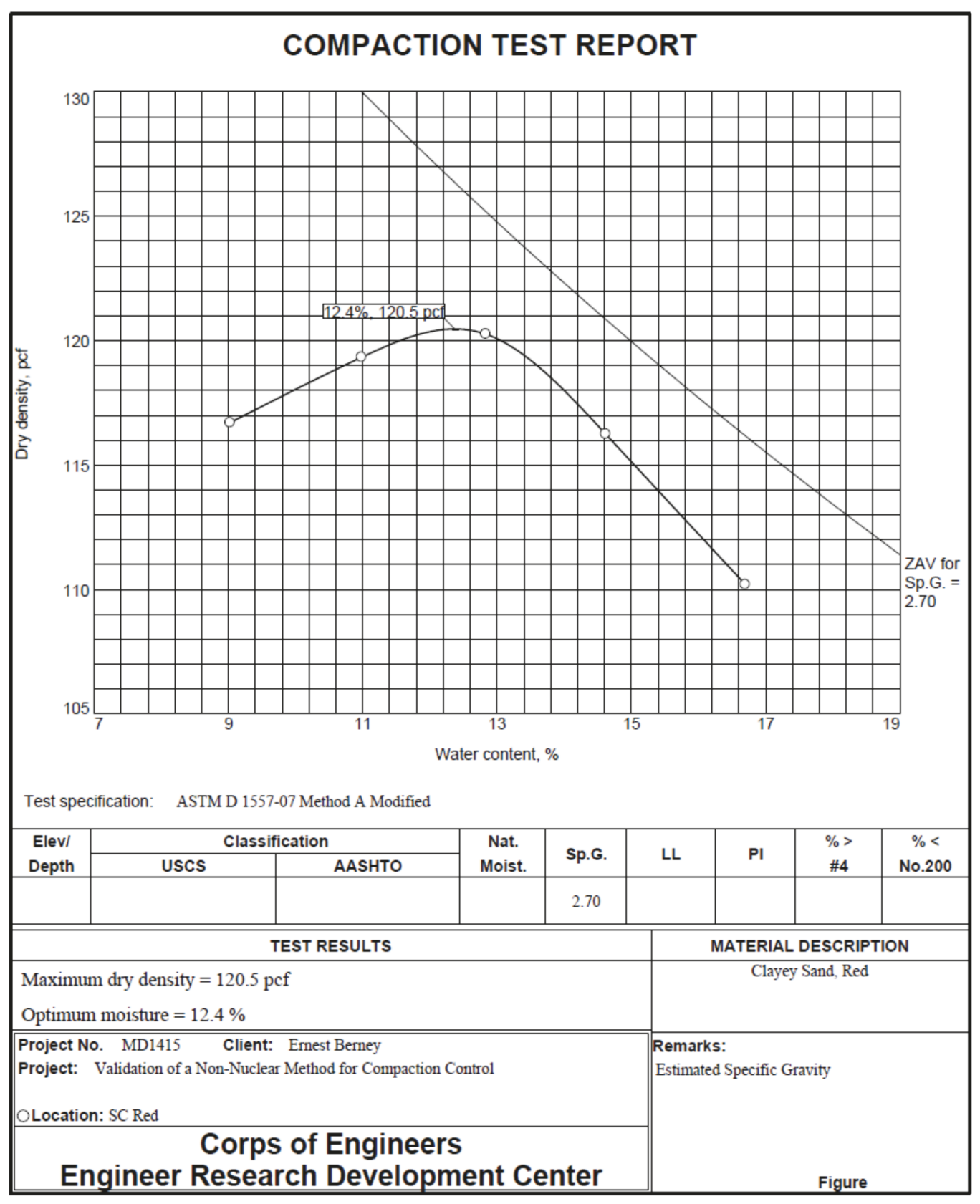




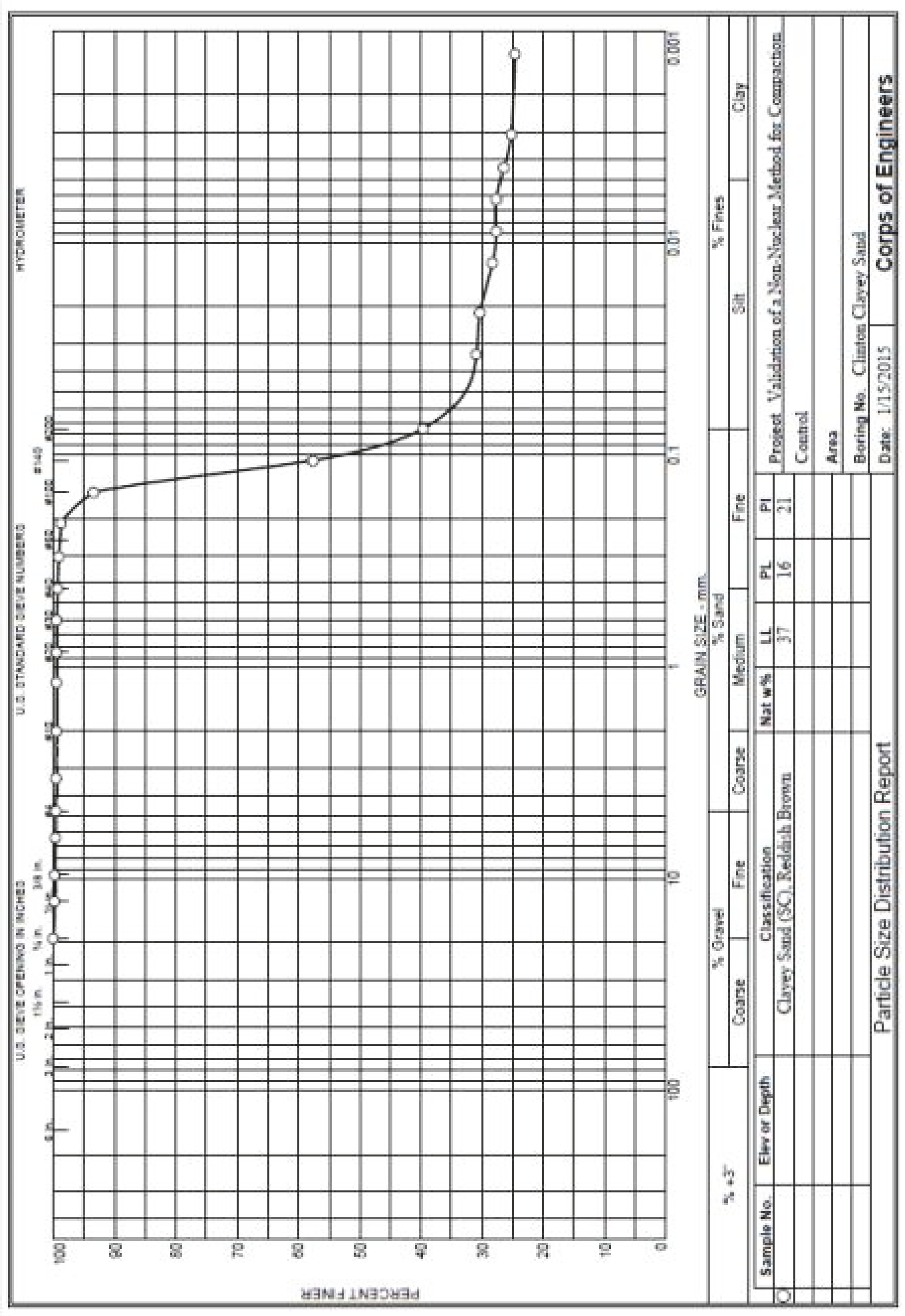




\section{A.4 Blended Clayey Sand}

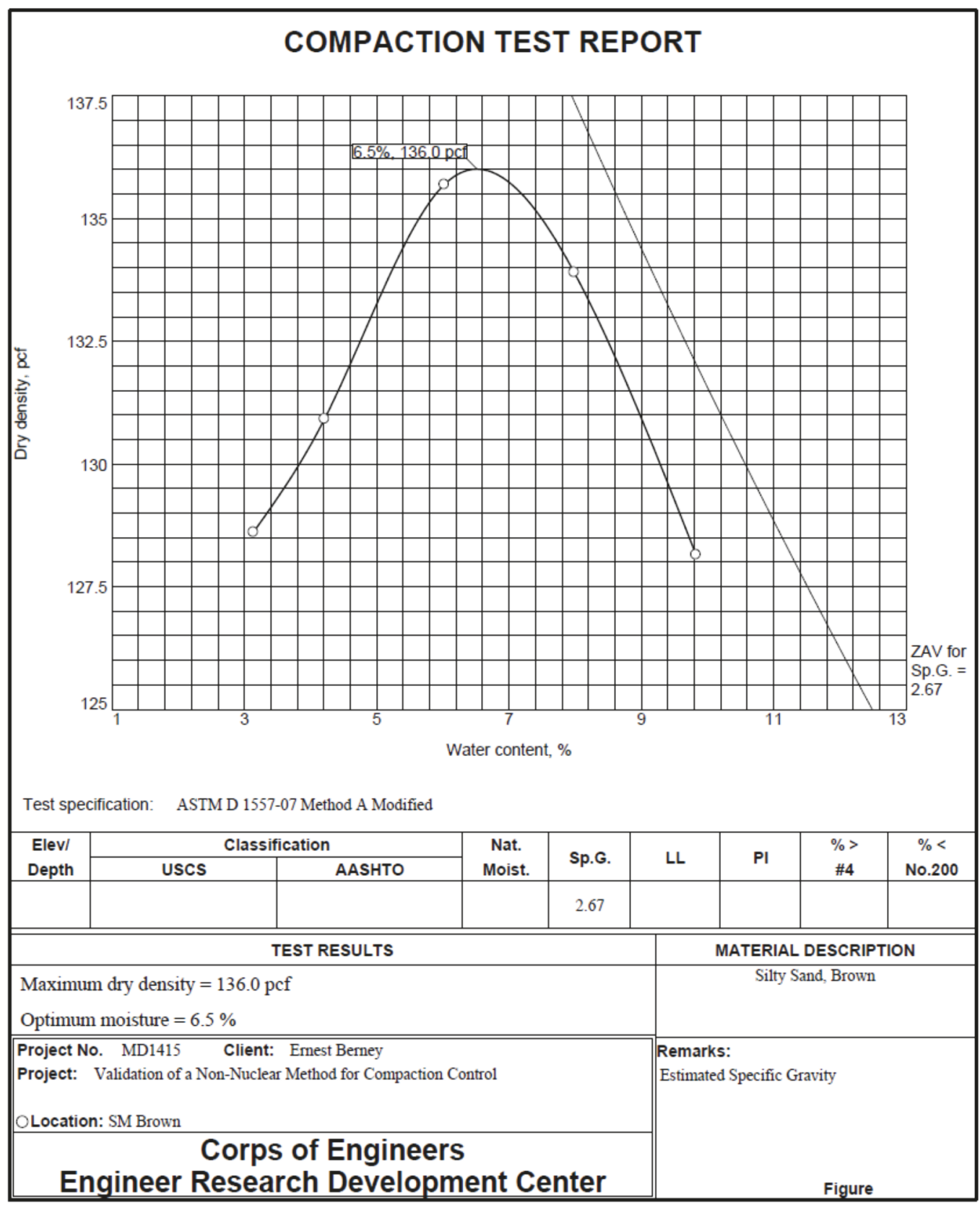




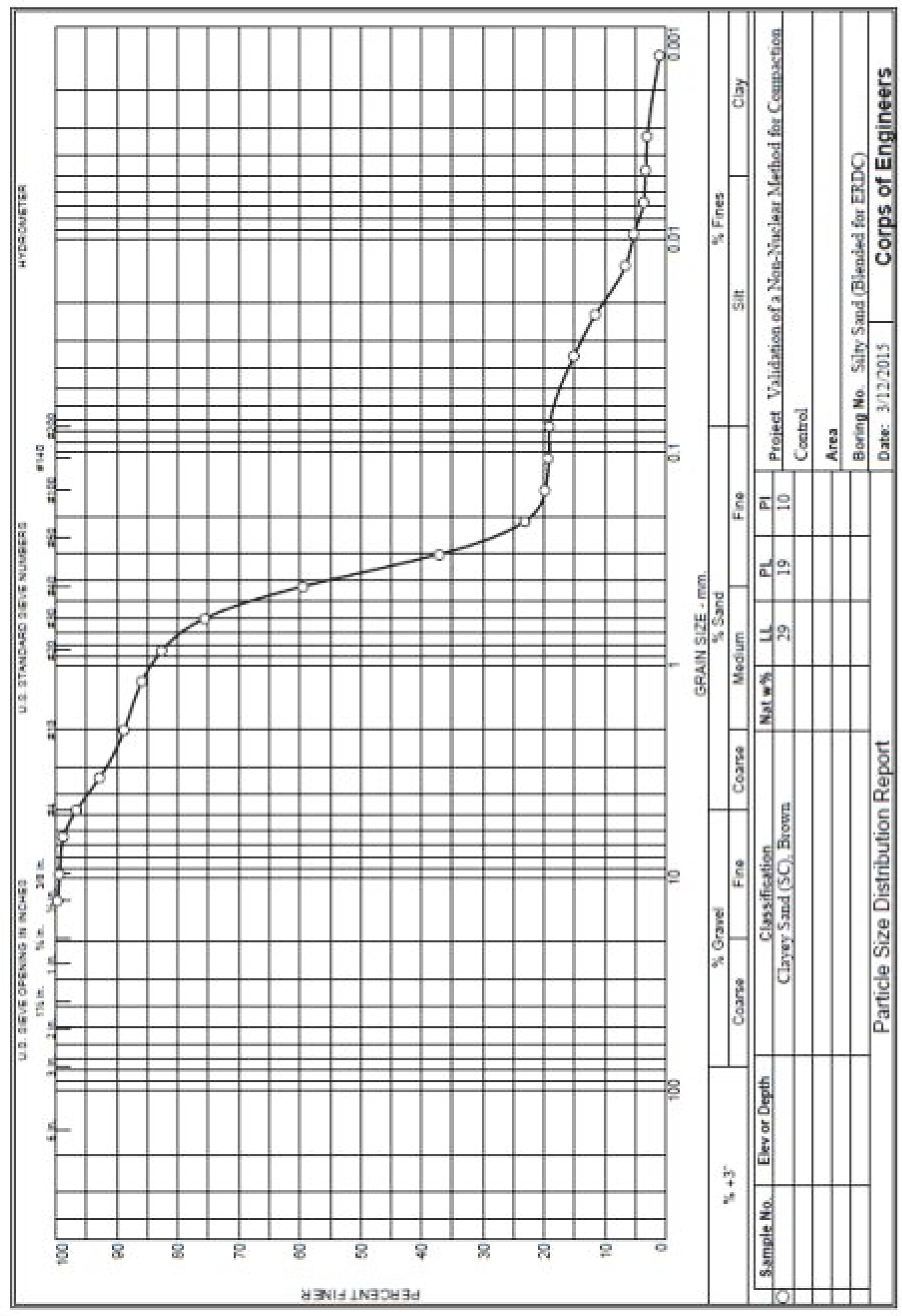




\section{A.5 Low Plasticity Clay}

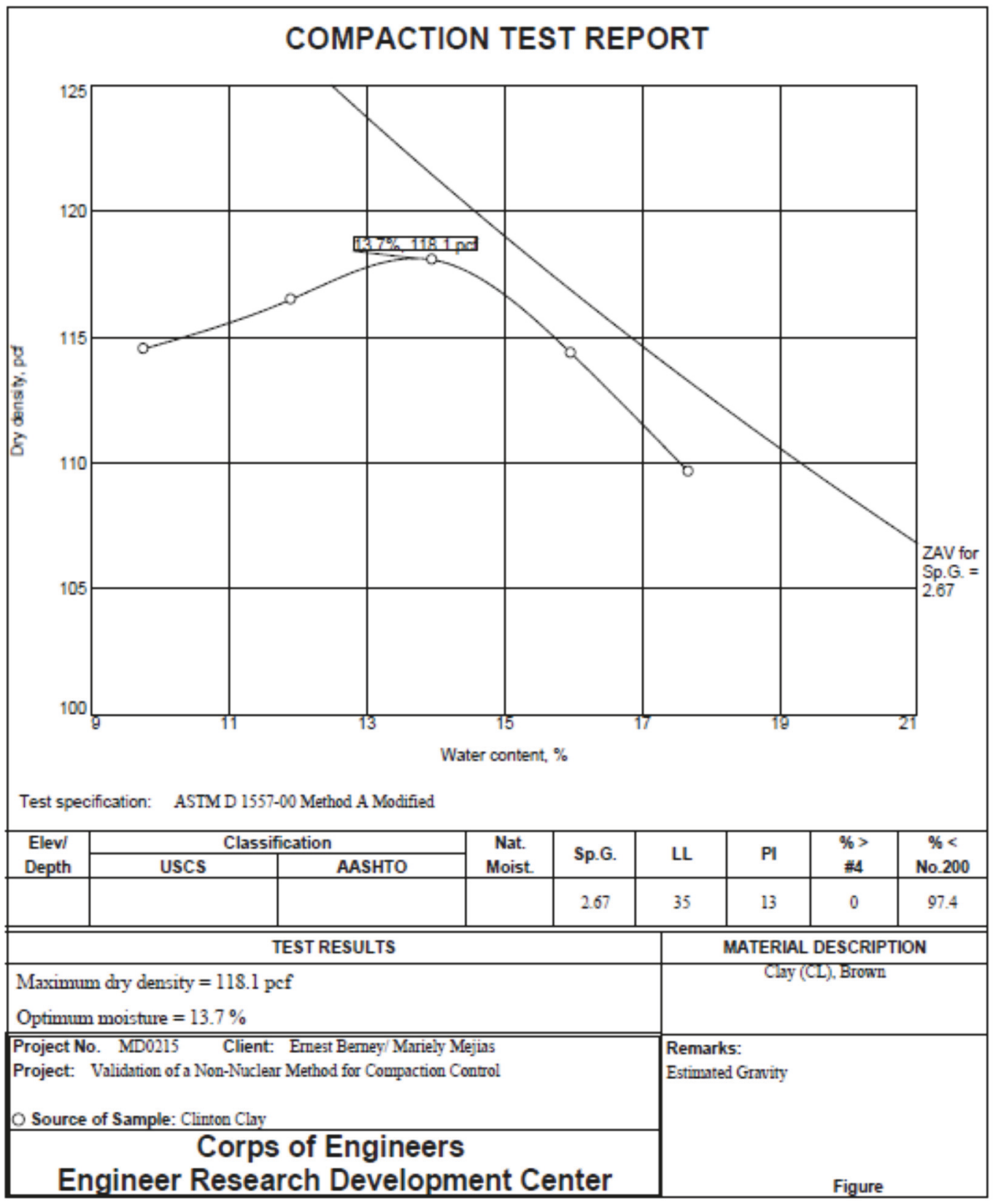




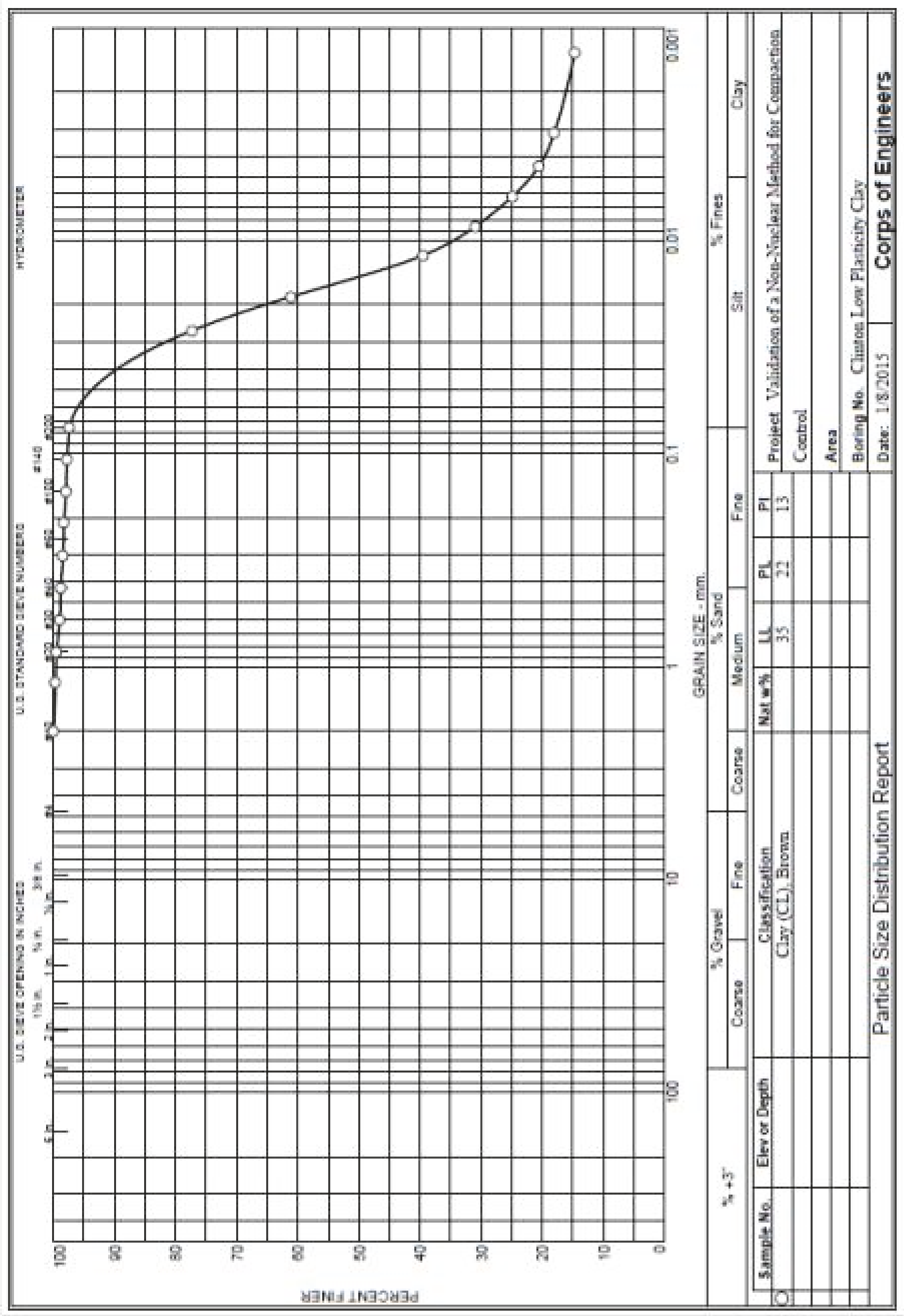




\section{A.6 High Plasticity Clay}

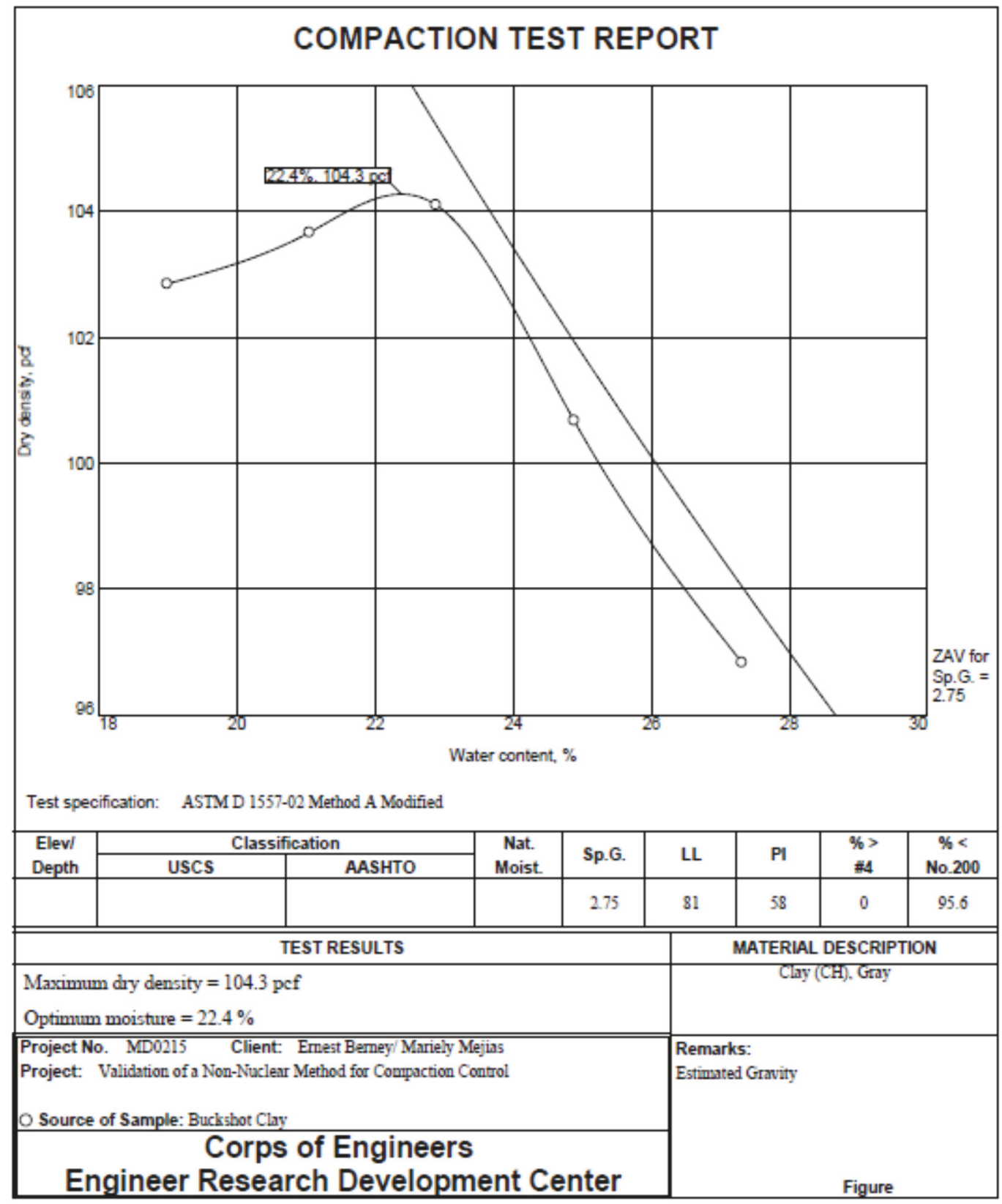




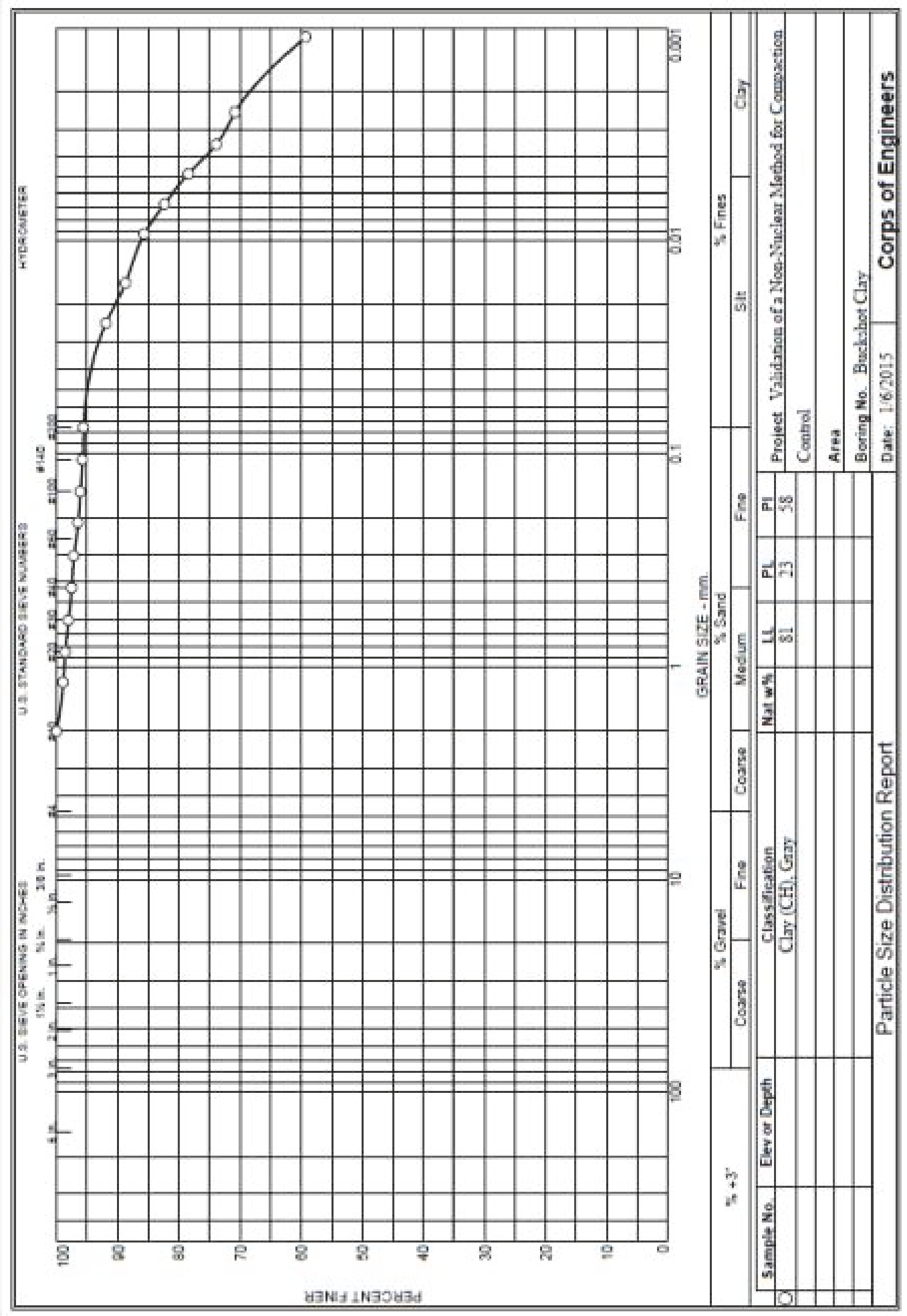




\section{Appendix B: Raw Experimental Data Collected and Photogrammetry Analysis}

The following two tables present the raw data collected in the field for the test items described in this research. The following data points were considered outliers as noted in Figure 47 and regressions recalculated minus these data points.

- SC-M1-Lo-2

- $\mathrm{GW}-\mathrm{M} 2-\mathrm{LO}-3$

- CL-M2-Lo-3

- Blended SC-M1-Hi-3

- Red SC-M2-Lo-1 


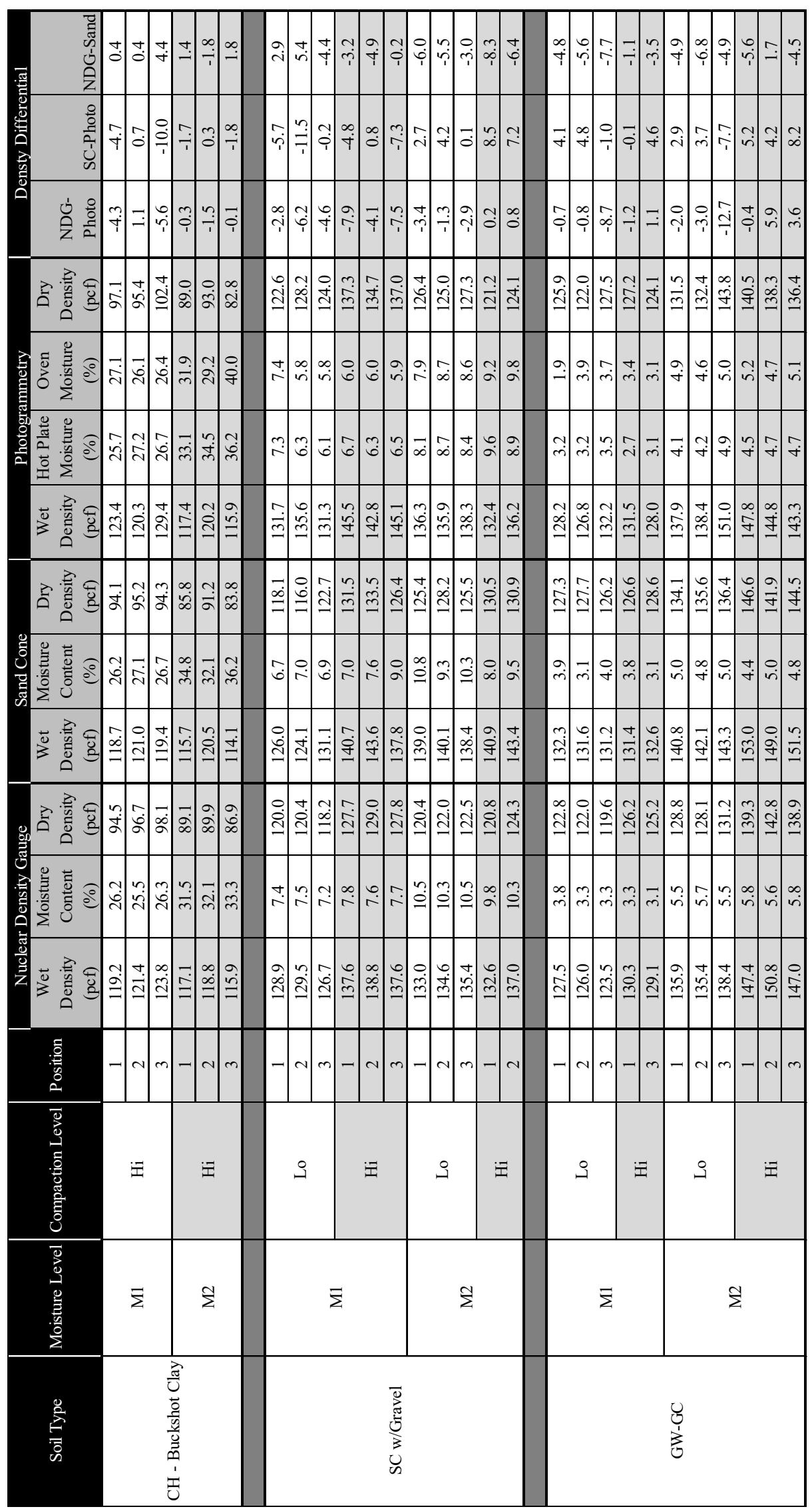




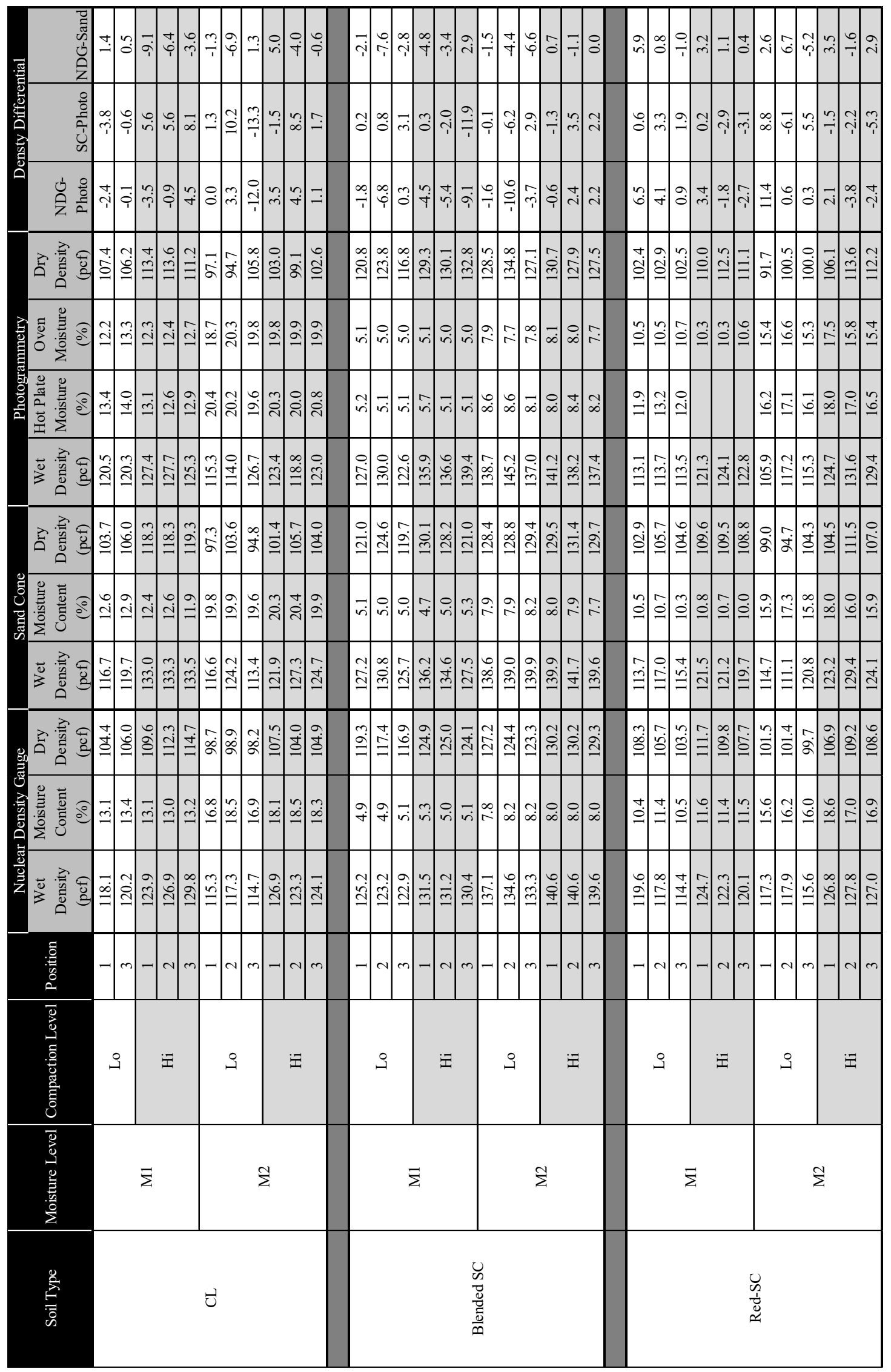




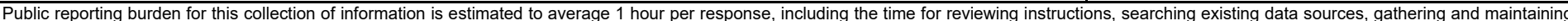

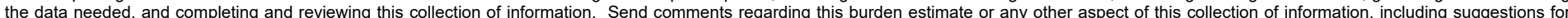

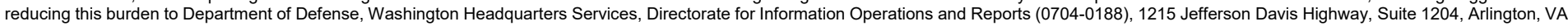

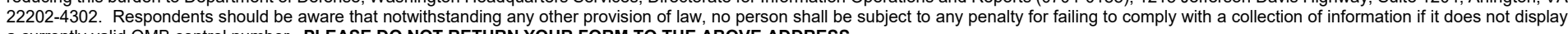
a currently valid OMB control number. PLEASE DO NOT RETURN YOUR FORM TO THE ABOVE ADDRESS.

\begin{tabular}{|l|l|l}
\hline 1. REPORT DATE (DD-MM-YYYY) & 2. REPORT TYPE & 3. DATES COVERED (FrOm - To)
\end{tabular} June 2018

\section{TITLE AND SUBTITLE} Final 5a. CONTRACT NUMBER

A Photogrammetric Method for Obtaining Soil Density

5b. GRANT NUMBER

5c. PROGRAM ELEMENT NUMBER

6. AUTHOR(S)

Ernest S. Berney IV, Naveen B. Ganesh, and Thad C. Pratt

5d. PROJECT NUMBER

447413

5e. TASK NUMBER

5f. WORK UNIT NUMBER

\section{PERFORMING ORGANIZATION NAME(S) AND ADDRESS(ES)}

8. PERFORMING ORGANIZATION REPORT NUMBER

Geotechnical and Structures Laboratory \&

Coastal and Hydraulics Laboratory

ERDC TR-18-6

U.S. Army Engineer Research and Development Center

3909 Halls Ferry Road

Vicksburg, MS 39180-6199

9. SPONSORING / MONITORING AGENCY NAME(S) AND ADDRESS(ES)

Headquarters, U.S. Army Corps of Engineers

Washington, DC 20314-1000

10. SPONSOR/MONITOR'S ACRONYM(S)

HQ-USACE

11. SPONSOR/MONITOR'S REPORT NUMBER(S)

\section{DISTRIBUTION / AVAILABILITY STATEMENT}

Approved for public release; distribution is unlimited.

\section{SUPPLEMENTARY NOTES}

\section{ABSTRACT}

There is a need for a simple, accurate soil density measurement system that does not require extensive calibration or significant health and safety measures for compaction quality control. This research describes the invention of a photogrammetric technique for obtaining the volume of an excavated hole in soil. This procedure requires a series of 8 to 16 digital photographs with a standard digital camera around the perimeter of an excavated hole with a reference scale in the scene. Algorithms convert the digital photographs into a colorized three-dimensional point cloud, which is automatically rotated into a plan view and displayed via the Matlab graphical user interface. Once the reference scale dimensions are input, the volume of the hole is calculated via a user selected ground plane. Once the mass of the excavated soil is input, the wet density of the soil is calculated by dividing by the volume of the hole. This procedure has been validated against both the nuclear density gauge and the sand cone apparatus and found to be equivalent in accuracy to both. This procedure enables soil density determination within 15 min with no replacement material, no specific excavated hole dimension, and no safety or health risks.

\begin{tabular}{lll}
\hline 15. SUBJECT TERMS & Sand cone & Image processing \\
Soil & Photogrammetry & Volume \\
Density & Field measurement & Soils - Testing \\
Soils - Density & Soil moisture - Measurement - Instruments & Photogrammetry
\end{tabular}

\begin{tabular}{|l|c|c|c|l|l|}
\hline \multicolumn{2}{|l|}{ 16. SECURITY CLASSIFICATION OF: } & $\begin{array}{l}\text { 17. LIMITATION } \\
\text { OF ABSTRACT }\end{array}$ & $\begin{array}{l}\text { 18. NUMBER } \\
\text { OF PAGES }\end{array}$ & $\begin{array}{l}\text { 19a. NAME OF RESPONSIBLE } \\
\text { PERSON }\end{array}$ \\
\cline { 1 - 2 } $\begin{array}{c}\text { a. REPORT } \\
\text { Unclassified }\end{array}$ & $\begin{array}{c}\text { b. ABSTRACT } \\
\text { Unclassified }\end{array}$ & $\begin{array}{c}\text { c. THIS PAGE } \\
\text { Unclassified }\end{array}$ & SAR & 83 & $\begin{array}{l}\text { 19b. TELEPHONE NUMBER (include } \\
\text { areade) }\end{array}$ \\
\end{tabular}

